\title{
ipen
}

INSTITUTO DE PESQUISAS ENERGÉTICAS E NUCLEARES

Autarquia associada à Universidade de São Paulo

\author{
FOTOTERAPIA COM LASER EM BAIXA INTENSIDADE EM PROCESSO \\ INFLAMATÓRIO AGUDO INDUZIDO POR CARRAGENINA EM PATA DE \\ CAMUNDONGOS - ESTUDOS DE DOSIMETRIA
}

DAIANE THAIS MENEGUZZO

Tese apresentada como parte dos requisitos para obtenção do Grau de Doutor em Ciências na Área de Tecnologia Nuclear - Materiais

Orientadora:

Profa. Dra. Martha Simões Ribeiro

SÃO PAULO

2010 


\section{FOTOTERAPIA COM LASER EM BAIXA INTENSIDADE EM PROCESSO \\ INFLAMATÓRIO AGUDO INDUZIDO POR CARRAGENINA EM PATA DE \\ CAMUNDONGOS - ESTUDOS DE DOSIMETRIA}

\section{DAIANE THAIS MENEGUZZO}

\section{RESUMO}

A importância da modulação da inflamação no tratamento de doenças inflamatórias bem como a dificuldade na determinação dos parâmetros de irradiação laser levou-nos a estudar os efeitos de diferentes protocolos de fototerapia com laser em baixa intensidade (potência, energia, local e momento de irradiação) no tratamento e prevenção do processo inflamatório agudo utilizando o modelo experimental de edema de pata induzido por carragenina (CGN) em três linhagens de camundongos (Balb-c, SWISS e C57BL/6). A primeira etapa do trabalho avaliou diferentes combinações de energia (1J e $3 \mathrm{~J}$ ) com diferentes potências (30, 60 e 100mW) em camundongos Balb-c irradiados na pata 1 e $2 \mathrm{~h}$ após a injeção da CGN. A segunda etapa estudou diferentes combinações de local (pata, linfonodo inguinal e ambos) e momentos de irradiação (2 e $1 \mathrm{~h}$ antes, $1 \mathrm{~h}$ e imediatamente antes da CGN, 1 e 2h após e 3,5 e 4,5h após a CGN) utilizando parâmetros de irradiação fixos $\left(1 \mathrm{~J}, 100 \mathrm{~mW}, 35 \mathrm{~J} / \mathrm{cm}^{2}\right.$, área do spot $\left.0,028 \mathrm{~cm}^{2}\right)$. A terceira etapa comparou diferentes linhagens de camundongos (Balb-c e C57BI/6) nos melhores parâmetros de local e momento encontrados na etapa 2. Em todas as etapas foi avaliada a alteração de volume da pata através da pletismografia e o infiltrado inflamatório por histomorfometria ou análise da mieloperoxidase (MPO). Os resultados mostraram que a fototerapia com laser preveniu e tratou o edema assim como modulou o processo inflamatório com irradiações na pata e no linfonodo inguinal, de acordo com os parâmetros e a linhagem utilizada. 


\title{
PHOTOTHERAPY WITH LOW INTENSITY LASER IN CARRAGEENAN-INDUCED ACUTE INFLAMMATORY PROCESS IN MICE PAW - DOSIMETRY STUDIES
}

\section{DAIANE THAIS MENEGUZZO}

\begin{abstract}
The importance of modulation of inflammation on the treatment of inflammatory diseases and the difficulty in determining the laser irradiation parameters has led us to study the effects of different protocols of phototherapy with low intensity laser (power, energy, time and place of irradiation) in the treatment and prevention of edema in acute inflammatory process using the experimental model of paw edema induced by carrageenan (CGN) in three strains of mice (Balb-c, Swiss and C57BL/6). The first stage of the study evaluated different combinations of energy ( $1 \mathrm{~J}$ and $3 \mathrm{~J}$ ) with different powers (30, 60 and $100 \mathrm{~mW})$ in Balb-C mice paw irradiated 1 and $2 \mathrm{~h}$ after injection of CGN. The second stage studied different combinations of location (foot, inguinal lymph nodes and both) and exposure time ( 2 and $1 \mathrm{~h}$ before, $1 \mathrm{~h}$ and immediately before the CGN, 1 and $2 \mathrm{~h}$ and 3.5 and $4.5 \mathrm{~h}$ after $C G N)$ using fixed irradiation parameters $\left(1 \mathrm{~J}, 100 \mathrm{~mW}, 35 \mathrm{~J} / \mathrm{cm}^{2}\right.$, spot area of $0.028 \mathrm{~cm}^{2}$ ). The third stage compared different strains of mice Balb-c and C57BL/6) in the best local and time parameters found in step 2. At all stages, we evaluated the change in paw volume by plethysmography and inflammatory infiltrate by histomorphometry or analysis of myeloperoxidase (MPO). The results showed that laser phototherapy treated and prevented edema and modulated the inflammatory process with paw and inguinal lymph nodes irradiations accordingly with the parameters and mice strain used.
\end{abstract}


"Ninguém vale pelo que sabe, mas pelo que faz com aquilo que sabe"

L. Boff 


\section{AGRADECIMENTOS}

agRAdEÇO A DEUS E AO MEU ANJO dA GUARDA QUE ESTÁ SEMPRE PRESENTE ME GUIANDO E ACONSELHANDO PARA FAZER O QUE É REALMENTE IMPORTANTE PARA A MINHA EVOLUÇÃO.

AGRADEÇO AO MEU QUERIDO PAI, RICARDO E A MINHA QUERIDA MÃE THAIS PELO AMOR INCONDICIONAL E APOIO EM CADA CONQUISTA DA MINHA VIDA, VOCÊS SÃO MARAVILHOSOS!!!

AGRADEÇO AO MEU QUERIDO MARIDO THOMAS, PELA FELICIDADE MAIOR DE PODER COMPARTILHAR A VIDA COM AMOR, ALEGRIA E A SABEDORIA DE SABER VIVER CADA INSTANTE INTENSAMENTE.

AGRADEÇO AS MINHAS MARAVILHOSAS fAMÍLIAS MENEGUZZO, PASSUELLO, REBOUÇAS E SMITS PELO SUPORTE, AMIZADE, CARINHO E AMOR.

aOs fUNCIONÁRIOS, COLEGAS E PROFESSORES DO CLA E IPEN, À MINHA QUERIDA ORIENTADORA MARTHA PELA MARAVILHOSA ORIENTAÇÃO ACADÊMICA E AMIZADE VERDADEIRA. AOS FUNCIONÁRIOS E COLEGAS DE LABORATÓRIO DO ICB, AO MEU CO-ORIENTADOR RODRIGO PELA AMIZADE E OPORTUNIDADE DE PARCERIA CIENTÍFICA.

AOS MEUS PROFESSORES E COLEGAS DA ODONTO USP, ESPECIALMENTE DO LELO ONDE EU COMECEI A MINHA CAMINHADA NO MUNDO DAS IRRADIAÇÕES.

A MINHA QUERIDA AMIGA E COLEGA LEILA POR TODA A NOSSA CAMINHADA JUNTAS NA LASERTERAPIA DA VIDA... 
AO GRUPO DE LASER DA FÍSICA, AOS AMIGOS DA SÃO LEOPOLDO MANDIC E A COMUNIDADE CIENÍFICA NACIONAL E INTERNACIONAL DE LASER.

TODOS VOCÊS CONTRIBUIRAM PARA A CONSTRUÇÃO DA MINHA HISTÓRIA ACADÉMICA NO MUNDO dO LASER, dA SAÚdE E dA FÍSICA, E SEREI ETERNAMENTE GRATA.

AOS MEUS QUERIDOS AMIGOS, QUE NADA TEM A VER COM O LASER... MAS QUE TUDO TEM A VER COM A VIDA QUE NÃO SERIA TÃO MARAVILHOSA SEM VOCÊS! VOCÊS SABEM O QUÃO IMPORTANTES VOCÊS SÃO PARA MIM.

TODOS VOCÊS ESTÃo NO MEU CORAÇÃO E SEMPRE ESTARÃo!

E FINALMENTE, AGRADEÇO AO IPEN, AO CLA, AO ICB, À USP, AO CNPQ E À FAPESP POR TEREM VIABILIZADO O MEU DOUTORAMENTO.

COM CARINHO, DAIANE 


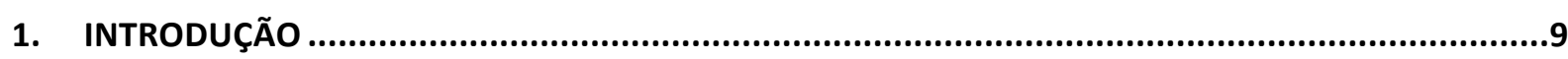

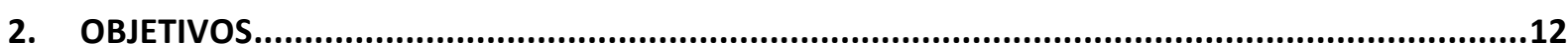

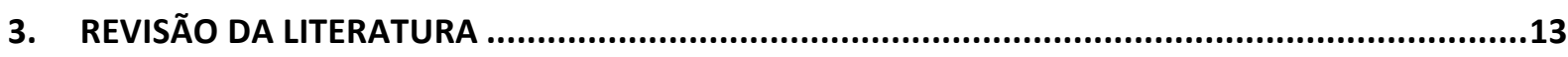

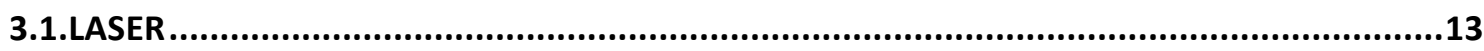

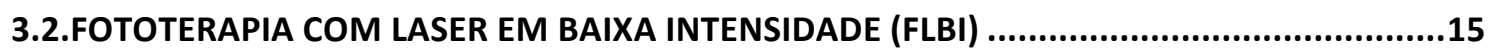

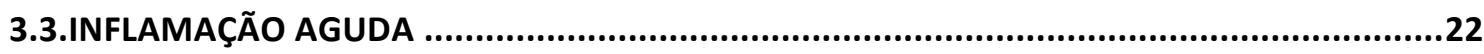

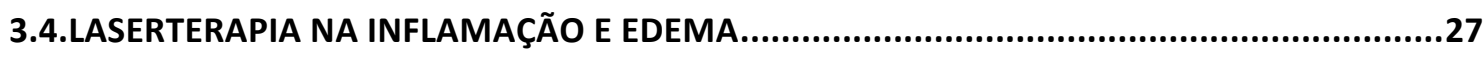

3.5.ESTUDOS DE DOSIMETRIA E PROTOCOLOS EM LASERTERAPIA ....................................31

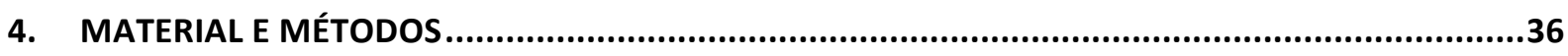

4.1.MODELO DE EDEMA DE PATA INDUZIDO POR CARRAGENINA EM CAMUNDONGOS ........36

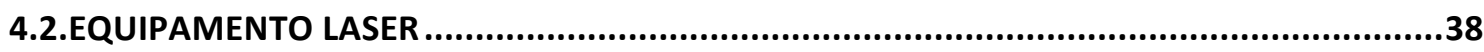

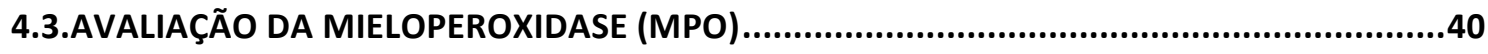

4.4.ANÁLISE HISTOLÓGICA - COLORAÇÃO HEMATOXILINA E EOSINA (HE)............................41

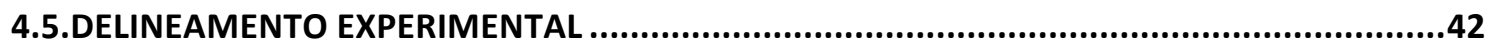

4.5.1.ETAPA 1: AVALIAÇÃO DA INFLUÊNCIA DA ENERGIA E POTÊNCIA .......................42

4.5.2.ETAPA 2: AVALIAÇÃO DA INFLUÊNCIA DO LOCAL E MOMENTO DE IRRADIAÇÃO 45

4.5.3.ETAPA 3: AVALIAÇÃO DA INFLUÊNCIA DOSIMÉTRICA EM DIFERENTES LINHAGENS

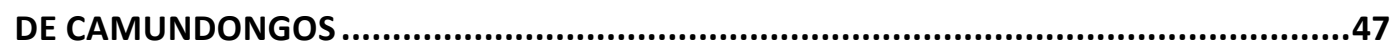

4.6.CONSIDERAÇÕES SOBRE A DENSIDADE DE ENERGIA $\left(\mathrm{J} / \mathrm{cm}^{2}\right)$ UTILIZADA NESTA TESE ......48

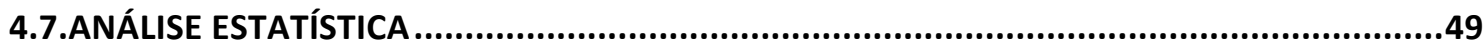

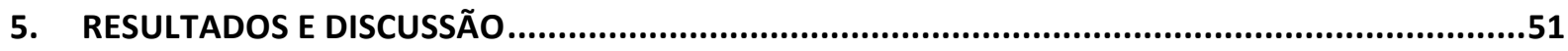

5.1.ETAPA 1: AVALIAÇÃO DA INFLUÊNCIA DA ENERGIA E POTÊNCIA .................................51

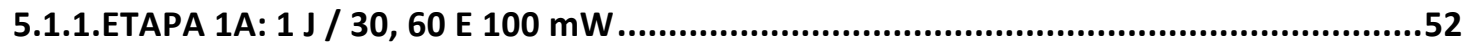

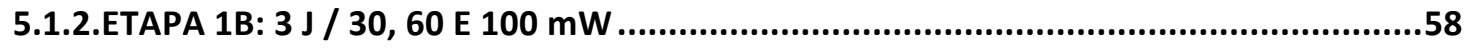

5.2.ETAPA 2: AVALIAÇÃO DA INFLUÊNCIA DO LOCAL E MOMENTO DE IRRADIAÇÃO ...........65 


\subsubsection{ETAPA 2A - AVALIAÇÃO DO EFEITO PREVENTIVO DA IRRADIAÇÃO}

(irradiações feitas $2 \mathrm{~h}$ e $1 \mathrm{~h}$ antes da injeção da carragenina)

5.2.2.ETAPA 2B - AVALIAÇÃO DO EFEITO PREVENTIVO DA IRRADIAÇÃO

(IRRADIAÇÕES FEITAS 1H E IMEDIATAMENTE ANTES DA INJEÇÃO DA

CARRAGENINA)

5.2.3.ETAPA 2C - AVALIAÇÃO DO EFEITO INIBITÓRIO DA IRRADIAÇÃO (irradiações feitas $1 \mathrm{~h}$ e $2 \mathrm{~h}$ depois da injeção da carragenina)

5.2.4.ETAPA 2D - AVALIAÇÃO DO EFEITO DO LASER NO TRATAMENTO DO EDEMA

(irradiações feitas $3,5 \mathrm{~h}$ e $4,5 \mathrm{~h}$ depois da injeção da carragenina)

5.3.ETAPA 3: AVALIAÇÃO DA INFLUÊNCIA DOSIMÉTRICA EM DIFERENTES LINHAGENS DE CAMUNDONGOS.

5.3.1.ETAPA 3A: LINHAGEM BALB-C 91

5.3.2.ETAPA 3B: LINHAGEM C57BL/6. .96

6. CONCLUSÕES. .105

7. REFERÊNCIAS BIBLIOGRÁFICAS .107

8. ANEXO 1. APROVAÇÃO DO COMITÊ DE ÉTICA EM PESQUISA DO IPEN .116

9. APÊNDICES .117

9.1.APÊNDICE 1. FOTOS DAS LÂMINAS DE HISTOLOGIA DA ETAPA 1A, EM AUMENTO DE 40X COM AS CINCO ÁREAS DE CONTAGEM DE CÉLULAS INFLAMATÓRIAS .117

9.2.APÊNDICE 2. FOTOS DAS LÂMINAS DE HISTOLOGIA DA ETAPA 3A, EM AUMENTO DE 40X COM AS CINCO ÁREAS DE CONTAGEM DE CÉLULAS INFLAMATÓRIAS 118

9.3.APÊNDICE 3. FOTOS DAS LÂMINAS DE HISTOLOGIA DA ETAPA 3B, EM AUMENTO DE 40X COM AS CINCO ÁREAS DE CONTAGEM DE CÉLULAS INFLAMATÓRIAS .118

9.4.APÊNDICE 4. DIFICULDADES ENCONTRADAS DURANTE A TESE. 119 


\section{INTRODUÇÃO}

A radiação laser é classificada conforme os efeitos causados nos tecidos biológicos. Eles podem ser térmicos (alta intensidade) ou não térmicos (baixa intensidade), caracterizando assim a laser cirurgia e a laserterapia. Em ambas as situações, os efeitos ocorrem pela transferência de energia do feixe laser para o tecido irradiado.

$\mathrm{Na}$ fototerapia com laser em baixa intensidade (FLBI) ou simplesmente laserterapia, a absorção da energia irradiada pode ocorrer através da absorção específica de energia por moléculas ou átomos receptores, denominados cromóforos, ou pela aceleração inespecífica de elétrons, aumentando a vibração ou induzindo um campo elétrico nas moléculas receptoras da irradiação.

O tecido alvo da laserterapia é preferencialmente um tecido que se encontra alterado, ou seja, em estresse celular (KARU, 1989). A radiação restabelece a homeostase energética e, cada célula, dentro das suas funções geneticamente programadas irá gradativamente recuperar-se do estado lesionado, voltando a realizar suas funções normais como proliferação, diferenciação, secreção de proteínas, etc. Além das funções celulares individuais, as funções multicelulares serão conseqüentemente restabelecidas, como a cicatrização de feridas, modulação da inflamação, redução do edema, e ativação da resposta imunológica nos pacientes irradiados.

A laserterapia atua, portanto, diretamente e especificamente sobre os tecidos irradiados aptos a absorverem a radiação laser, ou seja, fora de homeostase. Por outro lado, a farmacologia convencional atua não apenas na região lesionada, mas sobre diversos receptores espalhados pelo organismo, causando efeitos colaterais em tecidos previamente saudáveis.

As vantagens da utilização da laserterapia fazem com que ela seja amplamente utilizada como um tratamento coadjuvante, alternativo e não invasivo promovendo a 
aceleração de processos cicatriciais (CATÃO, 2004; KUCEROVA et al., 2000) redução de dor (FERREIRA et al., 2005; BJORDAL et al. 2006a,), edema (AIMBIRE et al., 2006; ALBERTINI et al., 2004 e 2007a) e modulação da inflamação (HONMURA et al., 1992; LOPES-MARTINS et al., 2005; AIMBIRE et al., 2005; ALBERTINI et al., 2007b; CORREA et al., 2007; BOSCHI et al., 2008; MORAIS et al., 2010).

As doenças inflamatórias como a asma brônquica (MILOJEVIC; KURUC, 2003a); inflamação aguda em pleurisia (inflamação na membrana serosa que reveste os pulmões) (MILOJEVIC; KURUC, 2003b; LOPES-MARTINS et al., 2005), lesões esportivas entre elas bursites e tendinites, (HANG et al., 2000; BJORDAL et al., 2003 e 2006b; STERGIOULAS et al., 2008;) efeitos antiinflamatórios em hiperatividade traqueal de ratos (AIMBIRE et al., 2005) entre outras, são doenças que podem ser tratadas com a laserterapia.

A inflamação é um mecanismo de defesa do organismo caracterizado como próprio dos tecidos conjuntivos, pois depende dos vasos sanguíneos o transporte dos agentes de defesa que atuarão contra o agressor nas áreas agredidas. Apesar dos principais eventos da inflamação serem locais, muitas células de defesa são produzidas a distância, nos linfonodos. Assim, a reação inflamatória (local) e o sistema imunológico (sistêmico) trabalham juntos na resolução do processo patológico tanto na inflamação aguda como na crônica.

A grande importância da modulação da inflamação no tratamento de doenças inflamatórias bem como a dificuldade na determinação dos protocolos de irradiação laser no tratamento dos pacientes levou-nos a estudar as possíveis interferências destes protocolos de irradiação sobre o tratamento da inflamação aguda. A relação entre os parâmetros laser como energia e potência, e a fase da lesão inflamatória mais propícia para receber a irradiação laser ainda são pouco discutidos na literatura. Além disso, ainda 
não existem estudos sobre os efeitos da radiação laser sobre os linfonodos, à distância do local lesionado, na inflamação aguda. 


\section{OBJETIVOS}

Este trabalho tem como objetivo estudar os efeitos de diferentes protocolos de fototerapia com laser em baixa intensidade no tratamento e prevenção do edema em processo inflamatório agudo utilizando o modelo experimental de edema de pata em camundongos induzido por carragenina.

Os objetivos específicos são:

1. Avaliar os efeitos de diferentes parâmetros de energia e potência na evolução do edema em pata de camundongos;

2. Avaliar a influência do local e momento de irradiação no tratamento, evolução e prevenção do edema em pata de camundongos;

3. Avaliar a resposta de diferentes linhagens de camundongos (Balb-C e C57BL/6) na prevenção, evolução e tratamento do edema;

4. Estudar a influência das diferentes condições dosimétricas sobre a inflamação aguda através da avaliação da atividade da mieloperoxidase (MPO) e número de células inflamatórias (histologia HE). 


\section{REVISÃO DA LITERATURA}

\subsection{LASER}

O laser é um equipamento que produz e emite radiação eletromagnética. A radiação eletromagnética pode ser considerada como um conjunto de ondas (elétricas e magnéticas) cuja velocidade no vácuo é aproximadamente $3 \times 10^{8} \mathrm{~m} / \mathrm{s}$ (velocidade da luz). As várias formas de radiação, caracterizadas pelo seu comprimento de onda, compõem o espectro eletromagnético (FIG.1).

\section{ESPECTRO ELETROMAGNÉTICO}

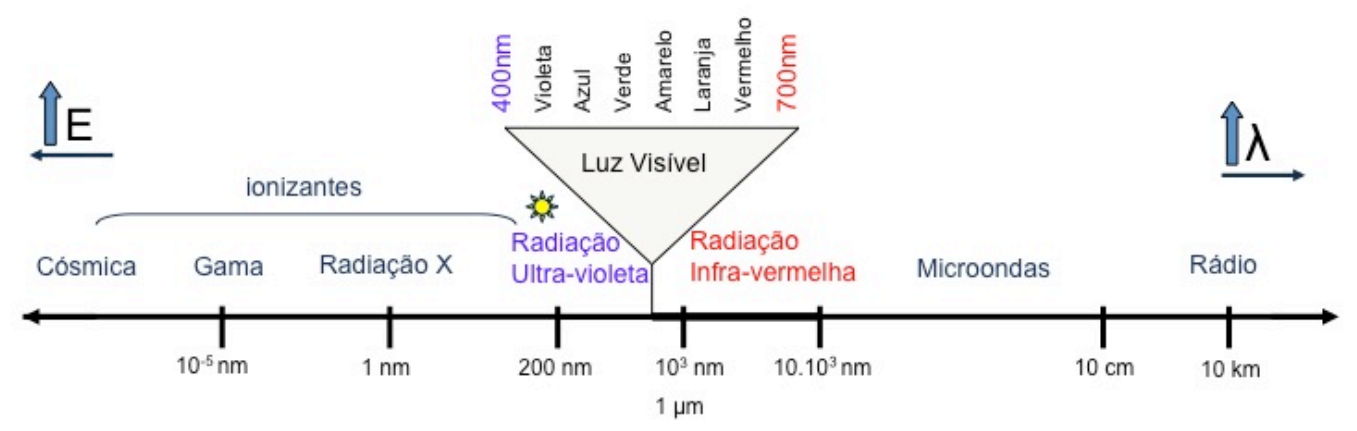

FIGURA 1 - Ilustração do espectro eletromagnético. Sendo $\lambda=$ comprimento de onda e $E=$ Energia do fóton.

Cada onda ou fóton que compõe o feixe de luz laser carrega uma quantidade de energia (E) na sua trajetória oscilatória. A distância entre dois picos (cristas ou vales) desta trajetória é chamada comprimento de onda $(\lambda)$ (FIG 2). A relação entre a freqüência $(\sqrt{ })$ que a onda oscila e o comprimento de onda é dado por: $\lambda . \sqrt{ }=\mathrm{c} / n$ onde $\mathrm{c}$ é a velocidade da luz no vácuo e $n$ o índice de refração do meio em que a radiação se propaga. 


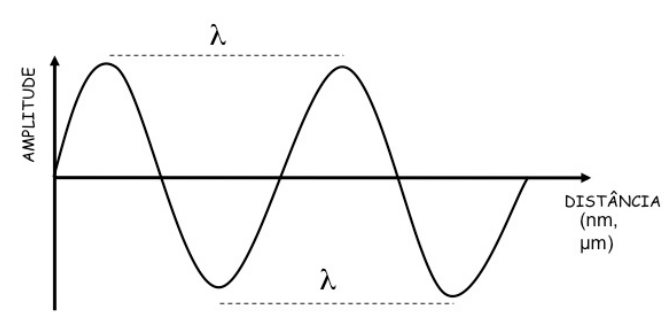

FIGURA 2 - llustração da trajetória de um fóton e o seu comprimento de onda (lambda, $\lambda$ )

O laser é composto por um feixe de fótons idênticos, oscilando na mesma freqüência e com mesmo $\lambda$, sendo, portanto monocromático. Uma vez que todos os fótons podem se propagar na mesma direção, outra característica da radiação laser é a direcionalidade (colimação), permitindo que a luz se propague como um feixe. Além disso, o laser é coerente, todos os seus fótons estão em fase, no tempo e espaço (EDUARDO, 2010).

A absorção da radiação eletromagnética ocorre quando um fóton é absorvido por um átomo (pelos elétrons deste átomo), fazendo com que um dos elétrons deste átomo pule para outro nível (órbita) de maior energia (estado excitado). Ao retornar ao seu nível inicial (estado fundamental), a energia é liberada em forma de outro fóton ou calor. A energia absorvida pelo átomo é correspondente a energia necessária para o elétron mudar de órbita, característica que varia entre os diferentes átomos. Se o nível de energia é suficiente, o elétron pula para outro nível de ainda maior energia, e pode escapar da atração do núcleo sendo liberado em um processo conhecido por fotoionização.

A radiação ionizante que provoca a fotoionização é considerada altamente energética com comprimento de onda $<100 \mathrm{~nm}$, como a radiação ultravioleta, raios $\mathrm{X} \mathrm{e}$ raios Gama. Um exemplo de reação química é a homólise da água por exposição à radiação ionizante, cujo produto é o radical $\mathrm{HO} \cdot$ (hidroxila) nas células da pele. O ataque intensivo e freqüente deste radical pode originar mutações no DNA podendo, conseqüentemente, levar ao desenvolvimento do câncer em seres humanos. 
A partir dos fenômenos físicos fenômenos químicos podem ocorrer como a dissociação de moléculas em seus componentes atômicos ou a formação de moléculas a partir de átomos instáveis. Ainda, a energia residual pode ser liberada em forma de fótons. Assim, após a absorção de um fóton por um átomo, este pode liberar outro fóton, liberar calor, promover ionização de átomos, ativar moléculas químicas, entre outros efeitos que irão provocar os efeitos biológicos que interferem nas funções específicas das células.

Ainda, em situações em que a energia é muito baixa, não ocorre absorção de energia pelo átomo, apenas aumenta a velocidade de rotação, translação ou vibração molecular. A radiação eletromagnética pode promover a aceleração e a desaceleração de elétrons (interferência construtiva e destrutiva de ondas), estimular o decaimento de átomos excitados (múltiplas colisões), promover transições rotacionais (microondas) e vibrações moleculares (infravermelho).

O mecanismo de funcionamento do equipamento laser é desta forma baseado na geração de fótons a partir da teoria de emissão estimulada de radiação de Albert Einstein de 1917. Esta teoria postula que um átomo excitado ao decair espontaneamente emite um fóton que pode estimular outro átomo a decair, e assim por diante. Esta emissão estimulada da radiação gera fótons com a mesma freqüência e, portanto, na mesma fase temporal e espacial do fóton que o estimulou. A palavra LASER é assim, um acrônimo de Light Amplification by Stimulated Emission of Radiation, ou seja, Amplificação da Luz por Emissão Estimulada de Radiação.

\subsection{FOTOTERAPIA COM LASER EM BAIXA INTENSIDADE (FLBI)}

A Fototerapia com laser em Baixa Intensidade (FLBI) ou simplesmente laserterapia, foi introduzida como modalidade terapêutica por Mester e colaboradores na década de 70, 
século XX (MESTER et al., 1971). Ela consiste na irradiação dos tecidos com equipamentos laser cujos efeitos térmicos no tecido irradiado não ultrapassem $1{ }^{\circ} \mathrm{C}$. Ou seja, sem lesão celular e o aquecimento causado não passa do nível molecular (BAXTER, 1997; KARU, 1987). Os efeitos biológicos da laserterapia não são térmicos, o que os difere dos lasers de alta potência que operam com potências acima de $1 \mathrm{~W}$ e cujos efeitos são relacionados com o alto e rápido aquecimento local do tecido.

Na laserterapia, a absorção da energia irradiada pode ocorrer através da absorção específica de fótons por átomos ou moléculas receptoras, denominados cromóforos, que alteram seu nível eletrônico de energia após a absorção de luz (LEVINE, 2001) ou pela aceleração de elétrons inespecífica induzindo um campo elétrico nas moléculas receptoras (AMAT et al., 2006).

Nas células existem alguns cromóforos já conhecidos que absorvem energia eletromagnética nos comprimentos de onda visível (V) entre 400 e 700 nm e infravermelho próximo (IVP) a partir de 700 nm até 2500 nm, como é o caso do citocromo c oxidase, das flavinas (FADH e NADH) (KARU 1987), além de outras enzimas da mitocôndria celular e porfirinas endógenas (OLSON; SCHIMMERLING; TOBIAS, 1981). Estes cromóforos são tipicamente metais ou moléculas que contêm átomos metálicos (SILFVAST, 2004). O citocromo c oxidase, por exemplo, é uma molécula cuja parte protéica absorve luz ultravioleta (UV), enquanto a parte metálica absorve a radiação $\mathrm{V}$ e IVP (PASTORE;GRECO; PASSARELLA, 2000).

A absorção da luz laser pelos cromóforos presentes nas células irá promover uma série de reações químicas iniciais responsáveis pela resposta celular à radiação. Estas reações ocorrem na presença da luz, e por isso são denominadas reações primárias (SCHINDL et al., 2000). 
As possíveis reações primárias em moléculas fotorreceptoras (cromóforos) após a promoção de estados eletrônicos excitados estão descritas na FIG. 3. As reações que alteram o estado redox promovendo a ativação enzimática, dissociação de componentes e outras reações químicas envolvem as hipóteses da alteração das propriedades redox e do óxido nítrico. Reações mediadas por radicais livres aceleram o metabolismo celular e podem ser tóxicas se em excesso e envolvem as hipóteses do ânion superóxido e do oxigênio singleto. Já a hipótese do aquecimento local transitório ocorre diretamente sobre os vasos sanguíneos, causando o relaxamento térmico imediato (KARU, 2000).

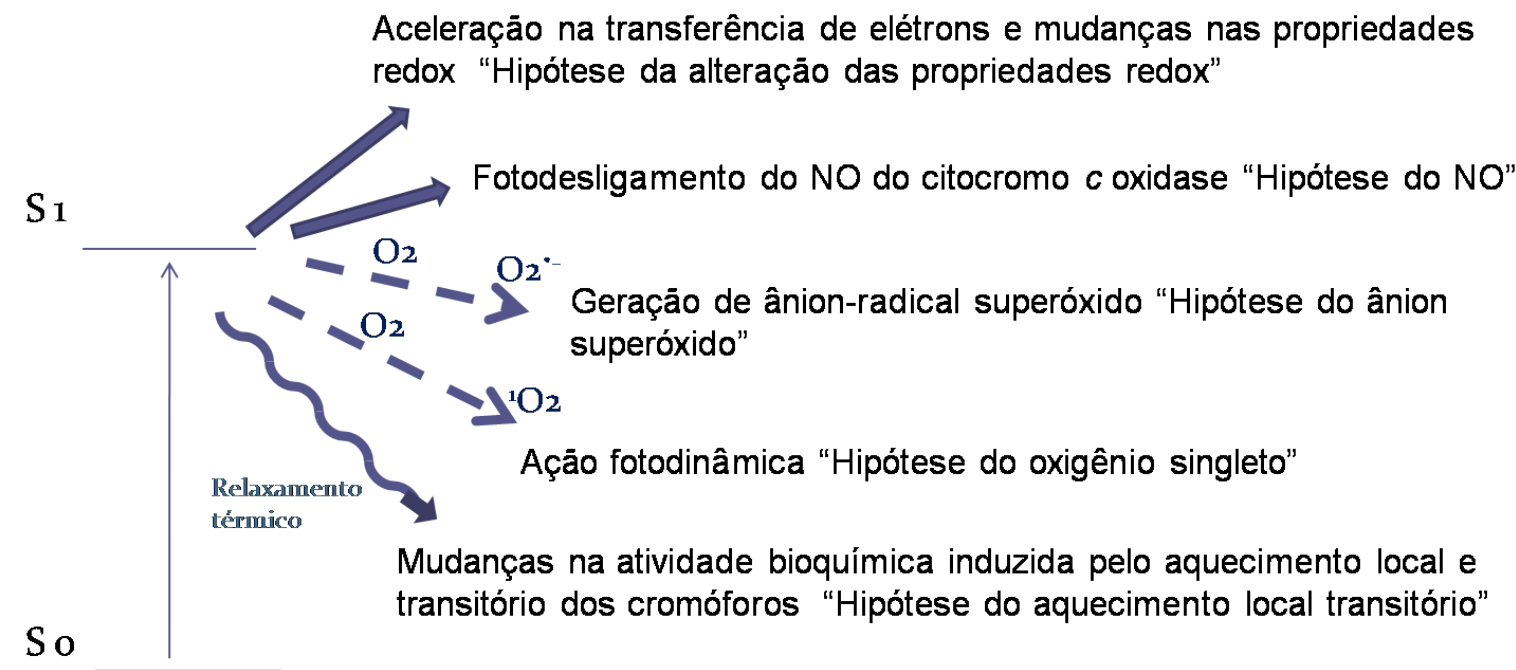

FIGURA 3 - Possíveis reações primárias em moléculas fotorreceptoras após a promoção de estados eletrônicos excitados: S0 (estado fundamental), S1 (estado excitado singleto). Adaptado de Karu, (2000).

Segundo Karu, o tecido alvo da laserterapia é um tecido que se encontra em estado redox alterado, ou seja, em estresse, lesionado, fora de sua homeostase natural. Isso ocorre devido a alguns fotorreceptores só serem expressos neste tipo de situação celular, como é o caso do composto NO-citocromo C oxidase. O óxido nítrico (NO) só é ligado ao 
citocromo C oxidase em situação de estresse celular, e estando ligado, interrompe a produção normal de ATP (adenosina trifosfato) na mitocôndria. A radiação laser, neste caso, dissocia este composto, liberando NO e restabelecendo a produção de ATP, molécula responsável pelo fornecimento de energia celular. Com a homeostase energética restabelecida, cada célula, dentro das suas funções geneticamente programadas irá gradativamente se recuperar do estado lesionado. Além das funções celulares individuais, as funções multicelulares também serão restabelecidas mais rapidamente, gerando os macroefeitos da laserterapia: modulação da inflamação, analgesia, redução do edema e ativação da resposta imunológica nos pacientes irradiados (BOSCHI et al., 2008; MORAIS et al., 2010; ALBERTINI et al., 2007a; AGAIBY et al., 2000; ).

Dá-se o início, desta forma as reações secundárias que correspondem a cascata de eventos que ocorrem a partir da irradiação, não mais dependentes da luz (SCHINDL et al., 2000). As alterações do pH intracelular, relacionadas com a ativação das ATPases e seguidas por alterações nos níveis de cálcio intracelular, parecem ser um caminho comum para a transdução do sinal e amplificação de todas as fotoreações primárias citadas. A mudança do estado redox para oxidação acarreta um aumento intracelular de $\mathrm{Ca}^{+2}$ que estimula o metabolismo celular, uma vez que estimula vários processos biológicos, como síntese de RNA e DNA, mitose celular e secreção protéica (LOEVSCHALL; ARENHOLT-BINDSLEY, 1994). Por outro lado, a redução leva à diminuição de $\mathrm{Ca}^{+2}$ intracelular e, portanto, inibição do metabolismo celular (FRIEDMAN; LUBART, 1996). Tanto a estimulação quanto a inibição da entrada de $\mathrm{Ca}^{+2}$ nas células de mamíferos podem ser induzidos por luz vermelha monocromática dependendo da dosagem aplicada (KARU, 1996). Além disso, altas doses de energia podem provocar um dano fotodinâmico (produção exacerbada de radicais livres) ou danificar ou destruir os 
fotoreceptores (cromóforos), inibindo os processos celulares (KARU, 1989; FRIEDMAN, LUBART E LAULICHT, 1991, MESTER et al., 1985; SCHINDL et al., 2000).

Vários trabalhos tentam mostrar os efeitos fotoquímicos provocados pela radiação laser , como o é o caso da reativação da enzima Cu-Zn superóxido dismutase (SOD) com grande importância na medicina (VLADIMIROV, et al., 2004). A inativação da enzima se dá pela protonação do resíduo de histidina no centro ativo da enzima em pH ácido e na presença da $\mathrm{H}_{2} \mathrm{O}_{2}$, em condição de lesão celular. A radiação laser provoca a deprotonação da enzima no meio ácido com subseqüente formação da estrutura ativa da enzima. A função da SOD é reduzir a concentração do ânion superóxido $\left(\mathrm{O}_{2}^{-}\right)$que ao reagir com outras substâncias dá origem a radicais superóxidos altamente reativos como, por exemplo, o radical hidroxila $\mathrm{OH}^{*}$, de ação citotóxica e mutagênica. Uma vez que a concentração de $\mathrm{O}_{2}$ diminui nas células onde o radical está sendo amplamente produzido, a ação protetora da SOD se dá ao catalisar a reação de dismutação do radical superóxido $\left(\mathrm{O}_{2}{ }^{-}\right),\left(\mathrm{OO}^{-} \Rightarrow{ }^{\mathrm{SOD}_{\Rightarrow}} \mathrm{O}_{2}+\mathrm{H}_{2} \mathrm{O}_{2}\right)$, produzindo $\mathrm{O}_{2}$. Estes efeitos protetores da SOD quando recuperados podem evitar um dano cardíaco e cerebral devido à deficiência de oxigênio, que em certos pontos destes tecidos é uma das principais causas de morte (TUBY et al., 2006).

Ainda, a laserterapia tem ação fotodinâmica em membranas quando a hematoporfirina e/ou seus derivados + fosfolipídeos acumulados na membrana celular em certas doenças são irradiadas, promovendo a peroxidação lipídica da camada fosfolipídica da membrana diminuindo a estabilidade elétrica da membrana e lesionando as bombas de cálcio ( $\mathrm{Ca}^{++}$ATPase) . Os efeitos do aumento da permeabilidade e concentração intracelular de íons cálcio, variam dependendo do tipo celular, no entanto, geralmente resultam em ativação e/ou proliferação celular (VLADIMIROV et al., 2001). 
Além dos efeitos locais da irradiação, efeitos sistêmicos são observados. Produtos de peroxidação lipídica e lipoproteínas do plasma sanguíneo oxidadas após a irradiação no sangue induzem uma pré-estimulação de leucócitos que quando em contato com membranas bacterianas, lectinas, antibióticos carregadores de cálcio e outras substâncias, aumentam em duas ou três vezes a geração de radicais livres em resposta ao estímulo (VLADIMIROV, et al., 2004). Ainda, a radiação no sangue promove a dissociação do óxido nítrico (NO) com a hemoglobina, (laser+HbNO $\Rightarrow \mathrm{Hb}(\mathrm{Fe} 2+)+\mathrm{NO})$ e a liberação do NO provoca vasodilatação, aumentando o fluxo sanguíneo além de ativar genes do fator de crescimento vascular endotelial (VEGF) promovendo aumento da angiogênese após a radiação.

Segundo Campana e cols. (1998), o aumento do metabolismo tecidual, a normalização da homeostase e ainda o aumento da formação de cGMP (guanosina cíclica monofosfato) formado pelas células endoteliais levam a uma vasodilatação e aumento no fluxo sanguíneo, não sendo portanto resultado de efeito térmico sobre os tecidos.

A radiação laser também tem demonstrado ser efetiva sobre moléculas dipolares não absorvedoras da radiação $\mathrm{V}$ e IVP, como enzimas sem átomos metálicos, bombas iônicas, material nuclear e moléculas de nucleotídeos. A miosina ATPase inativada com $\mathrm{CO}_{2}$ foi parcialmente ativada com o laser de $\mathrm{He}-\mathrm{Ne}(632,8 \mathrm{~nm})$ e diodo $(904 \mathrm{~nm})$, e a produção de ATP foi aumentada com a irradiação e também por um campo elétrico pulsado (BOLOGNANI et al., 1992). Segundo Amat e colaboradores (2006), vias celulares podem ser ativadas quando um campo elétrico induzido por luz interage com moléculas de ATP, $\mathrm{Na}^{+} / \mathrm{K}^{+}$ATPase (bomba $\mathrm{Na}^{+} / \mathrm{K}^{+}$), mitocôndrias, enzimas e fosfolipídios de membrana que regulam a sinalização do cálcio. Nestes casos, não ocorre a absorção eletrônica pelos átomos e moléculas, mas a indução das cargas das moléculas irradiadas 
pelo componente elétrico da energia eletromagnética (CHANG et al., 2004; QUAGLINO et al., 2004; LIU et al., 2005; BLANK, 1992).

A molécula de adenosina, presente no ATP, ADP (adenosina difosfato) e AMP (adenosina monofosfato) só é capaz de absorver a luz ultravioleta. No entanto, a irradiação V e IVP causam modificação na cinética das reações químicas que elas estão envolvidas (sem aumento de temperatura) (GAGLIARDI et al.,1997; AMAT et al., 2004; 2005). Ainda, quando um campo elétrico induzido por luz é aplicado uma nova isoforma do fosfato pode ser produzida, levando a modificações na distribuição das cargas na estrutura do fosfato o que torna a molécula mais instável e fácil de ser clivada pela enzima. A bomba de $\mathrm{Na}^{+} / \mathrm{K}^{+}$ATPase é uma enzima de membrana que faz hidrólise de ATP na presença de $\mathrm{Na}^{+}$e $\mathrm{K}^{+}$para seu transporte ativo. $\mathrm{O}$ gradiente de $\mathrm{Na} / \mathrm{K}$ controla o volume celular, conduz transporte ativo de açúcares e aminoácidos, controla excitação elétrica de células nervosas e musculares e é responsável pelo consumo de $1 / 3$ da energia (ATP) em repouso das células. Esta bomba apesar de ser estimulada pelo laser de He-Ne (KILANCZYK, et al., 2002), não possui cromóforos para a absorção no $V$, assim, um potencial transmembrana gerado pelo campo elétrico induzido por luz, ativa a bomba $\mathrm{Na} / \mathrm{K}$ sem a quebra de ATP. Outro fosfolipídio estrutural de membrana, cujo grupo fosfato pode ser modificado pelo deslocamento de carga, o $\mathrm{PIP}_{2}$ (fosfatidilinositol 4,5bifosfato), também fica mais instável e é mais facilmente quebrado pela fosfolipase C originando $\mathrm{IP}_{3}$ (inositol trifosfato) + DAG (diacliglicerol). $\mathrm{O} \mathrm{IP}_{3}$ atua abrindo os canais de cálcio no retículo endoplasmático (RE). O cálcio liberado promove fosforilação de proteínas e expressão gênica. Além disso, o cálcio é importante na síntese de ATP pela mitocôndria: diminui o potencial de membrana e ativa síntese de ATP.

Após a irradiação, o ATP no citoplasma reage com enzimas, é quebrado, o que aumenta a quantidade de ADP, que pelo feedback negativo estimula a síntese de ATP. A 
luz também altera o potencial de membrana mitocondrial estimulando a síntese de ATP, e quando o metabolismo celular está em condições anaeróbicas a luz aumenta a cinética da reação da hexokinase estimulando a síntese de ATP fora da mitocôndria.

Desta forma, o aumento no metabolismo celular (HAWKINS E ABRAHAMSE, 2006), proliferação e síntese de colágeno mais acentuado em fibroblastos (EFENDIEV et al., 1992; PEREIRA et al., 2002); síntese protéica (MARQUES et al., 2004); aumento no potencial de ação de células nervosas (ANDERS et al., 1993; ROCHKIND et al., 1986); estimulo da formulação de DNA e RNA no núcleo celular (LOEVSCHALL; ARENHOLTBINDSLEY, 1994); efeitos sobre o sistema imunológico pela ativação de linfócitos (TONG et al., 2000); formação de capilares estimulada pela liberação de fatores de crescimento e aumento na atividade de leucócitos (AGAIBY et al., 2000; SALATE et al., 2005; MIRSKY et al., 2002;) e ação antiinflamatória da irradiação laser (LOPES-MARTINS et al., 2005; STERGIOULAS et al., 2008; CORREA et al., 2007; BOSCHI et al., 2008; MORAIS et al., 2010) são outros efeitos secundários da fototerapia com laser em baixa intensidade.

\subsection{INFLAMAÇÃO AGUDA}

A resposta inflamatória consiste em um conjunto de alterações morfológicas e bioquímicas do tecido conjuntivo, envolvendo eventos vasculares e celulares e tem como objetivo recompor a homeostase do tecido lesionado. Os diversos agentes desencadeantes sensibilizam, evadem ou destroem as barreiras primárias (células epiteliais ou endoteliais e suas estruturas especializadas), iniciando o processo de defesa, inicialmente denominado inflamação aguda.

Os diversos agentes (ou estímulos) inflamatórios podem ser os mais variados como patógenos (bactérias, vírus, parasitas), substâncias exógenas irritantes (carragenina, por exemplo) ou endógenas (cristais de urato, complexos imunes); podem ser ainda, 
estímulos mecânicos (traumáticos), físicos (queimaduras, radiação ionizante) e químicos (substâncias cáusticas) (VOLTARELLI, 1994; CIRINO et al., 2006).

Independentemente da natureza do estímulo desencadeante, as células lesionadas ativam o sistema fagocítico mononuclear (monócitos circulantes e macrófagos teciduais) iniciando a cascata de eventos pela secreção de citocinas da família da IL-1 e TNF (fator de necrose tumoral). Estas moléculas têm ação pleiotrópica (células alvo múltiplas e múltiplas ações), tanto a nível local como sistêmico. Localmente, agem sobre células da matriz ou estroma tecidual, principalmente fibroblastos e células endoteliais, causando a liberação de um segundo conjunto de citocinas que incluem, além da própria IL-1 e TNF, também IL-6 e IL-8 e as proteínas inflamatórias (MIP-1) e quimiotáticas (MCP) de macrófagos. Esta última proteína, juntamente com IL-1, IL-8 e TGF-ß, atrai para o foco inflamatório monócitos e neutrófilos, os quais, por sua vez, secretam um terceiro conjunto de citocinas, incluindo o TNF e outros fatores quimiotáticos, que retroalimentam o processo inflamatório.

O endotélio vascular desempenha papel central na comunicação entre o sítio inflamatório e os leucócitos circulantes, tanto pela expressão de moléculas de adesão, que facilitam a migração tecidual das células de defesa (monócitos e neutrófilos), como pela modificação do tônus vascular mediado por metabólitos do ácido araquidônico (prostaglandinas, tromboxanos e leucotrienos), pelo óxido nítrico e pelas cininas, causando vasodilatação (eritema), aumento da permeabilidade vascular pela histamina (edema) e hipotensão arterial. A outra manifestação clássica da inflamação, a dor, é mediada basicamente, além das prostaglandinas, pela bradicinina, um nanopeptídio que também participa da ativação da cascata da coagulação além das mais recentemente descritas neurocininas (BAUMANN; GAULDIE 1994; VOLTARELLI, 1994). 
As prostaglandinas são importantes mediadores de uma grande variedade de processos fisiológicos (TILLEY; COFFMAN; KOLLER, 2001). Elas são produzidas a partir do ácido araquidônico pela enzima ciclo-oxigenase (COX) que possui várias isoformas, entre elas a COX-1 e a COX-2. A COX-1 é expressa na maioria dos tipos celulares regulando funções fisiológicas normais como a contractibilidade gastrointenstinal (GI), a proteção da mucosa, agregação plaquetária e a manutenção da função renal. A COX-2, descoberta posteriormente (XIE et al.,1991), é considerada essencialmente, mas não exclusivamente inflamatória. Sua expressão é fisiológica em alguns tecidos (renal, cerebral e pulmonar), mas é predominante em locais de inflamação. Sua indução resulta na produção de prostaglandinas que contribuem para a dor, edema e destruição tecidual associada com os episódios agudos da inflamação (VANE; BAKHLE; BOTTING, 1998). Mais recentemente, foi demonstrado que a ativação da COX2 pode levar a produção de outros mediadores inflamatórios como as lipoxinas e resolvinas, que são importantes para a resolução da inflamação (XU et al., 2010) contribuindo, por exemplo, para a reparação de úlceras gástricas (FU et al., 1999; JONES et al., 1999; MIZUNO et al., 1997; MA et al., 2002).

O processo inflamatório que ocorre após a injúria tecidual é mediado em parte pela quebra da fosfolipase A2, constituinte da membrana da célula lesionada, em seus componentes lipídicos ácidos (FIG. 4) (MOORE; HERSH, 2001). Um destes componentes, o ácido araquidônico, é então convertido em prostaglandinas, prostaciclinas e tromboxanos por uma das suas várias enzimas COXs. Entre estes mediadores, as prostaglandinas são os mais importantes responsáveis pela hiperalgesia e inflamação sensibilizando as terminações nervosas às ações das bradicininas e histaminas aumentando a dor e a gravidade da inflamação (KESSENICH, 2001). Além disso, altas concentrações teciduais de prostaglandinas são responsáveis por iniciar a 
vasodilatação levando clinicamente ao eritema e edema. Por outro lado, enquanto o tromboxano liberado pelos trombócitos se caracteriza por determinar a agregação plaquetária assim como a vasoconstrição, as prostaciclinas inibem a agregação plaquetária e determinam o relaxamento vascular, tendo sua origem nas paredes arteriais (KESSENICH, 2001 e MOORE; HERSH, 2001).

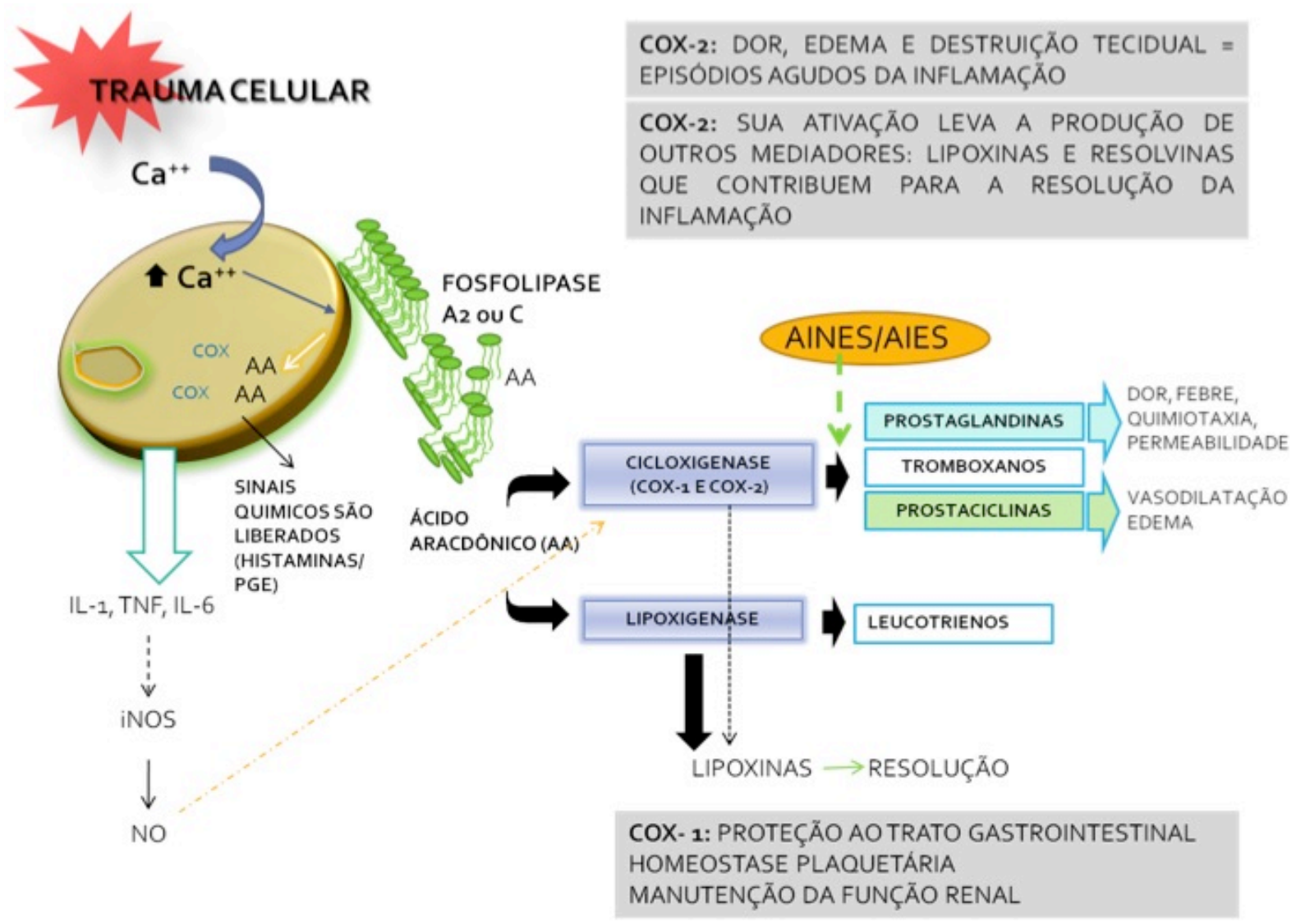

FIGURA 4 - Esquema da cascata da reação inflamatória após injuria tecidual. AINES/AIES (antiinflamatórios não esteroidais e esteroidais)

A progressão da reação inflamatória ocorre com o auxílio do sistema imunológico que juntos caminham em direção a resolução do processo patológico. Os linfonodos e outros órgãos linfáticos secundários como o baço, são os locais mais importantes onde as células imunológicas trocam informações, residem, desenvolvem-se, e iniciam a resposta 
imunológica adaptativa (SWARTZ et al., 2008). A partir da drenagem do líquido intersticial e transporte de potenciais antígenos para os gânglios linfáticos, o sistema linfático agiliza a resposta imunológica permitindo o patrulhamento de linfócitos antígenos-específicos ainda nos gânglios linfáticos sem necessidade de estarem presentes nos tecidos periféricos (SWARTZ et al., 2008).

O sistema linfático complementa o ramo venoso da circulação drenando o excesso de fluido e solutos do espaço intersticial e devolvendo-os para o sangue. Durante a inflamação, a drenagem do líquido do tecido pode ser aumentada de 10 vezes ou mais, o que aumenta tanto a taxa de entrega do antígeno da periferia para o linfonodo como para as células dendríticas circulantes, que estão fisicamente posicionadas para levar o antígeno dos tecidos periféricos para os nódulos linfáticos.

Além disso, as citocinas que são produzidas no local afetado são levadas para os linfonodos de drenagem, onde podem provocar alterações que permitem aumentar o tráfego de células imunológicas, incluindo a expansão da arteríola que aumenta o fluxo sanguíneo e, portanto, o tráfego de linfócitos para os linfonodos afetados. A inflamação também pode, aparentemente, induzir a expansão da rede linfática nos linfonodos o que pode ajudar a recrutar mais células dendríticas da periferia para os linfonodos ou aumentar o tráfego de células $T$ para fora dos linfonodos. Assim, uma série de mecanismos de feedback positivo existentes fazem com que a inflamação induza uma maior exposição de antígenos periféricos para os linfonodos (SWARTZ et al., 2008).

O tratamento da inflamação é atualmente realizado com os tradicionais fármacos antiinflamatórios esteroidais (AIEs) como a dexametasona e a prednisolona e nãoesteroidais (AINEs) como, por exemplo, o ibuprofeno, diclofenaco e naproxeno além dos inibidores específicos da COX-2 (celecoxib e rofecoxib). Estes últimos, também chamados de COXIBs, têm sido utilizados como substitutos dos AINEs por não provocarem os 
efeitos colaterais usuais (úlceras gástricas, sangramento e toxicidade hepática) causados pela também inibição da isoforma COX-1 (MOORE; HERSH, 2001). No entanto, seus efeitos deletérios cardiovasculares têm sido bastante questionados além de novos trabalhos mostrarem que a COX-2 tem grande importância na resolução do processo inflamatório. (XU et al., 2010)

Além destes fármacos, outras técnicas alternativas como a estimulação elétrica, ondas curtas, infravermelho, ultra-som e a laserterapia têm sido utilizadas com resultados satisfatórios no tratamento das doenças inflamatórias (FULGA et al., 1995; KITCHEN; PARTRIDGE, 1991; LOPES-MARTINS et al., 2005).

\subsection{LASERTERAPIA NA INFLAMAÇÃO E EDEMA}

As vantagens terapêuticas da laserterapia na inflamação têm sido sugeridas por vários autores (BOULNOIS, 1985; BJORDAL et al., 2003; NUNEZ et al., 2006; FERREIRA et al., 2005; NES; POSSO, 2005: QUADRI et al., 2005). Os principais mecanismos responsáveis pela modulação da inflamação desencadeada pela radiação laser envolvem o aumento da microcirculação local (SHAFFER et al., 2000), promoção da angiogênese (MIRSKY 2002), vasodilatação (CAMPANA et al., 1998), inibição de mediadores inflamatórios como a PGE2 (CAMPANA 1998; CASTANO 2007), ativação das células de defesa (AGAIBY et al., 2000), efeitos antioxidantes (FILLIPIN et al., 2005) e aceleração da cicatrização celular (DEMIDOVA-RICE et al., 2007). Todos estes efeitos podem ocorrer simultaneamente resultando no efeito modulador do laser na resposta inflamatória, que envolve ações pró-inflamatórias e antiinflamatórias.

Já a ação analgésica da laserterapia pode ser explicada a partir de algumas hipóteses: a partir da modulação dos processos inflamatórios (HONMURA et al. 1992); alterando a excitação e condução nervosa dos neurônios periféricos (BASFORD et al., 
1993) e pela liberação de endorfinas endógenas estimulada pela radiação laser (LAAKSO et al., 1995).

A ação bloqueadora do laser sobre os neurônios ocorre a partir da redução do potencial de membrana mitocondrial (PMM) promovida pela radiação, com a conseqüente diminuição do ATP disponível, fundamental para a transmissão do estímulo nervoso pelo axônio (CHOW et al., 2007). Em experimentos realizados em ratos, o laser em 830 nm induziu a formação de varicosidades, reduziu o PMM e bloqueou a transmissão axonal em neurônios da raiz ganglionar dorsal de diâmetro pequeno e médio (CHOW et al., 2007). A aplicação repetida da laserterapia em estudos clínicos mostrou modular a nocicepção e reduzir a dor, podendo ser uma alternativa não farmacológica no tratamento da dor crônica (CHOW et al., 2007; MENEGUZZO et al., 2010).

Os efeitos antiinflamatórios do laser como a redução do edema podem, segundo Schaffer (2000), estar parcialmente relacionados com o aumento da circulação sanguínea. A laserterapia estimula a microcirculação sanguínea, vasodilatação e angiogênese (SCHINDL et al., 2003, NÚÑEZ et al., 2004, IHSAN, 2005) e segundo Jan Tunér, a melhora na microcirculação dos tecidos promovida pela radiação laser é um dos aspectos mais importantes da laserterapia. A capacidade de auto-regeneração e defesa tecidual irá aumentar consideravelmente se a circulação sanguínea local for aumentada assim como a absorção dos agentes farmacológicos também será beneficiada (TUNER \& HODE, 2010).

Mirsky e cols. (2002) propõe a utilização clínica da laserterapia como opção terapêutica para melhorar a angiogênese em condições isquêmicas. Seu estudo, realizado em coração infartado de frango mostrou que o laser promove significativamente a angiogênese além de aumentar a proliferação de células endoteliais em cultura. 
Além disso, os efeitos do laser na modulação dos mediadores inflamatórios são amplamente relatados na literatura. Entre os mediadores envolvidos na inflamação, o mais citado é a $\mathrm{PGE}_{2}$. $\mathrm{A} \mathrm{PGE}_{2}$ é um potente mediador envolvido nos processos inflamatórios e álgicos, sendo o mediador chave na artrite (JARVIS et al., 1990). Ele causa hiperalgesia e vasodilatação e, em combinação com outros agentes, o extravasamento de líquidos para os tecidos adjacentes, o que promove a formação do edema (CAMPANA et al., 1998).

Campana (1998) demonstrou que o laser inibe a síntese de $\mathrm{PGE}_{2}$ em processo inflamatório induzido em ratos e também em pacientes com artrite no joelho. Em artrite induzida por zymozan, a radiação infravermelha mostrou reduzir o edema articular de forma correlacionada com a redução do marcador inflamatório de prostaglandina E2 (PGE2) (CASTANO et al., 2007) também demonstrado em estudo recente de Morais e cols. (2010).

Além da redução dos níveis de $\mathrm{PGE}_{2}$, a laserterapia também inibe a expressão da cicloxigenase-2 (HONMURA et al., 1993; SHIMIZU et al., 1995). Ferreira e colaboradores (2005), usando um modelo de hiperalgesia induzida por carragenina demonstraram que o efeito analgésico causado pelo laser não envolve um receptor opióide periférico, mas os eventos posteriores de liberação de $\mathrm{PGE}_{2}$ durante a inflamação aguda.

Em revisão publicada por Bjordal e cols. (2006) sobre os efeitos biológicos e clínicos da laserterapia na dor aguda de tecidos moles lesionados, a laserterapia mostrou modular a dor inflamatória reduzindo os níveis de marcadores bioquímicos $\left(\mathrm{PGE}_{2}, \mathrm{mRNA}, \mathrm{COX}-2\right.$, IL-1, TNF), o influxo de neutrófilos, estresse oxidativo e reduzindo a formação de edema e hemorragia. Em outra revisão sistemática, o laser mostrou ser efetivo em desordens articulares crônicas como a osteoartrite (BJORDAL et al., 2003). 
Morais (2010) demonstrou que a laserterapia inibiu a formação de edema, a permeabilidade vascular e a hiperalgesia em artrite induzida por zymosan. A redução da permeabilidade vascular foi de $24 \%$, a formação de edema foi reduzida em $23 \%$, e a incapacitação articular em 59\%.

Milojevic e Kuruc (2003) estudaram os efeitos do laser de baixa intensidade no tratamento da asma brônquica e relataram que o laser foi capaz de aumentar a complacência e ventilação pulmonar. Outro estudo clínico revelou os benefícios da laserterapia nas patologias inflamatórias como bursites e tendinites (HANG et al., 2000).

Lopes-Martins e colaboradores (2005) estudaram os efeitos da fototerapia com laser em baixa intensidade na inflamação aguda em pleurisia (inflamação na membrana serosa que reveste os pulmões) e relataram que irradiações realizadas entre uma e três horas após a indução da inflamação reduzem significativamente a migração de células inflamatórias. Em trabalho realizado em camundongos com indução de peritonite a partir de lipopolisacarídeos, a irradiação com laser infravermelho de 904 nm demonstrou reduzir a migração de células inflamatórias (CORREA et al., 2007).

Além disso, a laserterapia mostrou alterar a expressão de mRNA de receptores de cinina em modelo de edema de pata de rato induzida por carragenina. Ambos receptores B1 e B2 tiveram sua expressão diminuída após a irradiação indicando outra contribuição da laserterapia nos efeitos antiinflamatórios (BORTONE et al., 2008). Os receptores B1 e B2 são fundamentais para a etiologia da dor e inflamação, sendo o B2 constitutivo e comumente associado com a fase aguda da inflamação e nocicepção, enquanto que o B1 é induzível e ligado à fase crônica da inflamação (CAMPOS et al., 2006).

Aimbire e colaboradores (2005) demonstraram que a laserterapia produz efeitos antiinflamatórios em hiperatividade traqueal de ratos, lavagem broncoalveolar e no influxo 
pulmonar de neutrófilos em ratos tratados com lipopolisacarídeos de bactérias gramnegativas.

Albertini e colaboradores (2004) estudaram os efeitos do laser de baixa intensidade sobre a inflamação aguda no modelo experimental de edema de pata em ratos e os resultados demonstraram redução no edema induzido por carragenina pelo laser de baixa potência. Os efeitos antiinflamatórios promovidos pelo laser puderam ser comparados com o efeito do fármaco diclofenaco de sódio na dose de $1 \mathrm{mg} / \mathrm{kg}$. Além disso, neste estudo, ratos adrenalectomizados também foram utilizados e os resultados sugeriram que a terapia laser depende da liberação de corticosteróides, já que estes animais não foram afetados pela laserterapia. Uma vez que a potente ação antiinflamatória dos corticosteróides é através da inibição da enzima fosfolipase A2, chave na cascata inflamatória, os autores sugeriram que os mecanismos de ação antiinflamatória do laser de Ga-Al-As (650nm) utilizado neste estudo poderia ser devido a liberação do cortisol pela glândula supra-renal e ativação do eixo hipófise - hipotálamo - adrenal.

Em 2007 o mesmo autor (Albertini et al., 2007) demonstrou em modelo animal de edema a redução da expressão do mRNA da COX-2 causada pela irradiação laser. E em 2008 (Albertini et al., 2008) mostrou uma redução de 30 a 40\% na expressão gênica de mediadores inflamatórios (TNF, IL-2, IL-6 mRNA) em lesão inflamatória em pata induzida por carragenina irradiada quando comparadas com o grupo controle não irradiado.

\subsection{ESTUDOS DE DOSIMETRIA E PROTOCOLOS EM LASERTERAPIA}

O sucesso que se busca em qualquer tratamento é baseado na resposta favorável do tecido caracterizando a efetividade da terapia. Na laserterapia, muitos fatores podem interferir no sucesso do tratamento clínico como as características do paciente, o tipo e fase da lesão, os tecidos que serão irradiados, os parâmetros físicos associados com a 
irradiação (energia, fluência, potência, intensidade, área do feixe laser, área da lesão, comprimento de onda, tempo de exposição, modo de aplicação), a freqüência, local e o número de irradiações, e ainda o momento certo de fazer a irradiação conforme o tipo e fase da doença a ser tratada.

Essa grande variedade de fatores que interferem nos resultados clínicos torna crítica a elaboração individualizada de protocolos, acarretando muitas vezes em tratamentos mal sucedidos. Isso ainda contribui para a difícil aceitação da laserterapia como alternativa de tratamento, sendo necessárias pesquisas não mais com o intuito de comprovar a eficácia da laserterapia, como foi o foco até então na literatura, mas sim estudar os fatores que interferem na elaboração dos protocolos e que podem contribuir para o sucesso no tratamento.

Em relação a escolha do comprimento de onda a ser utilizado na laserterapia, muitos trabalhos mostram uma tendência na utilização do laser de emissão vermelha em lesões superficiais como na cicatrização de tecidos (REDDY, 2003; CARVALHO et al., 2006; HAWKINS e ABRAHAMSE, 2006), enquanto que o laser de emissão infravermelha é mais utilizado em tecidos profundos e na modulação da inflamação (BJORDAL et al., 2006). A própria WALT (World Association for laser Therapy), após Simpósio de Dosimetria realizado no INCOR, Brasil, em 2007, publicou um guia de protocolos recomendando o uso da radiação laser infravermelha para o tratamento das lesões inflamatórias ${ }^{1}$.

A maior absorção do comprimento de onda vermelho pelo sangue justifica sua menor penetração nos tecidos em relação à irradiação infravermelha. No entanto, muitos são os fatores que influenciam na interação laser-tecido como as características de atenuação do tecido, número de fótons emitidos entre outros, sendo assim, ambos os

\footnotetext{
${ }^{1}$ http://www.walt.nu/dosage-recommendations.html
} 
comprimentos de onda podem ser efetivos. Os efeitos do laser e do Diodo Emissor de Luz (LED) sobre o edema, aumento da permeabilidade vascular e hiperalgesia articular foram estudados em modelo experimental de artrite induzida por zymosan (MORAIS et al., 2010). Neste estudo o efeito antiinflamatório da laserterapia mostrou ser eficiente independente do comprimento de onda utilizado, vermelho (685nm) ou infravermelho (830nm). O LED (628nm) utilizado nas mesmas condições dosimétricas que o laser não apresentou nenhum efeito neste modelo experimental de artrite induzida por zymosan. Além disso, um estudo realizado por Demidova-Rice e cols, (2007) em cicatrização de feridas em camundongos, demonstrou que a radiação infravermelha (820nm) foi a que apresentou os melhores resultados em relação ao grupo controle e as outras irradiações realizadas com 636, 670 e $720 \mathrm{~nm}$. Isso demonstra que outros fatores mais importantes que o comprimento de onda podem estar influenciando na efetividade da laserterapia.

O número de irradiações realizadas também é uma variável importante no intuito de se obter o melhor efeito bioestimulatório possível pela laserterapia. Este foi o tema da dissertação de Mestrado de MENEGUZZO (2007) que verificou em cultura de fibroblastos pulpares humanos, que repetidas irradiações (3) promovem maior proliferação celular que duas ou que uma única irradiação. Além disso, concluiu-se que é preferível múltiplas irradiações com baixa energia que uma única irradiação com energia total equivalente, dentro das condições do estudo realizado (MENEGUZZO et al., 2008).

Com o intuito de estudar o número mínimo de irradiações necessárias para se obter um efeito antiinflamatório, além de investigar a melhor densidade de energia (DE) e o melhor momento de irradiação, Albertini e cols. (2004) realizaram um estudo in vivo, com o modelo experimental de indução da inflamação pela carragenina em pata de ratos. Neste estudo, utilizou-se um laser de diodo, com 650nm (vermelho) em várias combinações de irradiação sendo os melhores resultados obtidos com 1 e 2,5J/cm² $(0,08$ 
J e 0,22 J respectivamente), com 2 ou 3 irradiações a cada hora, iniciando 1 h após a indução do edema. Estes resultados também concordam com Herman \& Khosla (1989) que utilizaram o laser de Nd:YAG, em baixa intensidade e não observaram eficácia em uma única irradiação mas em 3 irradiações na modulação da inflamação. Além disso, no trabalho de Albertini e cols (2004) observou-se que a irradiação imediatamente após a injeção da carragenina mais 2 irradiação após 1 e 2h, promovem um efeito próinflamatório, induzindo ao aumento do edema. Com duas irradiações, uma realizada 10 minutos antes e uma 1h após, não foi observado redução no edema em relação ao grupo controle.

Ainda, Lopes-Martins e colaboradores (2005) estudaram os efeitos da radiação vermelha (650nm) na inflamação aguda em pleurisia e relataram que irradiações realizadas entre uma e 3 horas após a indução da inflamação reduzem significativamente a migração de células inflamatórias. Os autores também relatam a presença de um padrão dose-resposta para os efeitos antiinflamatórios dependente do tempo, dose e total de energia entregue no tecido.

Em modelo experimental de artrite induzida por zymosan, Castano e cols. (2007) investigaram diferentes regimes de irradiação variando a densidade de energia $\left(\mathrm{J} / \mathrm{cm}^{2}\right)$, tempo de irradiação e a intensidade $\left(\mathrm{W} / \mathrm{cm}^{2}\right)$ utilizando um laser de emissão infravermelha (810nm) com irradiações diárias por 5 dias. Os resultados mostraram que a irradiação com infravermelho foi eficiente na redução do edema e na redução da $P \mathrm{FE}_{2}$, sendo o tempo de irradiação mais relevante que a fluência e que a intensidade nos efeitos antiinflamatórios observados.

Observa-se, portanto, que poucos trabalhos na literatura buscam respostas que elucidam a forma como os protocolos de laserterapia devem ser elaborados. E, ainda, como agravante, além de muitos resultados controversos, a resposta tecidual parece ser 
bastante específica, podendo existir várias janelas terapêutica em um mesmo tecido, como foi observado no estudo de Demidova-Rice e cols (2007) que observaram uma curva de dose-resposta bifásica. Nesse trabalho, os autores encontraram para um mesmo tecido (região dorsal de camundongos incisionados) uma curva onde a fluência de $1 \mathrm{~J} / \mathrm{cm}^{2}$ e $10 \mathrm{~J} / \mathrm{cm}^{2}$ não foram tão eficazes quanto $2 \mathrm{~J} / \mathrm{cm}^{2}$ na contração de feridas, e $50 \mathrm{~J} / \mathrm{cm}^{2}$ teve um efeito contrário à cicatrização esperada retardando o processo de reparação tecidual. 


\section{MATERIAL E MÉTODOS}

Este trabalho foi realizado em colaboração com o Laboratório de Farmacologia e Fototerapia da Inflamação do Departamento de Farmacologia do ICB-I/USP, sob responsabilidade do Prof. Dr. Rodrigo Álvaro Brandão Lopes Martins. O modelo experimental foi realizado de acordo com as regras de experimentação animal com aprovação do comitê de ética do IPEN (CEPA-IPEN/SP N.21/2008) (ANEXO 1). Foram utilizados camundongos adultos machos das linhagens SWISS (heterogênica), BALB-C e C57BL/6 (isogênicas) (FIG. 5) com massa corpórea entre 20 e 30g (animais entre 40 e 50 dias), mantidos com água e ração à vontade e sob condições ideais de temperatura e ciclo de claro/escuro 12/12h no biotério do ICB-I ou do IPEN.

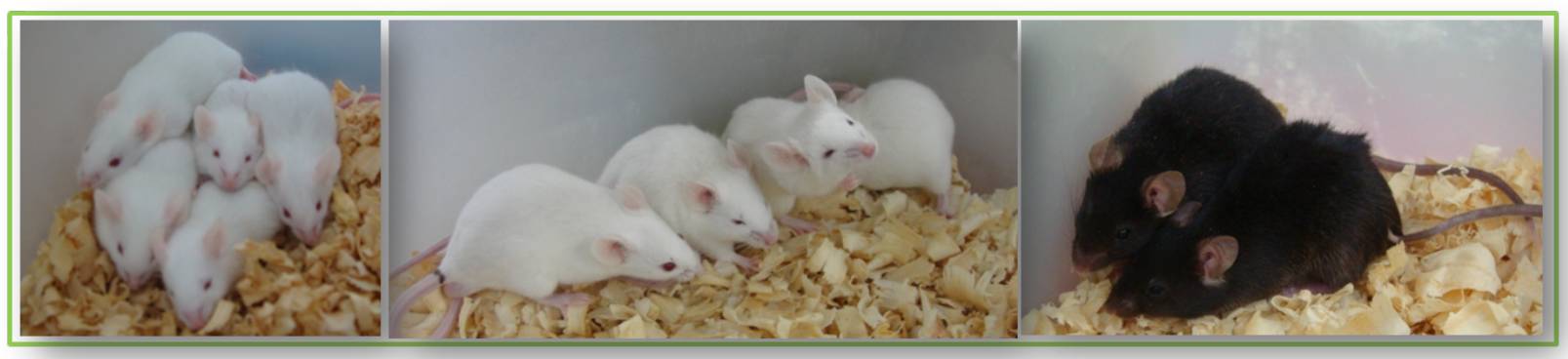

FIGURA 5 - Linhagens de camundongos utilizadas: SWISS, BALB-C e C57BL/6 respectivamente.

\subsection{MODELO DE EDEMA DE PATA INDUZIDO POR CARRAGENINA EM}

\section{CAMUNDONGOS}

A carragenina (CGN) é um polissacarídeo amplamente utilizado para a indução da resposta inflamatória aguda em modelo experimental animal promovendo a liberação de diferentes mediadores inflamatórios como a histamina, bradicinina, prostraglandinas e outros (DI ROSA, 1972). A utilização da carragenina com um irritante para induzir o edema de pata em rato foi introduzido por Winter et al., (1962) e tornou-se um dos métodos mais populares para testes de drogas e avaliação de novas terapias antiinflamatórias. 
A indução do edema de pata foi realizada através de $50 \mu \mathrm{L}$ de carragenina (CGN) a 1\% (10mg CGN diluída em 1ml de solução salina 0,9\%) (Sigma Chemical Co., St. Louis, MO, USA) na dose de $0,5 \mathrm{mg} /$ pata injetados na região plantar da pata esquerda do camundongo (ALBERTINI et al., 2004) (FIG. 6). Uma vez que a injeção da carragenina é um procedimento rápido e com sintomatologia comparável à injeção de um anestésico, este foi dispensado.

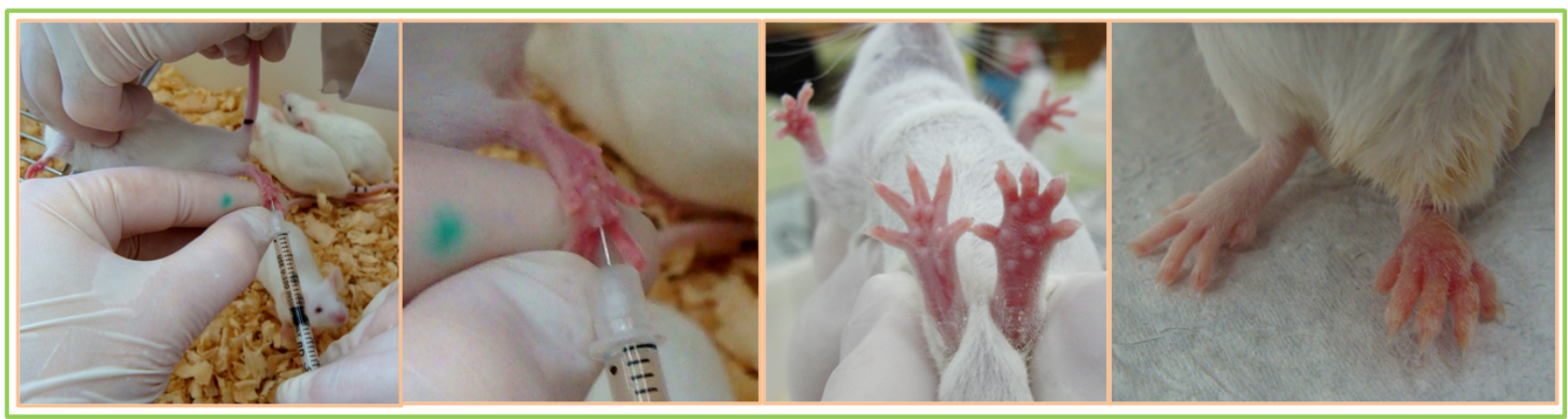

FIGURA 6 - Injeção da carragenina e edema provocado no grupo controle após $3 \mathrm{~h}$ da indução.

O edema formado na pata de cada animal foi mensurado através da pletismografia realizada com o equipamento Pletismógrafo 7150 (Ugo Basile, Itália). Este equipamento possui 2 tubos transparentes, sendo que o menor contém o transdutor responsável por medir a condutância entre dois eletrodos verticais compensando mudanças na condutividade trazidas por alterações na salinidade e temperatura do tubo maior, onde a pata do camundongo era posicionada (FIG. 7). A solução que transmite a condutância era composta por $1 \mathrm{ml}$ de detergente líquido (Limpol® BomBril, Brasil) e 100ml de solução salina $0,9 \%$. Esta solução foi adaptada da original que consistia em: $200 \mathrm{ml}$ de água destilada $+9 \mathrm{~g}$ de $\mathrm{NaOH}+1 \mathrm{ml}$ de solução de ornano. A variação volumétrica é dada com a precisão de duas casas decimais e as avaliações foram feitas imediatamente antes (medida inicial - MI) e 1, 2, 3, 4 e 6h após a injeção de carragenina. A variação do volume da pata, ou seja, o volume relativo (\%) foi calculado para cada pata a partir do volume 
inicial (vi) e volume final (vf), sendo: (vf-vi)x100/vi (ALBERTINI et al., 2004). Em cada medição foram realizadas três leituras e as médias obtidas foram utilizadas para análise estatística.

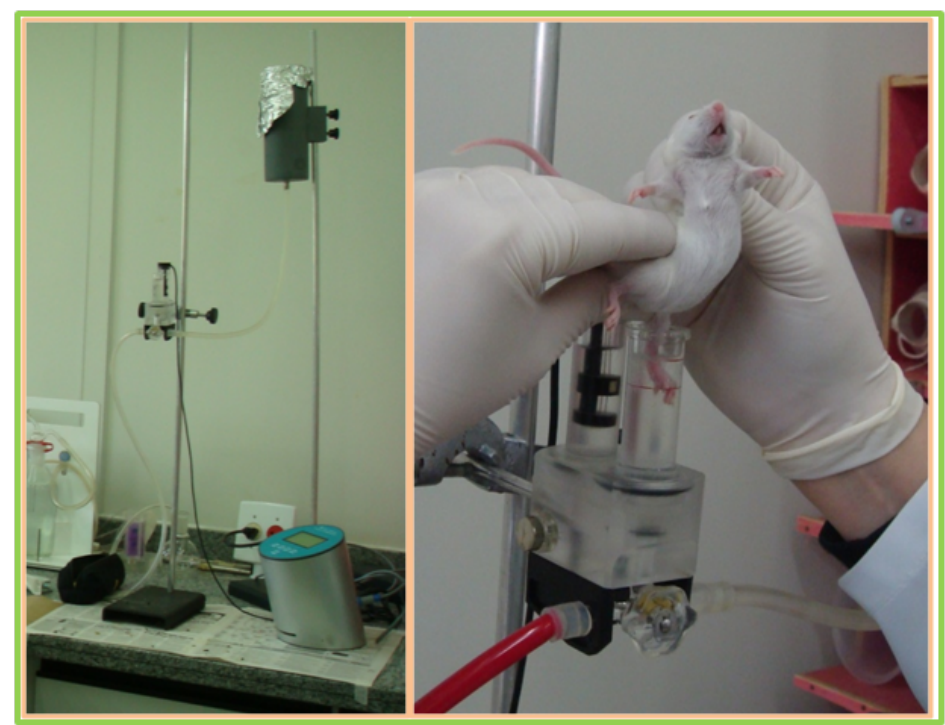

FIGURA 7 - Pletismógrafo e medição do volume da pata esquerda do camundongo

Após a última leitura no pletismógrafo (6h após a injeção da CGN), os animais foram anestesiados com halotano e sacrificados por deslocamento cervical. O tecido plantar da pata esquerda dos animais foi removido e imediatamente congelado em nitrogênio líquido. O armazenamento do material para posterior análise da atividade da Mieloperoxidase (MPO) foi em freezer - $80^{\circ} \mathrm{C}$ e para histologia as amostras foram fixadas em formol $10 \%$.

\subsection{EQUIPAMENTO LASER}

O equipamento laser utilizado foi o Thera Lase (DMC Equipamentos, São Carlos, SP, Brasil) constituído por dois lasers de diodo, emitindo nos comprimentos de onda vermelho $(660 \mathrm{~nm})$ e infravermelho (810nm) (FIG. 8). A potência do equipamento é ajustável sendo a potência máxima $100 \mathrm{~mW}$. A área do feixe laser é de $0,0028 \mathrm{~cm}^{2}$ sendo a área de irradiação de $0,028 \mathrm{~cm}^{2}$ (afastado $2 \mathrm{~mm}$ do tecido alvo). Antes de cada 
irradiação, a potência de saída do laser foi mensurada através de um medidor de potência (Coherent, EUA). A aplicação foi feita de modo pontual e perpendicular ao tecido. O comprimento de onda utilizado para todos os experimentos foi o infravermelho emitindo em $\lambda=810 \mathrm{~nm}$, comprimento de onda recomendado pela WALT (World Association for laser Therapy) para modulação do processo inflamatório.

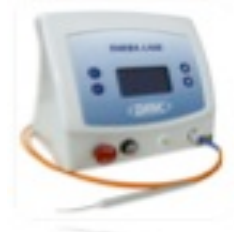

FIGURA 8 - Equipamento laser Thera Lase, DMC Equipamentos

As irradiações foram realizadas na ausência de anestesia, no centro da pata esquerda dos animais (FIG. 9A) ou no linfonodo inguinal esquerdo (FIG. 9B), cuja localização foi descrita por Harrell et al., 2008 (FIG. 9C). Os parâmetros como potência, energia, tempo de irradiação e momento de irradiação ao longo da evolução do edema variaram conforme o grupo experimental e estão descritos no item 4.5 (delineamento experimental).

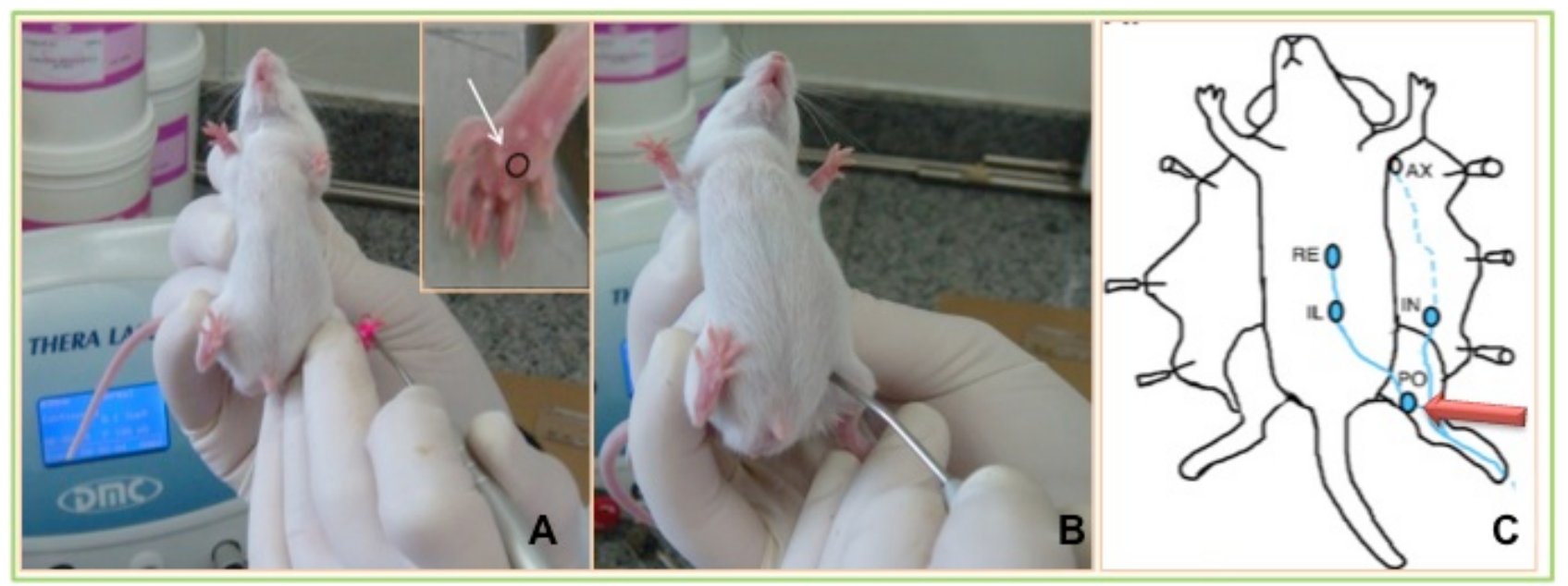

FIGURA 9 - Irradiação na pata (A), linfonodo inguinal (B) e localização anatômica do linfonodo inguinal (C). 


\subsection{AVALIAÇÃO DA MIELOPEROXIDASE (MPO)}

A mieloperoxidase (MPO) é um marcador específico de neutrófilo, cuja quantidade indica maior ou menor atividade desta proteína. O método da medida de atividade de MPO baseia-se na velocidade de oxidação do substrato o-dianisidina na presença de água oxigenada, que é evidenciada pela mudança de absorbância medida por espectrofotometria a $460 \mathrm{~nm}$. A análise da atividade da MPO foi realizada com o material coletado após 6 horas da injeção da carragenina sendo, portanto, um dado específico para este tempo experimental.

As amostras foram retiradas do freezer $-80^{\circ} \mathrm{C}$ e os tecidos suplantares das patas foram pesados. $O$ valor em gramas foi multiplicado por 20 e o valor encontrado foi o valor do tampão HTAB (Brometo de hexadeciltrimetil-amônio, Sigma Chem. Co., EUA) acrescentado em cada amostra. Exemplo: 0,0364g de tecido foram diluídos em $728 \mu \mathrm{l}$ de HTAB. As amostras foram trituradas com o auxílio de um homogeneizador elétrico por 30 segundos, aquecidas durante $2 \mathrm{~h}$ a $60^{\circ} \mathrm{C}$ em estufa para inativação da atividade endógena de catalase, e centrifugadas a $12.000 \mathrm{~g}$ durante $2 \min .10 \mu \mathrm{L}$ do sobrenadante foram pipetados (em duplicata) em microplaca de 96 poços e acrescidos de $200 \mu \mathrm{L}$ de uma solução tampão de fosfato de potássio $(\mathrm{pH}=6)$ contendo $0,164 \mathrm{mg} / \mathrm{mL}$ de dihidrocloreto de o-dianisidina (Sigma Chemical Co., EUA) e 0,0005\% de peróxido de hidrogênio $\left(\mathrm{H}_{2} \mathrm{O}_{2}\right)$ (Merck, Alemanha).

$\mathrm{O} \mathrm{H}_{2} \mathrm{O}_{2}$ é quebrado pela MPO liberada dos tecidos homogeneizados com o detergente HTAB. O radical oxigênio resultante combina com a o-dianisidina (doador de hidrogênio) o qual é convertido em um composto colorido. A formação deste composto ao longo do tempo é medida utilizando-se um espectrofotômetro que determina a quantidade de MPO no tecido. A mudança de absorbância a 460nm foi medida em um leitor de microplacas (Espectra Max plus 384, EUA) durante 10min, e a atividade de MPO foi 
calculada a partir da velocidade máxima de reação (Vmax) por segundo. O resultado foi expresso em UMPO/cavidade, sendo que uma unidade de MPO é definida como a quantidade em $\mu$ mol de $\mathrm{H}_{2} \mathrm{O}_{2}$ degradado por minuto. (FIG. 10). Os dados foram expressos em média +/- EPM (erro padrão médio) e um teste não pareado t-student e análise de variância (ANOVA) foram utilizados para mensurações repetidas, considerando um valor significante $p<0.05$.
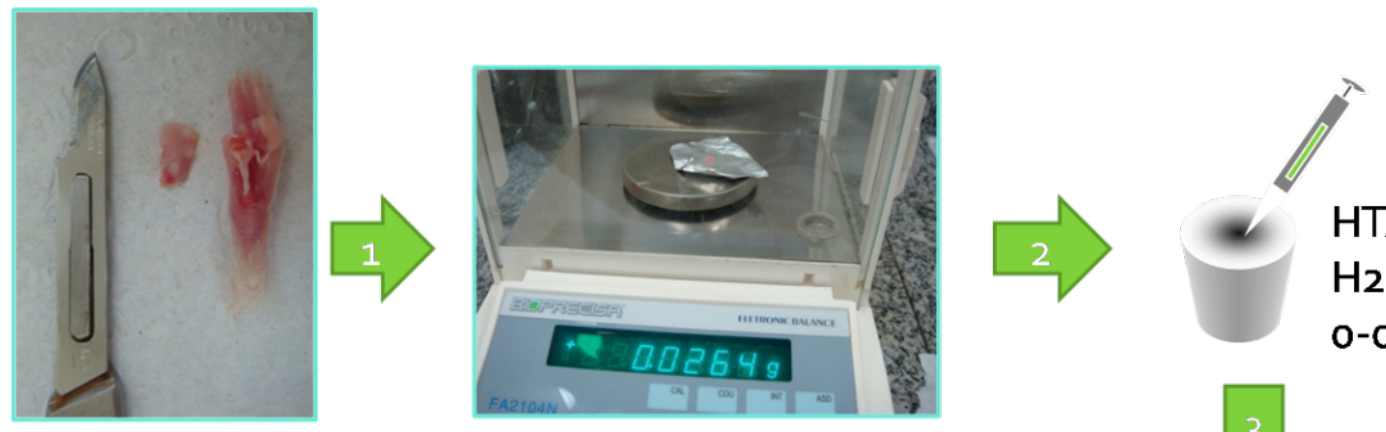

$\mathrm{HTAB}$ $\mathrm{H}_{2} \mathrm{O}_{2}$ o-dianisidina
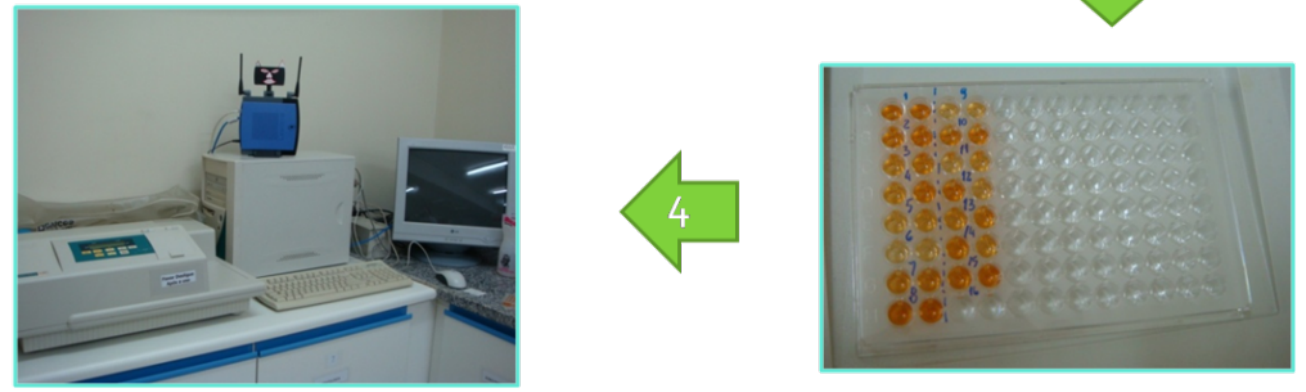

Espectrofotômetro (460 nm)

FIGURA 10 - Passo a passo da análise da MPO

\subsection{ANÁLISE HISTOLÓGICA - COLORAÇÃO HEMATOXILINA E EOSINA (HE)}

As amostras fixadas em formol $10 \%$ foram processadas para a análise histológica em parafina e coradas com Hematoxilina e Eosina (HE). Foram feitas 4 lâminas por animal contendo em cada uma dois cortes histológicos.

Para a contagem de células inflamatórias, três cortes histológicos por animal foram fotografados em microscópio óptico (4, 10 e 40X) e as imagens digitalizadas. As imagens 
fotografadas em 40x foram selecionadas, e dentro de um campo de visão de $20 \times 15 \mathrm{~cm}$ cinco retângulos foram desenhados e as células localizadas dentro ou pelo menos $50 \%$ de sua estrutura dentro foram contadas (APÊNDICES 1, 2 e 3). A média do número de células foi calculada e os dados foram analisados estatisticamente.

\subsection{DELINEAMENTO EXPERIMENTAL}

\subsubsection{ETAPA 1: AVALIAÇÃO DA INFLUÊNCIA DA ENERGIA E POTÊNCIA}

Foram testadas duas energias de irradiação 1 e $3 \mathrm{~J}$ e três potências de irradiação: 30, 60 e $100 \mathrm{~mW}$. A escolha dos parâmetros foi baseada em trabalho prévio desenvolvido pelo grupo do Prof. Rodrigo A. B. Lopes-Martins (LEAL JUNIOR et al., 2009) e de acordo com os lasers comercializados no mercado brasileiro cujas potências variam de 30 a 100 $\mathrm{mW}$.

Foram utilizados 100 camundongos machos BALB-C, com 40 dias de vida, divididos em 2 grandes grupos experimentais: etapas 1A e 1B (TAB. 1 e 2). Cada etapa foi subdividida em 2 experimentos idênticos, um com o objetivo de avaliar o edema e o outro para a avaliação histológica. Assim, cada experimento utilizou 25 animais subdivididos em 5 grupos $(n=5)$. Em todos os grupos experimentais, as irradiações foram feitas após $1 \mathrm{e}$ $2 \mathrm{~h}$ da injeção da carragenina (FIG. 11).

O tempo de irradiação foi inversamente proporcional à potência utilizada segundo a fórmula: $\boldsymbol{t}=\boldsymbol{D E} . \boldsymbol{A} / \boldsymbol{P}$ sendo o tempo (t) em segundos, DE (densidade de energia) em $\mathrm{J} / \mathrm{cm}^{2}$, a A (área da irradiação) em $\mathrm{cm}^{2}$, e $\mathrm{P}$ (potência) em W (Watts). Ainda, $\boldsymbol{D E}=\boldsymbol{E} / \boldsymbol{A}$ sendo $E$ (energia) em joules $(\mathrm{J})$, a $D E$ está relacionada à área de irradiação.

Os grupos estudados incluíam três grupos experimentais (irradiados), um grupo controle (os animais foram submetidos ao edema por carragenina sem tratamento) e um 
grupo controle positivo (os animais receberam uma dose de $1 \mathrm{mg} / \mathrm{kg}$ do antiinflamatório diclofenaco de sódio 30 minutos antes da injeção da carragenina).

O diclofenaco de sódio é uma substância não-esteróide com potente ação antireumática, antiinflamatória, analgésica e antipirética. A inibição da biossíntese de prostaglandinas é considerada fundamental no seu mecanismo de ação. O protocolo do grupo diclofenaco foi baseado em Albertini e colaboradores (2004), cuja dose de 1mg/kg foi a dose equivalente a irradiação laser nos resultados antiinflamatórios estudados e é a dose que consta na bula do medicamento diclofenaco de sódio injetável. Segundo a bula, a ação analgésica do medicamento ocorre de 15 a 30 minutos após a injeção, e em humanos, o diclofenaco de sódio injetável é administrado 1 x ao dia $(75 \mathrm{mg})$ ou no máximo, 2x ao dia (150mg), o que corresponde em um indivíduo de $70 \mathrm{Kg}$ a uma dose aproximada de $1 \mathrm{mg} / \mathrm{kg}$.

TABELA 1 - Grupos experimentais da Etapa 1 A e parâmetros laser utilizados

\begin{tabular}{|c|c|c|c|c|c|}
\hline $\begin{array}{l}\text { GRUPOS ETAPA } \\
\text { 1A }\end{array}$ & $\begin{array}{c}\text { Energia } \\
\text { por } \\
\text { ponto } \\
\text { (J) }\end{array}$ & $\begin{array}{l}\text { Potência } \\
(\mathrm{mW})\end{array}$ & $\begin{array}{c}\text { Densidade } \\
\text { de Potência } \\
\left(\mathrm{W} / \mathrm{cm}^{2}\right)\end{array}$ & $\begin{array}{c}\text { Densidade } \\
\text { de energia } \\
\left(\mathrm{J} / \mathrm{cm}^{2}\right)\end{array}$ & $\begin{array}{c}\text { Tempo de } \\
\text { irradiação } \\
\text { (segundos) }\end{array}$ \\
\hline $1 / 30$ & 1 & 30 & 1 & 35,7 & 33 \\
\hline $1 / 60$ & 1 & 60 & 2,1 & 35,7 & 16 \\
\hline $1 / 100$ & 1 & 100 & 3,5 & 35,7 & 10 \\
\hline Controle (CGN) & \multicolumn{5}{|c|}{$\begin{array}{c}\text { Os animais foram submetidos ao edema por carragenina, porém não } \\
\text { foram irradiados. }\end{array}$} \\
\hline $\begin{array}{l}\text { Diclofenaco } \\
\text { (DICLO) }\end{array}$ & \multicolumn{5}{|c|}{$\begin{array}{l}\text { 30' antes da injeção de carragenina os animais receberam uma dose de } \\
1 \mathrm{mg} / \mathrm{Kg} \text { (Albertini et al., 2004) do antiinflamatório diclofenaco de sódio. }\end{array}$} \\
\hline
\end{tabular}


TABELA 2 - Grupos experimentais da Etapa 1B e parâmetros laser utilizados

\begin{tabular}{|c|c|c|c|c|c|}
\hline $\begin{array}{l}\text { GRUPOS ETAPA } \\
\text { 1B }\end{array}$ & $\begin{array}{l}\text { Energia } \\
\text { por } \\
\text { ponto } \\
(\mathrm{J})\end{array}$ & $\begin{array}{l}\text { Potência } \\
\text { (mW) }\end{array}$ & $\begin{array}{c}\text { Densidade } \\
\text { de Potência } \\
\left(\mathrm{W} / \mathrm{cm}^{2}\right)\end{array}$ & $\begin{array}{c}\text { Densidade } \\
\text { de energia } \\
\left(\mathrm{J} / \mathrm{cm}^{2}\right)\end{array}$ & $\begin{array}{c}\text { Tempo de } \\
\text { irradiação } \\
\text { (segundos) }\end{array}$ \\
\hline $3 / 30$ & 3 & 30 & 1 & 107 & 100 \\
\hline $3 / 60$ & 3 & 60 & 2,1 & 107 & 50 \\
\hline $3 / 100$ & 3 & 100 & 3,5 & 107 & 30 \\
\hline Controle (CGN) & \multicolumn{5}{|c|}{$\begin{array}{l}\begin{array}{l}\text { Os animais foram submetidos ao edema por carragenina, porém não } \\
\text { foram irradiados. }\end{array} \\
\end{array}$} \\
\hline $\begin{array}{l}\text { Diclofenaco } \\
\text { (DICLO) }\end{array}$ & \multicolumn{5}{|c|}{$\begin{array}{l}\text { 30' antes da injeção de carragenina os animais receberam uma dose de } \\
1 \mathrm{mg} / \mathrm{Kg} \text { (Albertini et al., 2004) do antiinflamatório diclofenaco de sódio. }\end{array}$} \\
\hline
\end{tabular}

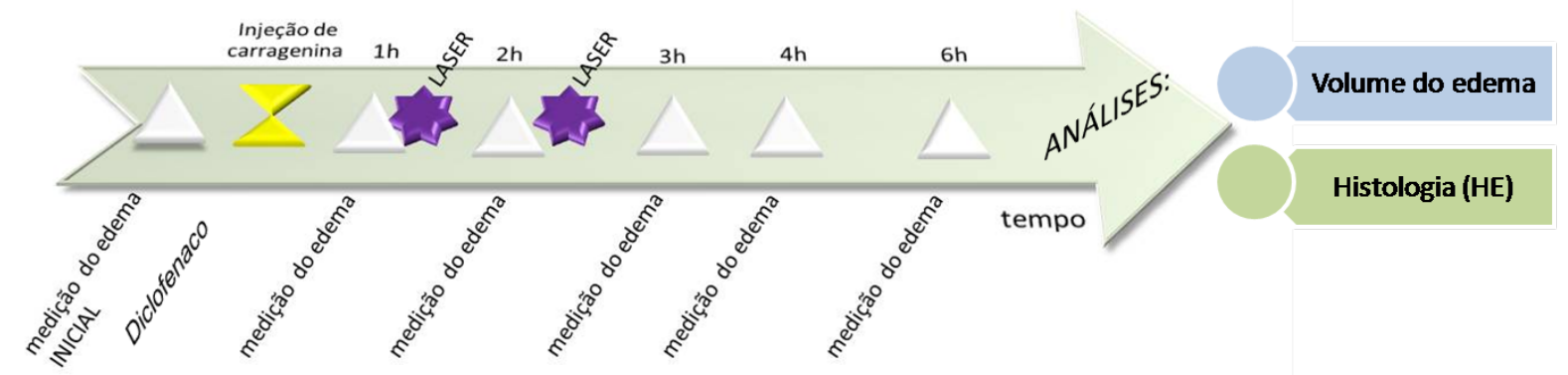

FIGURA 11 - Cronograma experimental das etapas 1A e 1B.

A avaliação da influência da energia e potência foi avaliada através da análise do edema pelo pletismógrafo e pela análise histológica com coloração HE (hematoxilina e eosina) para contagem das células inflamatórias. 


\subsubsection{ETAPA 2: AVALIAÇÃO DA INFLUÊNCIA DO LOCAL E MOMENTO DE IRRADIAÇÃO}

O objetivo desta etapa foi avaliar os efeitos do laser de emissão infravermelha $\quad(\lambda=$ $810 \mathrm{~nm}$ ) sobre o processo inflamatório agudo induzido por carragenina em pata de camundongo a partir da irradiação de diferentes sítios: pata, linfonodo inguinal ou ambos e em diferentes momentos da evolução do edema: antes, durante e depois.

Nesta etapa foram utilizados 100 camundongos machos SWISS com 40 dias. Os animais foram divididos em quatro experimentos de 25 animais cujas irradiações foram realizadas em diferentes momentos: etapas 2A, 2B, 2C e 2D (FIG. 13).

ETAPA 2

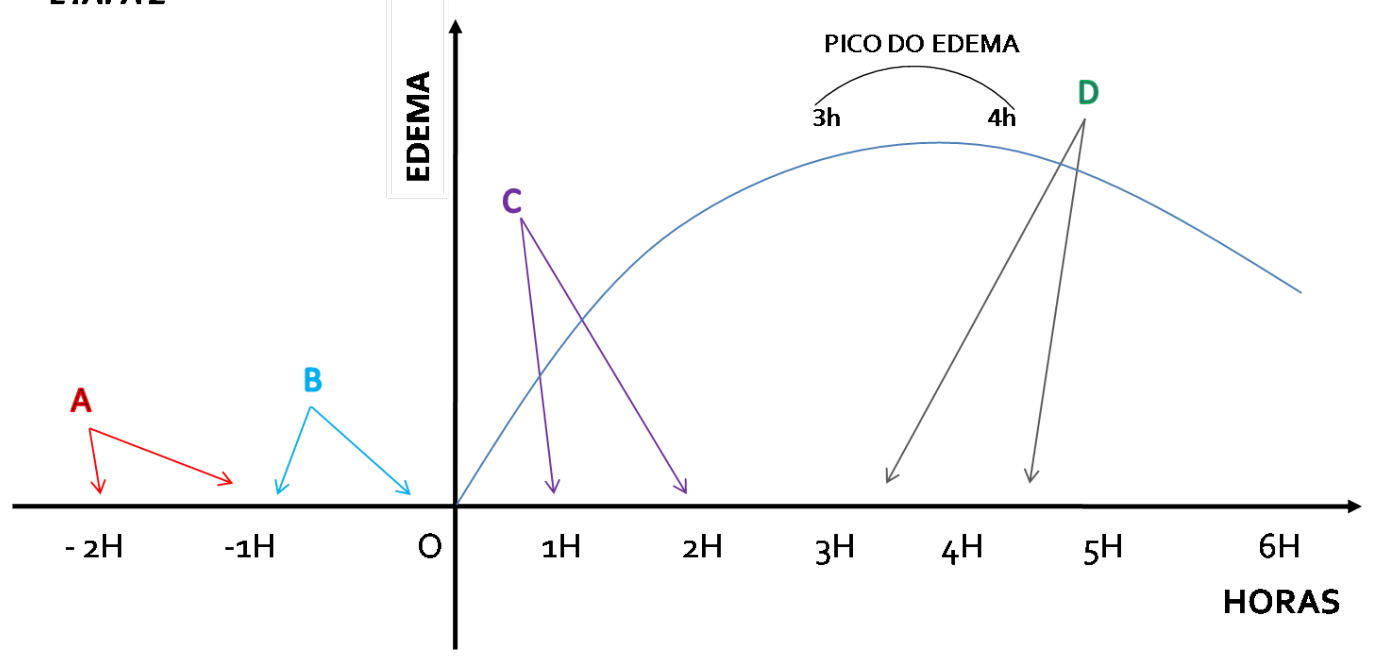

FIGURA 13 - Esquema das etapas 2A, 2B, 2C e 2D quanto ao momento de irradiação. 0 zero representa o momento da injeção da carragenina, momento inicial (MI). Neste modelo experimental o pico do edema encontra-se entre a $3^{\mathrm{a}}$ e $4^{\mathrm{a}}$ horas e a sua evolução está representada pela linha azul.

Momentos de irradiação:

Etapa 2A: As irradiações foram realizadas $2 \mathrm{~h}$ e $1 \mathrm{~h}$ antes da injeção da carragenina

Etapa 2B: As irradiações foram realizadas $1 \mathrm{~h}$ e imediatamente antes da injeção da carragenina

Etapa 2C: As irradiações foram realizadas $1 \mathrm{~h}$ e $2 \mathrm{~h}$ após a injeção da carragenina

Etapa 2D: As irradiações foram realizadas 3,5h e 4,5h após a injeção da carragenina 
Em todas as etapas os 25 animais foram submetidos ao edema por carragenina e subdivididos em 5 grupos: controle (CGN), diclofenaco (Diclo), pata, linfonodo e pata + linfonodo (TAB. 3).

TABELA 3 - Grupos experimentais das etapas 2A, 2B, 2C e 2D

\begin{tabular}{|l|l|}
\hline \multicolumn{2}{|c|}{ GRUPOS EXPERIMENTAIS ETAPA 2 } \\
\hline CGN & $\begin{array}{l}\text { Os animais foram submetidos ao edema por carragenina, porém não foram } \\
\text { irradiados. }\end{array}$ \\
\hline DICLO & $\begin{array}{l}30 \text { ' antes da injeção de carragenina os animais receberam uma dose de } \\
1 \mathrm{mg} / \mathrm{Kg} \text { (Albertini } \text { et al., 2004) do antiinflamatório diclofenaco de sódio. }\end{array}$ \\
\hline Pata & Os animais foram irradiados diretamente na pata \\
\hline Linfonodo & Os animais foram irradiados no linfonodo inguinal esquerdo \\
\hline $\begin{array}{l}\text { Pata + } \\
\text { linfonodo }\end{array}$ & Os animais receberam duas irradiações, uma na pata e uma no linfonodo \\
\hline
\end{tabular}

Os parâmetros de irradiação foram fixos para todos os grupos: 1J, $100 \mathrm{~mW}, 10 \mathrm{~s}$, irradiação pontual e fluência de $35,7 \mathrm{~J} / \mathrm{cm}^{2}$, considerando a área de $0,028 \mathrm{~cm}^{2}$. Estes parâmetros foram escolhidos conforme os melhores resultados na avaliação do edema encontrados na Etapa 1.

O edema foi avaliado pelo pletismógrafo conforme metodologia já descrita, e ao final do experimento as patas foram removidas e o material processado para avaliação da atividade da mieloperoxidase (MPO) como um marcador específico do acúmulo de neutrófilo na pata. 


\subsubsection{ETAPA 3: AVALIAÇÃO DA INFLUÊNCIA DOSIMÉTRICA EM DIFERENTES LINHAGENS DE CAMUNDONGOS}

Esta etapa foi subdividida de acordo com a linhagem de camundongos utilizada, sendo A (Balb-C) e B (B57BL/6). Os três grupos experimentais foram escolhidos de acordo com os melhores resultados observados na Etapa 2, quanto ao local e momento da irradiação somados aos grupos CGN e Diclo. Os grupos foram:

- Li -1h e Oh: Irradiação no linfonodo realizada 1h e imediatamente antes da CGN

- Pa 1h e 2h: Irradiação na pata realizada 1h e $2 \mathrm{~h}$ após a CGN

- Li 3,5h 4,5h: Irradiação no linfonodo realizado 3,5 e 4,5 h após a CGN

- Controle (CGN): só CGN sem tratamento

- Diclofenaco (Diclo): Diclofenaco 30'antes da CGN

ETAPA 3A: Influência da dosimetria em camundongos albinos Balb-c (linhagem isogênica).

Foram utilizados 25 animais Balb-c machos para este experimento. Os grupos controle e diclofenaco de sódio foram realizados juntamente com três grupos selecionados que apresentaram os melhores resultados da fase 2. O objetivo foi estudar em Balb-c as melhores combinações dosimétricas observadas na Etapa 2 comparando-as em relação ao edema e quantidade de células inflamatórias presentes através da histologia (coloração HE).

ETAPA 3B: Influência da dosimetria em camundongos pretos C57BL/6 (linhagem isogênica).

Foram utilizados 25 camundongos C57BL/6 machos para este experimento. O objetivo de utilizar camundongo de uma linhagem diferente, neste caso com coloração também diferente, foi avaliar se as melhores combinações dosimétricas observadas na 
Etapa 2 seguem o mesmo padrão que as outras linhagens estudadas além de comparálas em relação ao edema e quantidade de células inflamatórias presentes através da histologia (coloração HE).

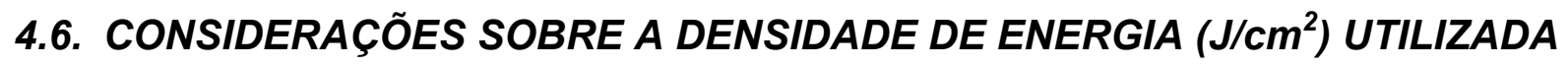 NESTA TESE}

O conceito dose é definido como a quantidade de energia depositada por área a ser tratada. Como os primeiros trabalhos na década de 70 utilizavam o laser de $\mathrm{He}-\mathrm{Ne}$, a "dose" $\left(\mathrm{J} / \mathrm{cm}^{2}\right)$ foi preconizada como a energia depositada em $1 \mathrm{~cm}^{2}$, visto que a radiação vermelha do He-Ne espalha anisotropicamente em aproximadamente $1 \mathrm{~cm}^{2}$ na pele. No entanto, com o advento dos lasers de diodo, que não possuem o perfil gaussiano do laser de $\mathrm{He}-\mathrm{Ne}$, começou-se a utilizar a área da ponteira laser para padronização das aplicações de forma pontual que, por outro lado, fez com que o conceito inicial de "dose" fosse perdido. Atualmente, como ambas as formas ainda são utilizadas (alguns autores consideram área total da lesão, outros a área da ponteira laser), é muito difícil identificar em cada trabalho publicado o que realmente foi considerado pelos autores. A solução encontrada pela WALT (World Association for laser Therapy) foi considerar também a energia $(E=P . t, E=D E . A)$ na descrição da metodologia e sugerir aos autores que colocassem todas as informações possíveis nos trabalhos, como a energia $(\mathrm{J})$, densidade de energia $\left(\mathrm{J} / \mathrm{cm}^{2}\right)$, tempo de irradiação, área da ponteira laser ou diâmetro do feixe, potência utilizada, área a ser irradiada e método de irradiação (pontual ou varredura). Deste modo, a densidade de energia de aproximadamente $35 \mathrm{~J} / \mathrm{cm}^{2}$ (uma das DE utilizadas nesta tese) pode parecer alta quando comparada na literatura, mas de acordo com a área do spot do equipamento que trabalhamos, a energia entregue foi de $1 \mathrm{~J}$. As energias, bem como a potência máxima de $100 \mathrm{~mW}$ utilizadas neste trabalho, estão de 
acordo com dosagens utilizadas para emissão infravermelha pelo grupo do Prof. Rodrigo A. B. Lopes-Martins (ICB-USP), que foi nosso colaborador (LEAL JUNIOR et al., 2008).

\subsection{ANÁLISE ESTATÍSTICA}

Os dados obtidos a partir da medição do volume da pata pelo pletismógrafo, volume inicial da pata, volume na $1^{a}, 2^{a}$ até $6^{a}$ hora respectivamente, foram normalizados em relação ao momento inicial $(\mathrm{MI})$ e transformados em aumento relativo de volume. $\mathrm{O}$ aumento relativo (\%) foi calculado para cada pata/animal em todos os tempos experimentais (1 a $6 \mathrm{~h}$ ) a partir do volume inicial (vi) e volume final (vf), sendo: (vf - vi) $x$ 100/vi (ALBERTINI et al., 2004). Como parte da análise descritiva, foi feito um gráfico de médias (dos volumes relativos) para cada grupo experimental ao longo do tempo experimental.

Os conjuntos de dados experimentais foram testados quanto à sua normalidade pelo teste de Shapiro-Wilk. Em todos os casos, o referido teste retornou um valor de $p \geq 0,05$, portanto não há indícios de que nenhum dos grupos possua uma distribuição não Gaussiana.

A comparação das médias do volume relativo dos grupos experimentais em cada hora do experimento foi realizada utilizando dois testes diferentes, conforme a necessidade. Para casos onde há indícios de que pelo menos um dos grupos estudados possui uma estimativa da variância diferente dos demais, foram utilizadas múltiplas comparações pelo t-test. Em uma análise envolvendo múltiplas comparações, com a finalidade de manter o nível de significância global menor ou igual a 0,05 , foi necessário aplicar uma correção nos valores de p obtidos. Para este trabalho a correção adotada foi o procedimento de Ryan-Holm Stepdown Bonferroni. Para os casos onde não há indícios 
de diferença entre as variâncias dos grupos estudados, foi utilizado a análise de variâncias (ANOVA), seguida, quando necessário, pelo teste de Tukey.

A partir do gráfico das médias, com o intuito de analisar qual dos grupos obteve o menor volume ao longo de todo o período experimental, foi calculada a área sob a curva para cada experimento com suas respectivas incertezas (a incerteza do tempo é estimada em 3 min para mais ou para menos em $68 \%$ dos casos). Após serem propagadas as respectivas incertezas, foi utilizado o teste $Z$ para determinar se há ou não indícios de diferenças estatisticamente significantes entre os grupos estudados. A correção dos valores de $\mathrm{p}$ para múltiplas comparações foi realizada pelo procedimento de Ryan-Holm Stepdown Bonferroni.

Ainda com os dados da área sob a curva, para facilitar a visualização dos resultados de redução do edema, foi calculada a \% de redução do volume dos grupos experimentais em relação ao grupo controle e seu respectivo erro, sendo (área CGN - área X) x 100 / área CGN o cálculo da \% redução.

$\mathrm{Na}$ etapa 2 deste trabalho todos os grupos controle (CGN) foram agrupados totalizando um $\mathrm{N}=27$ e todos os grupos diclofenaco foram agrupados, $\mathrm{N}=13$. $\mathrm{O}$ agrupamento foi possível após a determinação de que, pelo teste de hipóteses ANOVA e pelo teste de Levene para igualdade de variâncias, não há indícios de diferença estatisticamente significativa entre as médias e as variâncias, respectivamente, dos grupos controles e diclofenaco dos experimentos A,B,C e D.

A análise estatística para a contagem das células inflamatórias foi realizada com os testes de Shapiro-Wilk, ANOVA e Tukey Test.

Os programas estatísticos utilizados nesta tese foram: Excel, Estatística 8.0 e Origin. 


\section{RESULTADOS E DISCUSSÃO}

\subsection{ETAPA 1: AVALIAÇÃO DA INFLUÊNCIA DA ENERGIA E POTÊNCIA}

A influência da dosimetria, ou seja, dos parâmetros de irradiação como potência, intensidade, densidade de energia e tempo de irradiação tem sido bastante discutida na literatura (ENWEMEKA, 2009; HAWKINS; ABRAHAMSE, 2007; CASTANO et al., 2007). Muitos autores apontam a energia total como a principal variável na busca dos efeitos da irradiação laser (HAWKINS; ABRAHAMSE, 2007) enquanto que outros autores demonstram a influência do tempo de exposição (CASTANO et al., 2007). Todos os autores, no entanto, concordam que ainda faltam estudos sobre o assunto. Assim, nesta etapa, foram avaliados os efeitos de duas energias diferentes, 1 e $3 \mathrm{~J}$ (etapas 1A e 1B respectivamente) combinadas com três potências diferentes, 30, 60 e 100 mW na evolução do edema de pata, em irradiações realizadas após 1 e $2 \mathrm{~h}$ da injeção da carragenina em modelo de inflamação aguda induzida por carragenina em camundongos SWISS. A escolha das potências foi baseada nos equipamentos laser disponíveis no mercado brasileiro que possuem potência mínima de $30 \mathrm{~mW}$ e máxima em torno de $100 \mathrm{~mW}$. Conseqüentemente o tempo de exposição também variou segundo a fórmula física $T=D E . A / P$ sendo o tempo de irradiação inversamente proporcional à potência utilizada.

O outro objetivo desta etapa foi analisar a influência das diferentes combinações de parâmetros de energia e potência na quantidade de células inflamatórias encontradas na pata após $6 \mathrm{~h}$ experimentais, uma vez que muitos estudos relatam que um dos efeitos da laserterapia na modulação inflamação é a redução do infiltrado inflamatório no local irradiado (AIMBIRE e al., 2005; LOPES-MARTINS et al., 2005; CORREA et al., 2007). 


\subsubsection{ETAPA 1A: $1 \mathrm{~J} / 30,60 \mathrm{E} 100 \mathrm{~mW}$}

O aumento do volume da pata entre o momento inicial (MI) e $1 \mathrm{~h}$ demonstrou a variação de volume em decorrência da injeção de $50 \mu \mathrm{L}$ de carragenina na região plantar da pata observado em todos os grupos experimentais, exceto no grupo Diclo (FIG. 14). Neste grupo, pré-tratado com o fármaco diclofenaco de sódio 30 min antes da injeção da carragenina, a resposta antiinflamatória já pôde ser constatada na primeira hora pela inibição do edema observado em relação aos outros grupos. O grupo controle (CGN) a partir da $2^{a}$ hora experimental mostrou um aumento do volume relativo de forma progressiva seguindo o padrão normal do modelo de edema de pata induzido por carragenina já descrito na literatura (FIG. 14) (ALBERTINI et al., 2004, GUAY et al., 2004; KIM et al., 2008).

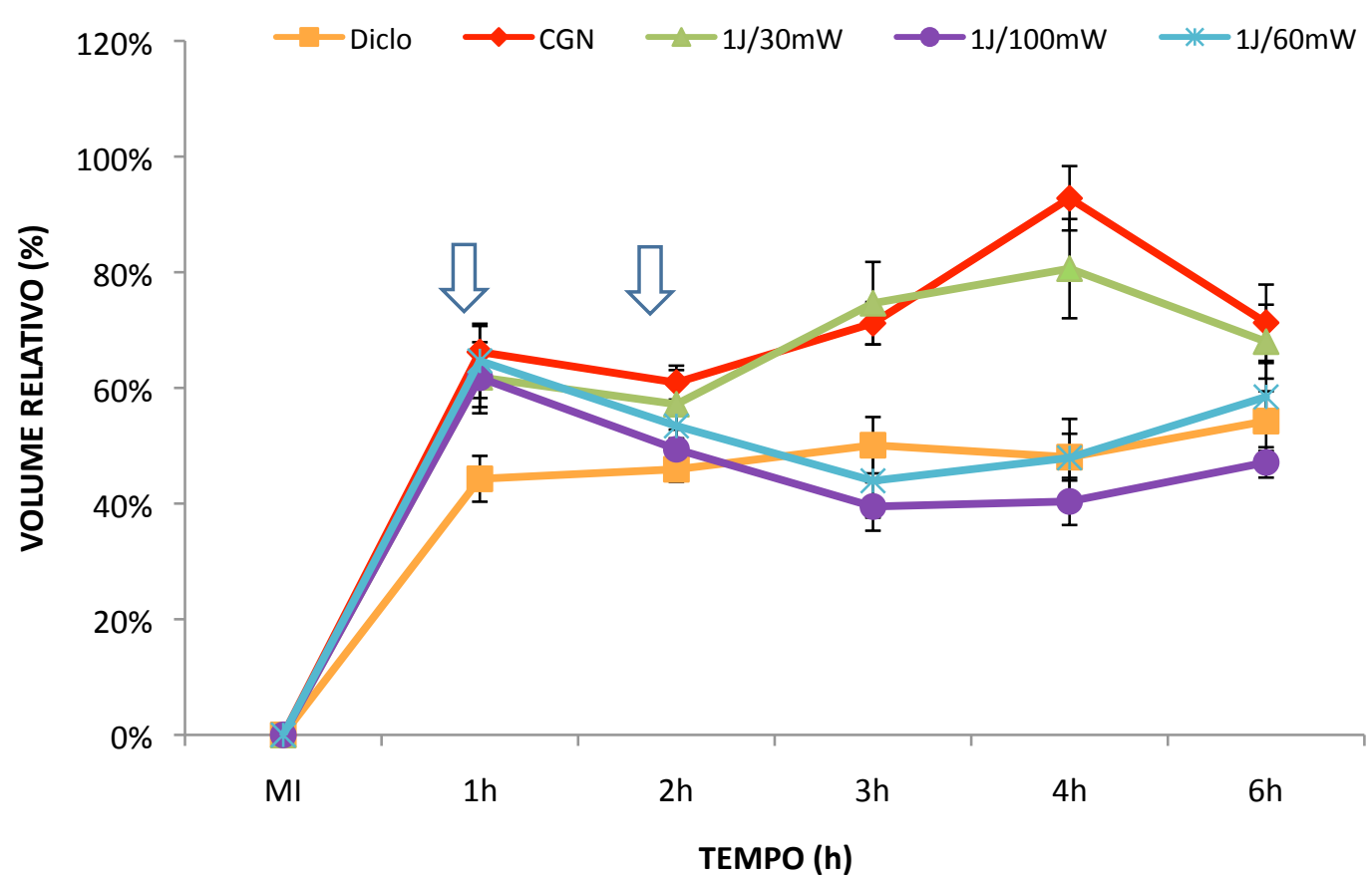

FIGURA 14 - Gráfico das médias do volume relativo do edema (\%) com os respectivos erros padrão da etapa 1A. As irradiações foram feitas $1 \mathrm{~h}$ e $2 \mathrm{~h}$ após a injeção de carragenina em MI (setas). $\mathrm{N}=5$ animais por grupo.

Entre a $1^{\text {a }}$ e a $3^{\text {a }}$ horas experimentais foi possível observar uma progressiva queda no volume relativo dos grupos irradiados com $1 \mathrm{~J} / 60 \mathrm{~mW}$ e $1 \mathrm{~J} / 100 \mathrm{~mW}$ apresentando na $3^{\mathrm{a}}$ e $4^{\mathrm{a}}$ 
horas volume relativo estatisticamente inferior ao grupo controle (CGN) (TAB. 5 e 6). O volume relativo do grupo Diclo, por sua vez, inibiu a evolução do edema de forma constante a partir da $1^{\text {a }}$ hora experimental sendo diferente estatisticamente do grupo controle em todas as medições exceto na $2^{\mathrm{a}}$ hora experimental, momento em que o controle mostrou-se similar a todos os tratamentos (TAB. 4,5 e 6).

O grupo irradiado $1 \mathrm{~J} / 30 \mathrm{~mW}$ não foi capaz de produzir um efeito inibitório sobre o edema apresentando comportamento similar ao grupo controle (CGN) e estatisticamente inferior ao grupo $1 \mathrm{~J} / 100 \mathrm{~mW}$ na $3^{\mathrm{a}}$ e $4^{\mathrm{a}}$ horas experimentais (TAB. 5 e 6 ).

TABELA 4 - Valores de $p$ obtidos pelo teste $t$ e corrigidos pelo procedimento de Ryan-Holm Stepdown Bonferroni para a comparação das médias do volume relativo na $2^{\mathrm{a}}$ hora experimental da etapa $1 \mathrm{~A}$. As diferenças estatisticamente significantes estão em negrito e itálico $(p<0,05)$.

\begin{tabular}{c|cccc}
$\mathbf{2 H}$ & $\mathbf{C G N}$ & Diclo & $\mathbf{1 J / 3 0 M w}$ & $\mathbf{1 J / 6 0 m W}$ \\
\hline \hline Diclo & $\mathbf{0 , 0 3 3 6}$ & & & \\
$\mathbf{1 J} / \mathbf{3 0 m W}$ & 1,0000 & 0,8903 & & \\
$\mathbf{1} / \mathbf{6 0} \mathbf{m W}$ & 1,0000 & 1,0000 & 0,6894 & \\
$\mathbf{1 J 1 0 0 m W}$ & 0,2964 & 1,0000 & 1,0000 & 1,0000 \\
\hline
\end{tabular}

TABELA 5 - Valores de $p$ obtidos pelo teste $\boldsymbol{t}$ e corrigidos pelo procedimento de Ryan-Holm Stepdown Bonferroni para a comparação das médias do volume relativo na $3^{a}$ hora experimental da etapa $1 \mathrm{~A}$. As diferenças estatisticamente significantes estão em negrito e itálico $(p<0,05)$.

\begin{tabular}{c|cccc} 
3H & CGN & Diclo & 1J/30mW & 1J/60mW \\
\hline \hline Diclo & 0,0603 & & & \\
1J/30mW & 0,6782 & 0,1091 & & \\
1J/60mW & $\mathbf{0 , 0 4 8 0}$ & 1,0000 & 0,0748 & \\
$1 \mathbf{J} 100 \mathrm{~mW}$ & $\mathbf{0 , 0 0 4 6}$ & 0,5488 & $\mathbf{0 , 0 2 5 3}$ & 1,0000 \\
\hline
\end{tabular}


TABELA 6 - Valores de $p$ obtidos pelo teste $\boldsymbol{t}$ e corrigidos pelo procedimento de Ryan-Holm Stepdown Bonferroni para a comparação das médias do volume relativo na $4^{\text {a }}$ hora experimental da etapa $1 \mathrm{~A}$. As diferenças estatisticamente significantes estão em negrito e itálico $(p<0,05)$.

\begin{tabular}{c|cccc} 
4H & CGN & Diclo & 1J/30mW & 1J/60mW \\
\hline \hline Diclo & $\mathbf{0 , 0 0 1 7}$ & & & \\
1J/30mW & 0,8047 & 0,0533 & & \\
$1 \mathrm{~J} / 60 \mathrm{~mW}$ & $\mathbf{0 , 0 0 7 1}$ & 0,9884 & 0,0853 & \\
$1 \mathrm{~J} 100 \mathrm{~mW}$ & $\mathbf{0 , 0 0 0 6}$ & 0,8766 & $\mathbf{0 , 0 1 9 9}$ & 0,7314 \\
\hline
\end{tabular}

Com o intuito de investigar qual dos tratamentos realizados foi o mais efetivo ao longo das 6 horas experimentais, foi realizado o cálculo da área sob a curva a partir do gráfico do volume relativo e os dados foram submetidos a análise estatística (TAB. 7, 8 e FIG.15). Ainda para facilitar a análise dos resultados, a porcentagem de redução do edema foi calculada a partir da área sob a curva em relação ao grupo controle (CGN) (TAB. 7). Os resultados demonstraram que o tratamento com diclofenaco de sódio e as irradiações com $1 \mathrm{~J} / 100 \mathrm{~mW}$ e $1 \mathrm{~J} / 60 \mathrm{~mW}$ (realizadas 1 e $2 \mathrm{~h}$ após a injeção da carragenina) foram estatisticamente mais eficazes na inibição do edema que os grupos Controle (CGN) e irradiado com 1J/30mW (TAB. 8, FIG. 15). A porcentagem de redução do edema do grupo $1 \mathrm{~J} / 100 \mathrm{~mW}$ foi de $36,8 \%$, ao passo que do grupo Diclo foi de $34,8 \%$ e do grupo $1 \mathrm{~J} / 60 \mathrm{~mW}$ foi de $28,5 \%$. O grupo irradiado com $1 \mathrm{~J} / 30 \mathrm{~mW}$ teve uma redução não significante em relação ao controle de $6,4 \%$ (TAB. 7).

TABELA 7 - Área sob a curva ( \pm erro) calculados nas 6 horas experimentais e \% (porcentagem) de redução do edema ( \pm erro da \% redução) calculados em relação ao grupo controle (CGN) da etapa $1 A$.

\begin{tabular}{ccccc} 
& Área & (士Erro) & \% Redução & (士Erro \% Redução) \\
\hline \hline CGN & 4,09 & 0,24 & & \\
Diclo & 2,67 & 0,17 & 34,8 & 4,6 \\
1J/30mW & 3,83 & 0,26 & 6,4 & 7,0 \\
1J/60mW & 2,92 & 0,22 & 28,5 & 5,7 \\
1J/100mW & 2,58 & 0,17 & 36,8 & 4,5 \\
\hline
\end{tabular}


TABELA 8 - Valores de $p$ obtidos pelo teste $Z$ para a comparação da área sob a curva dos diferentes grupos experimentais da etapa $1 \mathrm{~A}$ nas 6 horas experimentais. Os valores de $p$ foram corrigidos para múltiplas comparações pelo procedimento de Ryan-Holm Stepdown Bonferroni. $\mathbf{N = 5}$ animais por grupo. As diferenças estatisticamente significantes estão em negrito e itálico $(p<0,05)$.

\begin{tabular}{ccccc} 
& Diclo & CGN & $1 \mathrm{~J} / 30 \mathrm{~mW}$ & $1 \mathrm{~J} / 100 \mathrm{~mW}$ \\
\hline \hline CGN & $<0,0001$ & & & \\
$1 \mathrm{~J} / 30 \mathrm{~mW}$ & $\mathbf{0 , 0 0 1 4}$ & 0,9204 & & \\
$1 \mathrm{~J} / 100 \mathrm{~mW}$ & 0,73 & $<0,0001$ & 0,0005 & \\
$1 \mathrm{~J} / 60 \mathrm{~mW}$ & 1,0000 & $<0,0001$ & $\mathbf{0 , 0 4 0 8}$ & 0,8634 \\
\hline
\end{tabular}

Os resultados equivalentes na inibição de edema alcançados com a laserterapia e o tratamento com diclofenaco de sódio está de acordo com a literatura (BJORDAL et al., 2006) e concorda com estudos prévios que utilizaram a mesma dosagem de diclofenaco deste trabalho, 1mg/kg (ALBERTINI et al., 2004).

As diferentes potências utilizadas 30,60 e $100 \mathrm{~mW}$ mostraram influenciar na redução do edema, quando a energia de $1 \mathrm{~J}$ foi utilizada, sendo a inibição do edema proporcional ao aumento da potência.

O tempo experimental deste estudo foi de 6 horas, enquanto a maioria dos trabalhos publicados na literatura com metodologias parecidas avaliaram a evolução do edema em apenas 4 horas experimentais devido ao pico do edema neste modelo experimental estar ao redor da 4h experimental (ALBERTINI et al., 2004 e 2007). Com o intuito de comparar os nossos resultados de $6 \mathrm{~h}$ com os de $4 \mathrm{~h}$, a área sob a curva a partir do gráfico do volume relativo de 4 horas experimentais (TAB. 9) e as comparações entre os grupos (TAB. 10) foram realizadas. A mesma tendência dos resultados observados em 6 horas experimentais foi verificada, exceto pela similaridade entre as áreas dos grupos $1 \mathrm{~J} / 60 \mathrm{~mW}$ e $1 \mathrm{~J} / 30 \mathrm{~mW}$. Em 4h, o grupo $1 \mathrm{~J} / 100 \mathrm{~mW}$ foi o mais eficaz na redução do edema quando comparado aos outros dois grupos irradiados, CGN e Diclo. 


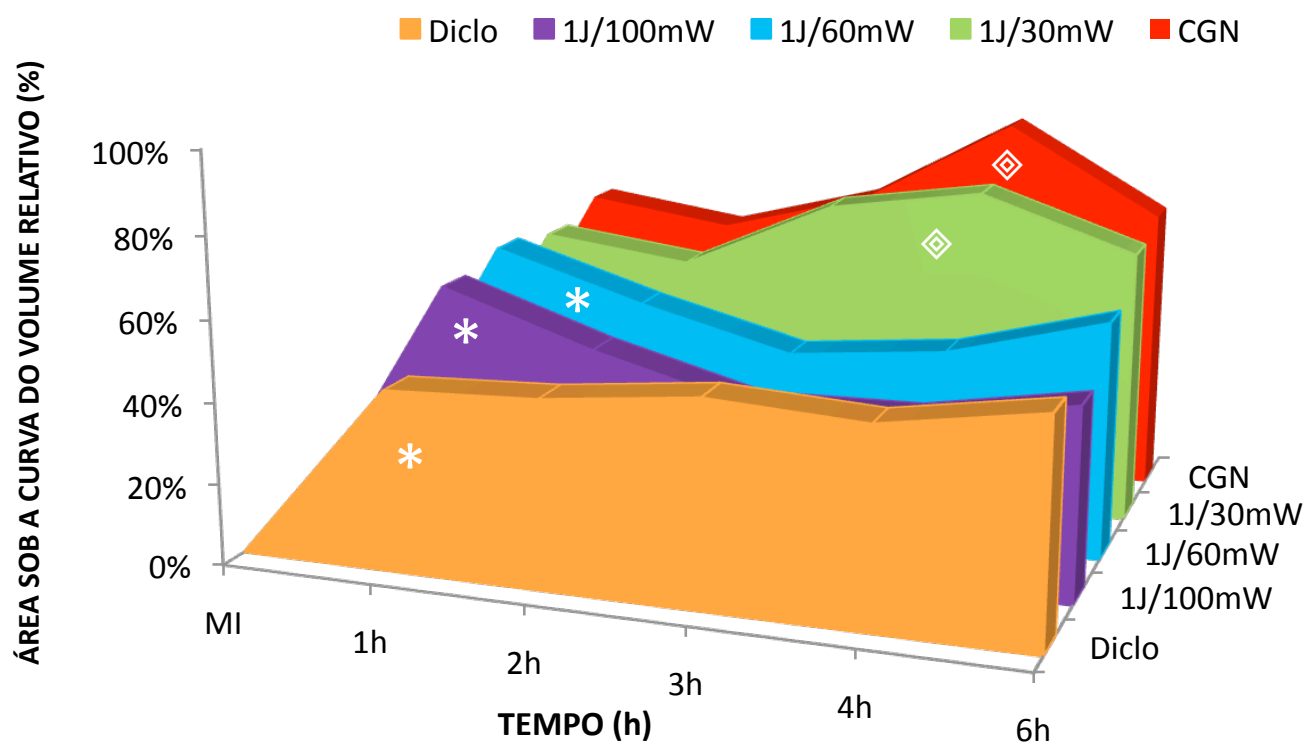

FIGURA 15 - Gráfico representando a área sob a curva do volume relativo (\%) em relação ao tempo experimental $(6 \mathrm{~h})$ da etapa $1 \mathrm{~A}$. Símbolos diferentes significam diferença estatística $(p<0,05)$.

TABELA 9 - Área sob a curva ( \pm erro) calculados nas 4 horas experimentais e \% (porcentagem) de redução do edema ( \pm erro da \% redução) calculados em relação ao grupo controle (CGN).

\begin{tabular}{|c|c|c|c|c|}
\hline & Área & ( \pm Erro) & \% Redução & ( \pm Erro \% Redução) \\
\hline CGN & 2,45 & 0,14 & & \\
\hline Diclo & 1,64 & 0,11 & 32,9 & 4,8 \\
\hline $1 \mathrm{~J} / 30 \mathrm{~mW}$ & 2,34 & 0,16 & 4,4 & 7,2 \\
\hline $1 \mathrm{~J} / 60 \mathrm{~mW}$ & 1,86 & 0,15 & 24,0 & 6,5 \\
\hline $1 \mathrm{~J} / 100 \mathrm{~mW}$ & 1,71 & 0,12 & 30,2 & 5,3 \\
\hline
\end{tabular}

TABELA 10 - Valores de $p$ obtidos pelo teste $Z$ para a comparação da área sob dos diferentes grupos experimentais da etapa $1 \mathrm{~A}$ nas 4 horas experimentais. Os valores de $p$ foram corrigidos para múltiplas comparações pelo procedimento de Ryan-Holm Stepdown Bonferroni. $\mathrm{N}=5$ animais por grupo. As diferenças estatisticamente significantes estão em negrito e itálico $(p<0,05)$.

\begin{tabular}{ccccc} 
& Diclo & CGN & $1 \mathrm{~J} / 30 \mathrm{~mW}$ & $1 \mathrm{~J} / 100 \mathrm{~mW}$ \\
\hline \hline CGN & $\mathbf{0 , 0 0 0 1}$ & & & \\
$1 \mathrm{~J} / 30 \mathrm{~mW}$ & $\mathbf{0 , 0 0 3}$ & 1,0000 & & \\
$1 \mathrm{~J} / 100 \mathrm{~mW}$ & 0,69 & $\mathbf{0 , 0 0 0 6}$ & $\mathbf{0 , 0 1 3 0}$ & \\
$1 \mathrm{~J} / 60 \mathrm{~mW}$ & 0,9657 & $\mathbf{0 , 0 3}$ & 0,1548 & 1,0000 \\
\hline
\end{tabular}


O número de células inflamatórias totais dos grupos experimentais da etapa $1 \mathrm{~A}$ mostram que todos os grupos apresentaram menor infiltrado inflamatório que o grupo controle (FIG. 16), confirmando o efeito de modulação da inflamação provocado pelo laser (LOPES-MARTINS et al., 2005; AIMBIRE et al., 2005, CORREA et al., 2007). Comparando os grupos irradiados, os grupos com 30 e 100mW apresentaram resultados semelhantes ao grupo Diclo e menor infiltrado inflamatório que o grupo irradiado com $60 \mathrm{~mW}$. Estes resultados mostram uma tendência diferente da encontrada nos resultados da avaliação do edema onde as maiores potências foram mais eficazes. Este padrão bifásico, onde as potências mínima e máxima foram mais eficazes já foi descrito na literatura (DEMIDOVARICE et al., 2007). Uma possível explicação para tal efeito pode ser a complexidade do tratamento do edema, que envolve vários eventos e células exigindo portanto uma maior potência de irradiação, enquanto que para a redução do infiltrado inflamatório uma combinação ideal de parâmetros seja necessária.

A grande variedade de metodologias da literatura sempre foi um agravante na determinação de protocolos. Entre as metodologias, o tempo de avaliação dos resultados mostrou-se bastante importante já que foram mostradas neste estudo modificações de resultados nas avaliações realizadas em 4h para 6h. Além disso, levando os resultados para a prática clínica, é importante não somente avaliar os tratamentos que mostraram melhor eficácia ao longo de todo o período experimental (resultados da área sob a curva) mas os resultados da evolução do edema ao longo de cada hora experimental. Isso porque, de acordo com o estágio que o edema estiver, um protocolo deverá ser utilizado com o intuito de promover menor desconforto para o paciente naquele momento clínico. 
HISTOLOGIA ETAPA 1. DOSIMETRIA

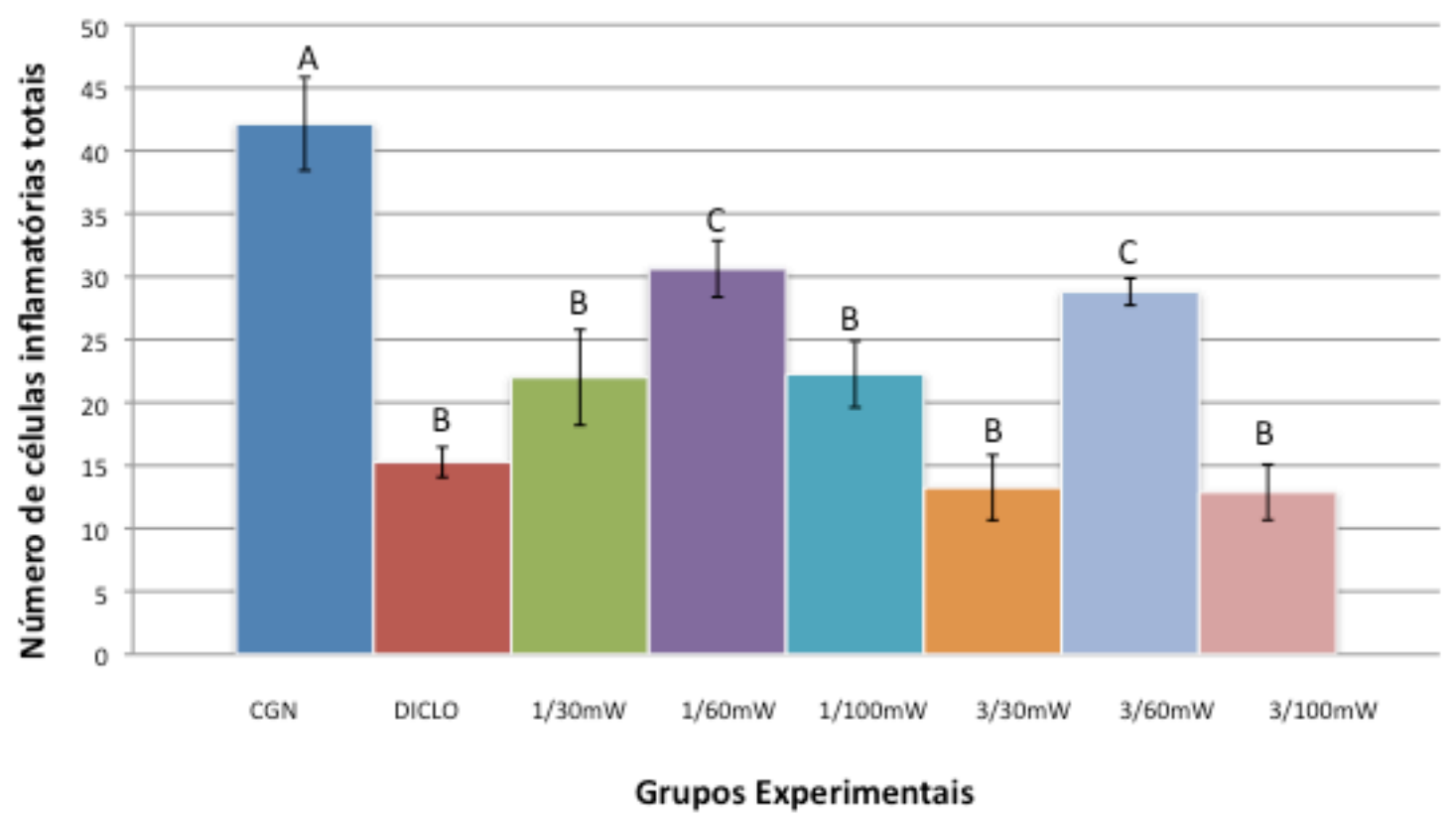

FIGURA 16 - Gráfico do número de células inflamatória totais nos diferentes grupos experimentais das etapas $1 \mathrm{~A}$ e 1B. Letras diferentes significam diferença estatística $(p<0,05)$.

\subsubsection{ETAPA 1B: $3 \mathrm{~J} / 30,60 \mathrm{E} 100 \mathrm{~mW}$}

O volume relativo dos grupos CGN e Diclo seguiu o padrão esperado com evolução progressiva e inibição constante, respectivamente, ao longo das 6h experimentais (FIG. 17).

Entre a $1^{\mathrm{a}}$ e $2^{\mathrm{a}}$ horas observarmos uma redução no volume relativo dos grupos $3 / 100 \mathrm{~mW}$ e $3 / 30 \mathrm{~mW}$. Até a $2 \mathrm{~h}$ no entanto, todos os grupos apresentaram volume semelhante (TAB.11). Na 3h experimental, os grupos irradiados com $3 / 100 \mathrm{~mW}$ e $3 / 30 \mathrm{~mW}$ e o grupo Diclo apresentaram redução significativa do volume da pata em relação ao grupo CGN (TAB. 12). 
As irradiações após 1 e $2 \mathrm{~h}$ da CGN mostraram serem importantes na inibição do edema em curto prazo e está de acordo com trabalhos anteriores que relataram que pelo menos duas irradiações são necessárias para a modulação da inflamação (ALBERTINI et al., 2004; LOPES-MARTINS et al., 2005). Além disso, este trabalho avaliou a duração destes efeitos ao longo de $6 \mathrm{~h}$ experimentais e resultados importantes foram encontrados. $\mathrm{Na} 4^{\mathrm{a}}$ hora experimental, 2 horas após a última irradiação o grupo 3J/30mW mostrou-se incapaz de manter a inibição do edema observada na 3h (TAB. 13). Este parâmetro de irradiação, mostrou-se desta forma mais susceptível ao tempo de avaliação dos efeitos em relação a irradiação com 3J/100mW, sendo os efeitos menos duradouros.

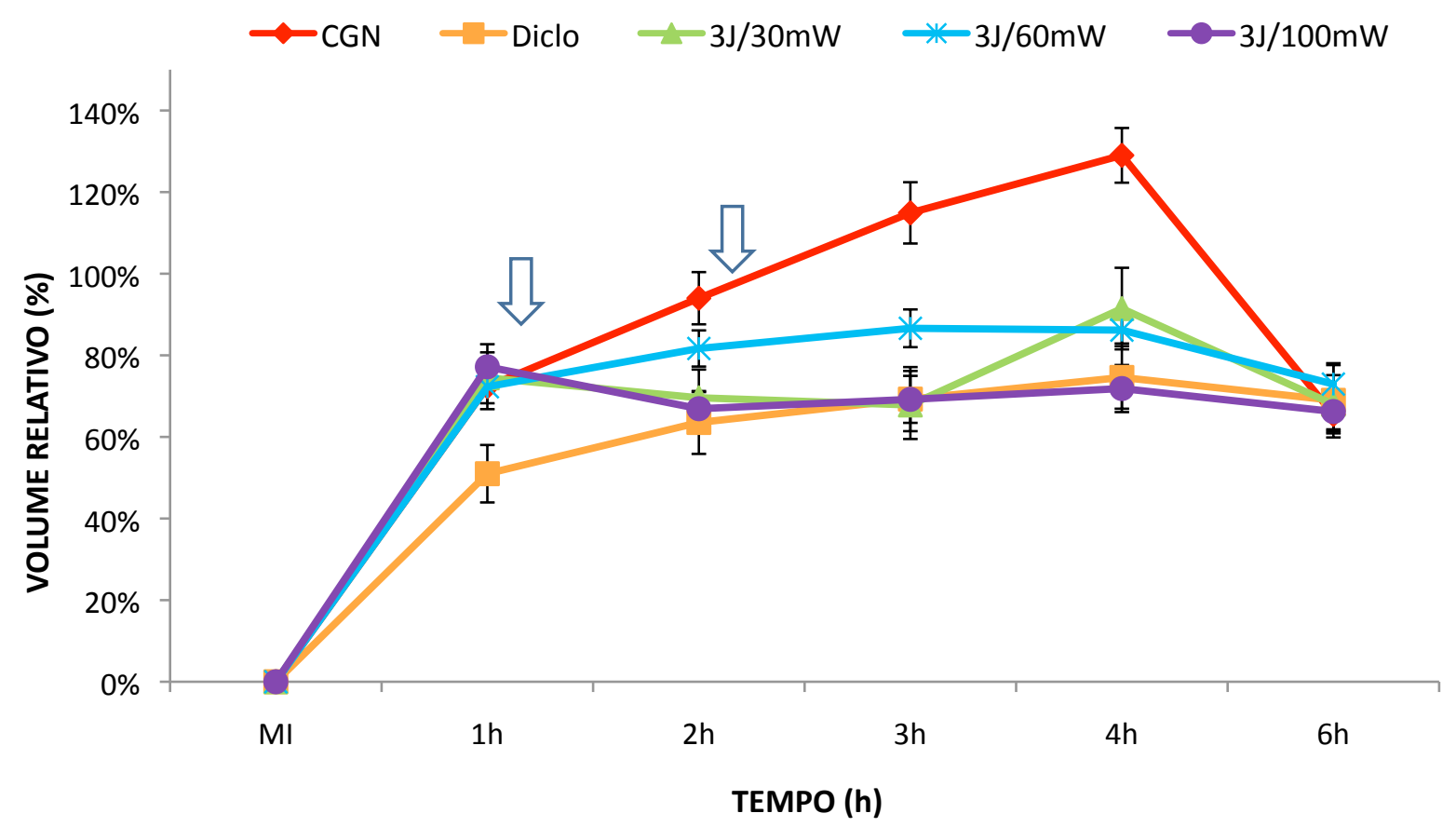

FIGURA 17 - Gráfico das médias do volume relativo do edema (\%) com os respectivos erros padrão da etapa 1B. As setas representam as irradiações. $\mathrm{N}=5$ animais por grupo. 
TABELA 11 - Valores de p obtidos pelo teste $t$ e corrigidos pelo procedimento de Ryan-Holm Stepdown Bonferroni para a comparação das médias do volume relativo na $2^{\mathrm{a}}$ hora experimental da etapa $1 \mathrm{~B}$.

\begin{tabular}{ccccc} 
2H & CGN & Diclo & 3J/30mW & 3J/60mW \\
\hline \hline Diclo & 0,1442 & & & \\
3J/30mW & 0,2564 & 1,0000 & & \\
3J/60mW & 0,7599 & 0,4535 & 0,7172 & \\
3J/100mW & 0,0729 & 1,0000 & 0,7470 & 0,2785 \\
\hline
\end{tabular}

TABELA 12 - Valores de p obtidos pelo teste $t$ e corrigidos pelo procedimento de Ryan-Holm Stepdown Bonferroni para a comparação das médias do volume relativo na $3^{\mathrm{a}}$ hora experimental da etapa $1 \mathrm{~B}$. As diferenças estatisticamente significantes estão em negrito e itálico $(p<0,05)$.

\begin{tabular}{ccccc} 
3H & CGN & Diclo & 3J/30mW & 3J/60mW \\
\hline \hline Diclo & $\mathbf{0 , 0 2 6 9}$ & & & \\
3J/30mW & $\mathbf{0 , 0 2 4 1}$ & 1,0000 & & \\
$\mathbf{3 J} / 60 \mathrm{~mW}$ & 0,0873 & 0,3735 & 0,4210 & \\
$\mathbf{3 J} / \mathbf{1 0 0 m W}$ & $\mathbf{0 , 0 1 3 0}$ & 0,9951 & 1,0000 & 0,2765 \\
\hline
\end{tabular}

TABELA 13 - Valores de $p$ obtidos pelo teste $t$ e corrigidos pelo procedimento de Ryan-Holm Stepdown Bonferroni para a comparação das médias do volume relativo na $4^{a}$ hora experimental da etapa 1B. As diferenças estatisticamente significantes estão em negrito e itálico $(p<0,05)$.

\begin{tabular}{ccccc} 
4H & CGN & Diclo & 3J/30mW & 3J/60mW \\
\hline \hline Diclo & $\mathbf{0 , 0 0 5 5}$ & & & \\
3J/30mW & 0,0996 & 0,6516 & & \\
3J/60mW & $\mathbf{0 , 0 0 3 9}$ & 0,8070 & 1,0000 & \\
3J/100mW & $\mathbf{0 , 0 0 2 0}$ & 0,7838 & 0,6401 & 0,3788 \\
\hline
\end{tabular}

No entanto, esta elevação pontual no volume relativo não influenciou no resultado geral do tratamento, quando a área sob a curva foi analisada tanto em $6 \mathrm{~h}$ experimentais (TAB. 14 e 15 e FIG. 18) como em $4 \mathrm{~h}$ experimentais (TAB. 16 e 17). De fato, o grupo 3J/30mW mostrou-se tão eficaz como os grupos 3J/100mW e Diclo na redução do edema apresentando volume estatisticamente menor que o grupo controle (TAB. 15 e 17).

Analisando os dados da área sob a curva, os grupos CGN e Diclofenaco foram diferentes, evidenciando a eficácia da injeção do diclofenaco 30 minutos antes da CGN para inibição do edema (TAB. 15). O grupo irradiado 3J/60 mW por sua vez, apresentou volume 
relativo total intermediário, sendo semelhante a todos os grupos experimentais estudados (TAB. 15 e 17).

TABELA 14 - Área sob a curva ( \pm erro) calculados nas 6 horas experimentais e \% (porcentagem) de redução do edema ( \pm erro da \% redução) calculados em relação ao grupo controle (CGN) da etapa $1 B$.

\begin{tabular}{|c|c|c|c|c|}
\hline & Área & (士Erro) & \% Redução & (士Erro \% Redução) \\
\hline CGN & 5,40 & 0,31 & & \\
\hline Diclo & 3,65 & 0,27 & 32,5 & 5,3 \\
\hline $3 \mathrm{~J} / 30 \mathrm{~mW}$ & 4,17 & 0,29 & 22,8 & 5,9 \\
\hline $3 \mathrm{~J} / 60 \mathrm{~mW}$ & 4,43 & 0,24 & 18,0 & 5,0 \\
\hline $3 \mathrm{~J} / 100 \mathrm{~mW}$ & 3,87 & 0,23 & 28,3 & 4,8 \\
\hline
\end{tabular}

TABELA 15 - Valores de $p$ obtidos pelo teste $Z$ para a comparação da área sob a curva entre os diferentes grupos experimentais da etapa 1B nas 6 horas experimentais. Os valores de $p$ foram corrigidos para múltiplas comparações pelo procedimento de Ryan-Holm Stepdown Bonferroni. $\mathrm{N}=5$ animais por grupo. As diferenças estatisticamente significantes estão em negrito e itálico $(p<0,05)$.

\begin{tabular}{ccccc} 
& Controle & Diclofenaco & 3J/30mW & 3J/60mW \\
\hline \hline Diclofenaco & $\mathbf{0 , 0 0 0 2}$ & & & \\
3J/30mW & $\mathbf{0 , 0 3 3 0}$ & 0,7502 & & \\
3J/60mW & 0,0942 & 0,1795 & 0,9977 & \\
3J/100mW & $\mathbf{0 , 0 0 0 8}$ & 0,5240 & 1,0000 & 0,4923 \\
\hline
\end{tabular}

TABELA 16 - Área sob a curva ( \pm erro) calculados nas 4 horas experimentais e \% (porcentagem) de redução do edema ( \pm erro da \% redução) calculados em relação ao grupo controle (CGN).

\begin{tabular}{|c|c|c|c|c|}
\hline & Área & ( \pm Erro) & \% Redução & (士Erro \% Redução) \\
\hline CGN & 3,46 & 0,21 & & \\
\hline Diclo & 2,21 & 0,18 & 36,1 & 5,4 \\
\hline $3 \mathrm{~J} / 30 \mathrm{~mW}$ & 2,58 & 0,19 & 25,5 & 5,8 \\
\hline $3 \mathrm{~J} / 60 \mathrm{~mW}$ & 2,84 & 0,16 & 17,9 & 5,2 \\
\hline $3 \mathrm{~J} / 100 \mathrm{~mW}$ & 2,49 & 0,16 & 27,9 & 5,0 \\
\hline
\end{tabular}




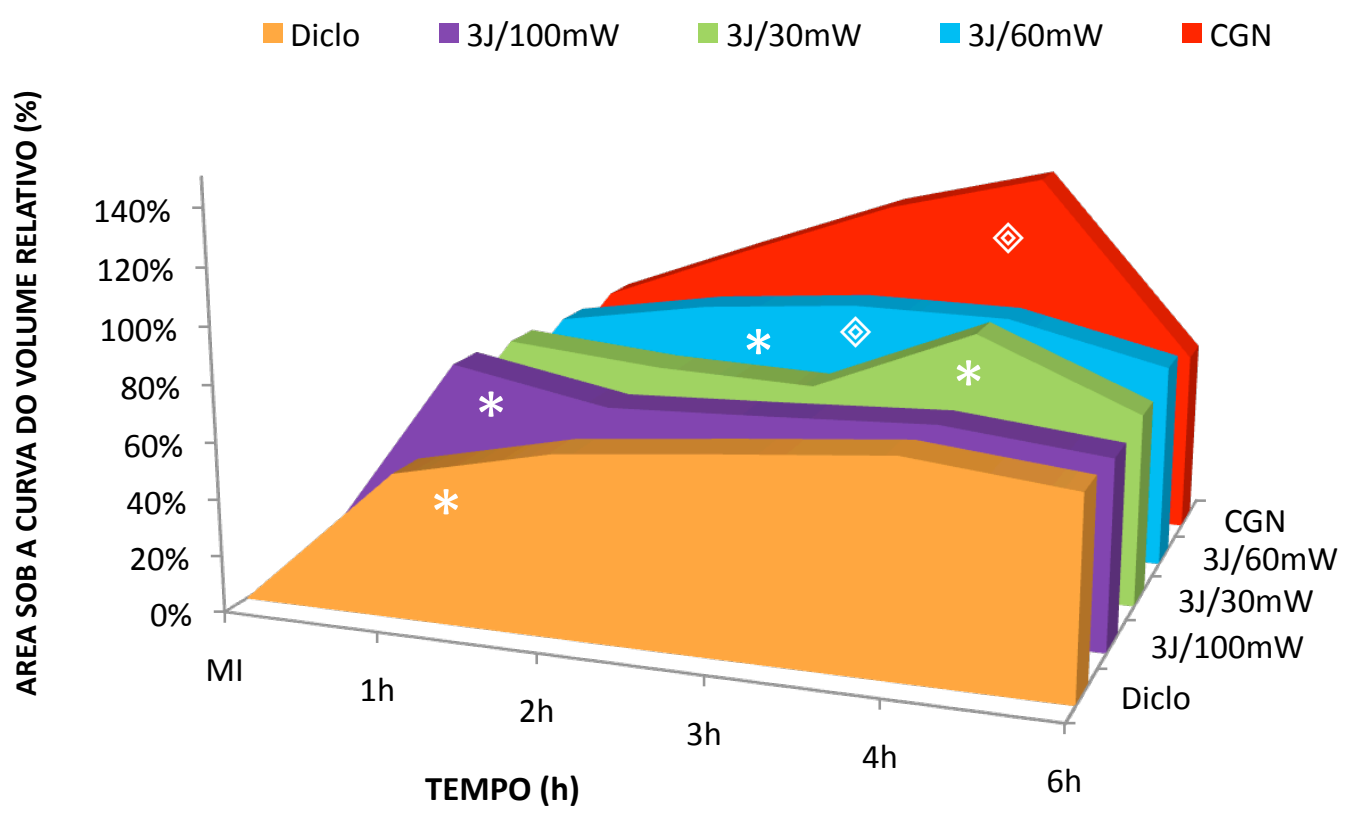

FIGURA 18 - Gráfico representando a área sob a curva do volume relativo (\%) em relação ao tempo experimental $(6 \mathrm{~h})$ da etapa 1B. Símbolos diferentes significam diferença estatística $(p<0,05)$.

TABELA 17 - Valores de $p$ obtidos pelo teste $Z$ para a comparação da área sob a curva entre os diferentes grupos experimentais da etapa 1B nas 4 horas experimentais. Os valores de $p$ foram corrigidos para múltiplas comparações pelo procedimento de Ryan-Holm Stepdown Bonferroni. $\mathrm{N}=5$ animais por grupo. As diferenças estatisticamente significantes estão em negrito e itálico $(p<0,05)$.

\begin{tabular}{ccccc} 
& Controle & Diclofenaco & 3J/30mW & 3J/60mW \\
\hline \hline Diclofenaco & $<\mathbf{0 , 0 0 0 1}$ & & & \\
3J/30mW & $\mathbf{0 , 0 1 3 3}$ & 0,6121 & & \\
$\mathbf{3 J} / 60 \mathrm{~mW}$ & 0,1062 & 0,0546 & 0,5699 & \\
$\mathbf{3 J} / \mathbf{1 0 0} \mathrm{mW}$ & $\mathbf{0 , 0 0 2 0}$ & 0,6919 & 0,7295 & 0,5985 \\
\hline
\end{tabular}

Nesta etapa, foi utilizada uma energia de irradiação três vezes maior que na etapa $1 \mathrm{~A}$, ou seja, 3J e avaliando seus efeitos com diferentes potências, verificamos que com esta energia a variação de potência apresentou uma influência diferente do experimento anterior. Interessantemente, a potência mínima $(30 \mathrm{~mW})$ e máxima $(100 \mathrm{~mW})$, e respectivamente o tempo de irradiação mínimo e máximo, 30 e 100 segundos demonstraram melhores resultados que a potência $(60 \mathrm{~mW})$ e tempo (50 s) intermediários quando comparados com o controle. Esta tendência de parâmetro ótimo em duas janelas dosimétricas já foi observada 
anteriormente na literatura (DEMIDOVA-RICE et al., 2007) e parece estar relacionada com o tipo de tecido irradiado e combinação de parâmetros utilizados. Neste trabalho esse evento só foi observado utilizando a energia de 3J, cuja variação de potência mostrou relação com a duração do efeito anti-edematoso.

Analisando a porcentagem de redução do edema em relação ao grupo controle de ambas as etapas, ao longo das $6 \mathrm{~h}$ experimentais, o parâmetro de $1 \mathrm{~J} / 100 \mathrm{~mW}$ foi o que apresentou maior redução, 36,8\%. O grupo Diclo apresentou 34,8\% e 32,5\% (etapas $1 \mathrm{~A}$ e 1B respectivamente), seguido pelos grupos $3 \mathrm{~J} / 100 \mathrm{~mW}$ e $1 \mathrm{~J} / 60 \mathrm{~mW}$ com redução de aproximadamente 28\%, 3J/30mW (22,8\%), 3J/60mW (18\%) e 1J/30mW (6,4\%) em relação ao controle.

Albertini e cols. (2004) utilizando o mesmo modelo experimental em ratos Wistar, e o mesmo número de irradiações apos 1 e $2 \mathrm{~h}$ da injeção da carragenina, conseguiram uma redução no edema após $4 \mathrm{~h}$ experimentais de 16,2\%. A energia utilizada foi de 0,22 J, potência de $2,51 \times 10^{-3} \mathrm{~W}$ em contato, com área de irradiação de $0,08 \mathrm{~cm}^{2}$, durante 80 s com laser vermelho (650nm). Apesar da dificuldade de comparação direta entre os estudos, já que muitos outros fatores também podem ter influenciado, como comprimento de onda e espécie animal (utilizamos camundongos, não ratos), nossos resultados levaram a uma redução máxima de $36,8 \%$, demonstrando que o protocolo utilizado foi bastante efetivo na inibição da evolução do edema de pata.

Neste trabalho, a combinação ideal entre energia e potência mostrou ser mais importante que estes fatores individualmente. Ainda, podemos especular que $100 \mathrm{~mW}$ é uma potencia efetiva na redução do edema, $30 \mathrm{~mW}$ pode se efetivo se a energia for mais alta, 3 $\mathrm{J}$, e ainda, que $60 \mathrm{~mW}$ é mais eficiente quando utilizado com uma energia menor, neste caso, $1 \mathrm{~J}$. O parâmetro $1 \mathrm{~J} / 100 \mathrm{~mW}$, foi o mais eficiente na redução do edema e por isso foi selecionado para ser utilizado na etapa 2 deste trabalho. 
O número de células inflamatórias totais encontradas nas patas dos grupos experimentais da etapa 1B mostraram os mesmos resultados encontrados na etapa $1 \mathrm{~A}$, onde todos os grupos tratados apresentaram menor infiltrado inflamatório que o grupo controle (FIG. 16, APÊNDICE 1). A comparação entre todos os grupos de ambas as etapas mostrou que independentemente da energia utilizada (1 ou $3 \mathrm{~J}$ ), as irradiações com 30 e $100 \mathrm{~mW}$ apresentaram resultados semelhantes ao grupo Diclo e menor infiltrado inflamatório que o grupo irradiado com $60 \mathrm{~mW}$. Estes resultados sugerem que a potência de irradiação pode ser mais importante que a energia total depositada no tecido, neste modelo experimental quando o número de células inflamatórias é avaliada. Ainda, confirma a existência de janelas dosimétricas, com diferentes potências ótimas, dentro de um mesmo tecido biológico. O interessante neste resultado é que foram encontrados bons resultados tanto com $30 \mathrm{~mW}$ como $100 \mathrm{~mW}$, potências cuja indicação clínica é motivo de discordância e questionamentos entre alguns clínicos e pesquisadores.

O tempo de irradiação foi apontado por alguns trabalhos como o principal parâmetro de irradiação (CASTANO et al., 2007). Principalmente em estudos de cicatrização, onde a energia e a potência utilizadas parecem ser reduzidas em relação ao protocolos para modulação da inflamação, o tempo é proporcional aos efeitos bioestimulatórios da FLBI encontrados (HAWKINS e ABRAHAMSE, 2007). O tempo de irradiação das três potências testadas (30, 60 e $100 \mathrm{~mW})$ com 1 e com $3 \mathrm{~J}$, foi de respectivamente: 33, 16, 10, 100, 50 e 30 segundos. Correlacionando o tempo de irradiação com a redução do edema proporcionado pela FLBI, não foi possível tirar nenhuma conclusão, mostrando que de acordo com a metodologia utilizada neste trabalho o tempo não influenciou nos resultados observados. Por outro lado, o parâmetro que mais influenciou nos resultados foi a potência de irradiação. 
Na prática clínica a principal vantagem de potências maiores, neste caso $100 \mathrm{~mW}$, é ter, ao mesmo tempo, menor tempo de irradiação por ponto que menores potências. Isso é muito relevante no dia a dia clínico, cuja velocidade de atendimento interfere no número de atendimentos realizados por dia. Para o paciente, a rapidez no tratamento também pode ser sinônimo de conforto. Por outro lado, no mercado brasileiro, a potência do equipamento é proporcional ao seu custo, dificultando sua compra pelos profissionais de saúde.

Na prática, é conhecido que equipamentos com potências elevadas e que permitem seu ajuste podem ser utilizados em um número maior de aplicações clínicas, desde a analgesia, que é obtida com maiores potências até a cicatrização de tecidos superficiais, cuja potência necessária para os efeitos biomodulatórios pode ser mais baixa.

\subsection{ETAPA 2: AVALIAÇÃO DA INFLUÊNCIA DO LOCAL E MOMENTO DE IRRADIAÇÃO}

Segundo Karu (2000), para que os efeitos do laser ocorram, o tecido biológico irradiado deve encontrar-se em estresse oxidativo, ou seja, com seu potencial redox alterado. Esta premissa é bem relatada na literatura e como exemplo, em cultura celular de fibroblastos, somente células em estresse nutricional obtiveram crescimento estimulado com a irradiação laser (MENEGUZZO et al., 2008). Nota-se no entanto, que esta condição de pré-irradiação é mais relevante em trabalhos realizados em culturas celulares (PEREIRA et al., 2002). Em trabalhos realizados in vivo, os efeitos da laserterapia, por menores que sejam estão sempre presentes. Além disso, o que geralmente ocorre em trabalhos cujos efeitos são nulos são erros de protocolo, especialmente no que diz respeito a dosagens sub clínicas, ou seja, dosagens muito baixas incapazes de promoverem um resultado clínico mensurável (LIMPANICHKUL et al., 2006). A diferença entre os resultados encontrados em estudos em 
cultura celular e em animais, pode estar portanto relacionada com a influência da laserterapia sobre a resposta imunológica sistêmica, só presente em estudos in vivo.

Alguns trabalhos relatam os efeitos sistêmicos da laserterapia, cuja irradiação é feita a distância do sítio alvo acelerando a cicatrização de tecidos (ROCHKIND et al., 1989), suprimindo a reação tardia da hipersensibilidade (INOUE et al.,1989) e tendo um efeito imunomodulatório sistêmico em hipersensibilidade causada por DNCB (1-chloro-2,4dinitrochlorobenzene) (KANDOLF-SEKULOVIC et al., 2003).

A FLBI é capaz de ativar células como os linfócitos, estimular o fluxo linfático e auxiliando na modulação da resposta inflamatória (AIMBIRE et al., 2005; AGAIBY et al., 2000; TONG et al., 2000; BOSCHI et al., 2008). Ainda, muitos estudos já mostraram a modulação sistêmica da resposta inflamatória a partir da FLBI, como a excreção aumentada de metabólitos de serotonina indicando uma mediação central no alivio da dor crônica (WALKER et al., 1983). Schindl e cols. (1997) demonstraram que a laserterapia é capaz de modular a resposta imunológica dependendo do estado imunológico do organismo irradiado.

Assim, ao irradiarmos tecidos previamente sadios é possível estimularmos a resposta imunológica do organismo em questão, o que possibilita uma nova abordagem da laserterapia, agora com ação preventiva e ainda muito pouco estudada pela literatura.

A etapa 2 avaliou os efeitos da laserterapia sobre o edema em diferentes momentos envolvendo irradiações preventivas (momentos A e B), irradiações durante a evolução do edema (momento C) e irradiações após o edema instalado, com o intuito de realizar o tratamento do edema (D). Ainda, para cada momento foi avaliado o melhor local de irradiação (pata, linfonodo ou pata+linfonodo) realizando irradiações padronizadas com o mesmo protocolo (1J, 100mW, 10s de irradiação) no modelo experimental de edema induzido por carragenina. 
Os dados dos grupos controle (CGN) e diclofenaco (Diclo) dos quatro experimentos realizados foram reunidos obtendo-se um padrão de comportamento do edema durante as 6 horas experimentais. O grupo controle foi composto por 27 animais e o grupo diclofenaco por 13. A evolução padrão do edema no grupo Diclo revelou a partir da primeira hora uma inibição do edema, com área sob a curva estatisticamente inferior ao grupo controle. A evolução do grupo controle (CGN) mostrou um pico de edema entre a 3 e 4 hs, com aumento de $65 \%$ do volume da pata em relação ao volume inicial e leve diminuição do edema a partir da quinta hora experimental chegando na sexta hora com volume aproximadamente $30 \%$ maior que o inicial (FIG. 19). Estes resultados estão de acordo com a literatura, e indicam que o modelo experimental foi corretamente padronizado (ALBERTINI et al., 2004).

\subsubsection{ETAPA 2.A - AVALIAÇÃO DO EFEITO PREVENTIVO DA IRRADIAÇÃO (irradiações feitas $2 h$ e $1 h$ antes da injeção da carragenina)}

No momento A, cujas irradiações foram feitas de forma preventiva, 2 e $1 \mathrm{~h}$ antes da indução do edema, o padrão da evolução do edema nos grupos irradiados mostrou-se bastante interessante (FIG. 19). Na segunda hora após a indução, todos os grupos irradiados apresentaram volume relativo (edema) semelhante ao grupo CGN e maior que o grupo Diclo (TAB. 18). O grupo pata + linfonodo apresentou uma queda gradativa no edema a partir da segunda hora, apresentando um volume intermediário na $3^{\mathrm{a}}$ hora (TAB. 19) significantemente menor que os outros grupos irradiados na $4^{a}$ hora (TAB. 20). O grupo linfonodo apesar de ter apresentado um crescente aumento do volume iniciou uma queda expressiva do edema a partir da $3^{\mathrm{a}}$ hora, apresentando na $4^{\mathrm{a}}$ hora um edema significantemente inferior ao grupo CGN (TAB. 20). O grupo irradiado na pata, apesar de demonstrar o mesmo perfil que o grupo linfonodo, ou seja, com aumento de volume até a $3^{\mathrm{a}}$ hora seguido de uma queda acentuada, na $4^{\mathrm{a}}$ hora o volume de edema foi semelhante ao 
grupo CGN. Durante todo o experimento, o grupo Diclo foi o que apresentou menor edema (FIG. 19).

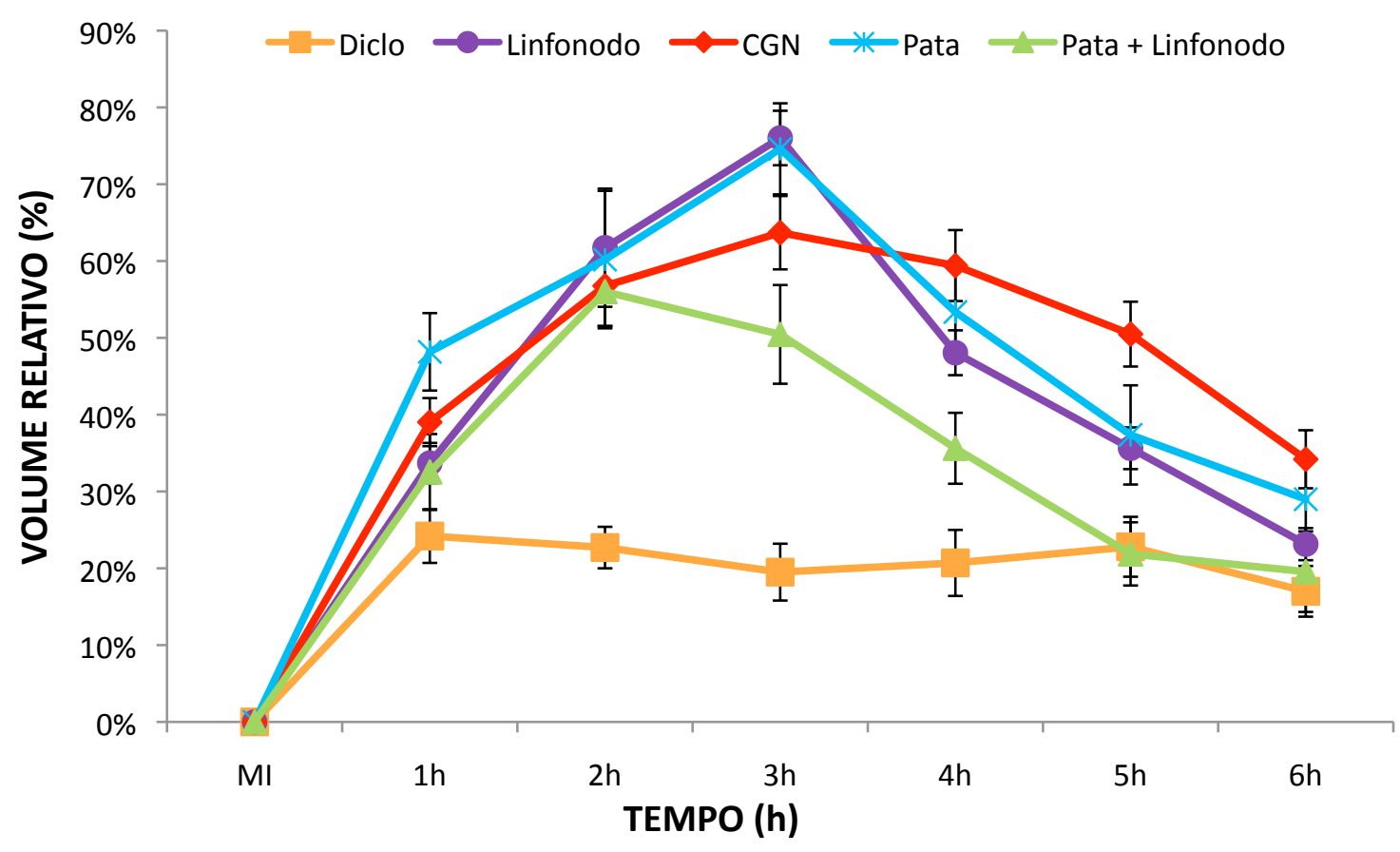

FIGURA 19 - Gráfico das médias do volume relativo do edema (\%) com os respectivos erros padrão da etapa 2A. As irradiações foram feitas $2 \mathrm{~h}$ e $1 \mathrm{~h}$ antes da injeção de carragenina em MI. N=27 para grupo CGN, $\mathrm{N}=13$ para o grupo Diclo e $\mathrm{N}=5$ para os demais grupos.

TABELA 18 - Valores de $p$ obtidos pelo teste $t$ e corrigidos pelo procedimento de Ryan-Holm Stepdown Bonferroni para a comparação das médias do volume relativo na $2^{\mathrm{a}}$ hora experimental da etapa $2 \mathrm{~A}$. As diferenças estatisticamente significantes estão em negrito e itálico $(p<0,05)$.

\begin{tabular}{ccccc} 
2H & CGN & Diclo & Linfonodo & Pata \\
\hline Diclo & $<0,0001$ & & & \\
Linfonodo & 1,0000 & $\mathbf{0 , 0 3 8 6}$ & & \\
Pata & 1,0000 & $\mathbf{0 , 0 2 8 8}$ & 1,0000 & \\
Pata+Linfonodo & 0,9146 & $\mathbf{0 , 0 0 3 2}$ & 1,0000 & 1,0000 \\
\hline
\end{tabular}


TABELA 19 - Valores de p obtidos pelo teste $t$ e corrigidos pelo procedimento de Ryan-Holm Stepdown Bonferroni para a comparação das médias do volume relativo na $3^{\text {a }}$ hora experimental da etapa $2 \mathrm{~A}$. As diferenças estatisticamente significantes estão em negrito e itálico $(p<0,05)$.

\begin{tabular}{ccccc} 
3H & CGN & Diclo & Linfonodo & Pata \\
\hline Diclo & $<0,0001$ & & & \\
Linfonodo & 0,2029 & $<0,0001$ & & \\
Pata & 0,3628 & $\mathbf{0 , 0 0 0 6}$ & 0,8444 & \\
Pata+Linfonodo & 0,3955 & $\mathbf{0 , 0 3 0 8}$ & 0,0740 & 0,1236 \\
\hline
\end{tabular}

TABELA 20 - Valores de p obtidos pelo teste $t$ e corrigidos pelo procedimento de Ryan-Holm Stepdown Bonferroni para a comparação das médias do volume relativo na $4^{\text {a }}$ hora experimental da etapa $2 \mathrm{~A}$. As diferenças estatisticamente significantes estão em negrito e itálico $(p<0,05)$.

\begin{tabular}{ccccc}
$4 \mathrm{H}$ & CGN & Diclo & Linfonodo & Pata \\
\hline \hline Diclo & $<0,0001$ & & & \\
Linfonodo & $<0,0001$ & $\mathbf{0 , 0 0 0 2}$ & & \\
Pata & 0,0985 & $\mathbf{0 , 0 0 8 2}$ & $\mathbf{0 , 0 0 0 2}$ & \\
Pata+Linfonodo & $\mathbf{0 , 0 0 0 5}$ & 0,1110 & $\mathbf{0 , 0 0 0 2}$ & 0,0502 \\
\hline
\end{tabular}

Analisando a eficácia do tratamento ao longo das 6 horas experimentais, através da área sob a curva, a irradiação preventiva realizada com $2 \mathrm{~h}$ e $1 \mathrm{~h}$ de antecedência à injeção da carragenina foi ineficaz nos grupos linfonodo e pata quando comparados com o grupo controle (CGN). No entanto, o grupo pata + linfonodo mostrou ser efetivo na redução do edema total formado quando comparado ao grupo controle e aos demais grupos irradiados. O grupo Diclo comparado com todos os outros grupos foi o que apresentou o menor edema ao longo das 6 horas experimentais (TAB. 22 e 21 e FIG. 20). 
TABELA 21 - Área sob a curva ( \pm erro) calculados nas 6 horas experimentais e \% (porcentagem) de redução do edema ( \pm erro da \% redução) calculados em relação ao grupo controle (CGN) da etapa $2 A$.

\begin{tabular}{ccccc} 
2A & Área & (士Erro) & \% Redução & (士Erro \% Redução) \\
\hline \hline CGN & 2,86 & 0,18 & & \\
Diclo & 1,18 & 0,10 & 58,7 & 3,8 \\
Linfonodo & 2,67 & 0,17 & 6,9 & 6,4 \\
Pata & 2,88 & 0,21 & $-0,6$ & 7,9 \\
Pata+Linfonodo & 2,06 & 0,15 & 28,0 & 5,8 \\
\hline
\end{tabular}

TABELA 22 - Valores de $p$ obtidos pelo teste $Z$ para a comparação da área sob a curva dos diferentes grupos experimentais da etapa 2A nas 6 horas experimentais. Os valores de $p$ foram corrigidos para múltiplas comparações pelo procedimento de Ryan-Holm Stepdown Bonferroni. N=27 para grupo CGN, $\mathrm{N}=13$ para $\circ$ grupo Diclo e $\mathrm{N}=5$ para os demais grupos. As diferenças estatisticamente significantes estão em negrito e itálico $(p<0,05)$.

\begin{tabular}{ccccc} 
& Diclof & Linfonodo & CGN & Pata \\
\hline \hline Linfonodo & $<0,0001$ & & & \\
CGN & $<0,0001$ & 1 & & \\
Pata & $<0,0001$ & 1 & 0,95 & \\
Pata + Linfonodo & $<0,0001$ & $\mathbf{0 , 0 3 0}$ & $\mathbf{0 , 0 0 3 6}$ & $\mathbf{0 , 0 0 8}$ \\
\hline
\end{tabular}

TABELA 23 - Área sob a curva ( \pm erro) calculados nas 4 horas experimentais e \% (porcentagem) de redução do edema ( \pm erro da \% redução) calculados em relação ao grupo controle (CGN) na etapa $2 A$.

\begin{tabular}{ccccc} 
2A 4H & Área & (士Erro) & \% Redução & (士Erro \% Redução) \\
\hline \hline CGN & 1,89 & 0,12 & & \\
Diclo & 0,768 & 0,073 & 59,4 & 4,1 \\
Linfonodo & 1,96 & 0,13 & $-3,3$ & 7,8 \\
Pata & 2,10 & 0,16 & $-10,8$ & 9,3 \\
Pata+Linfonodo & 1,57 & 0,12 & 17,1 & 7,1 \\
\hline
\end{tabular}




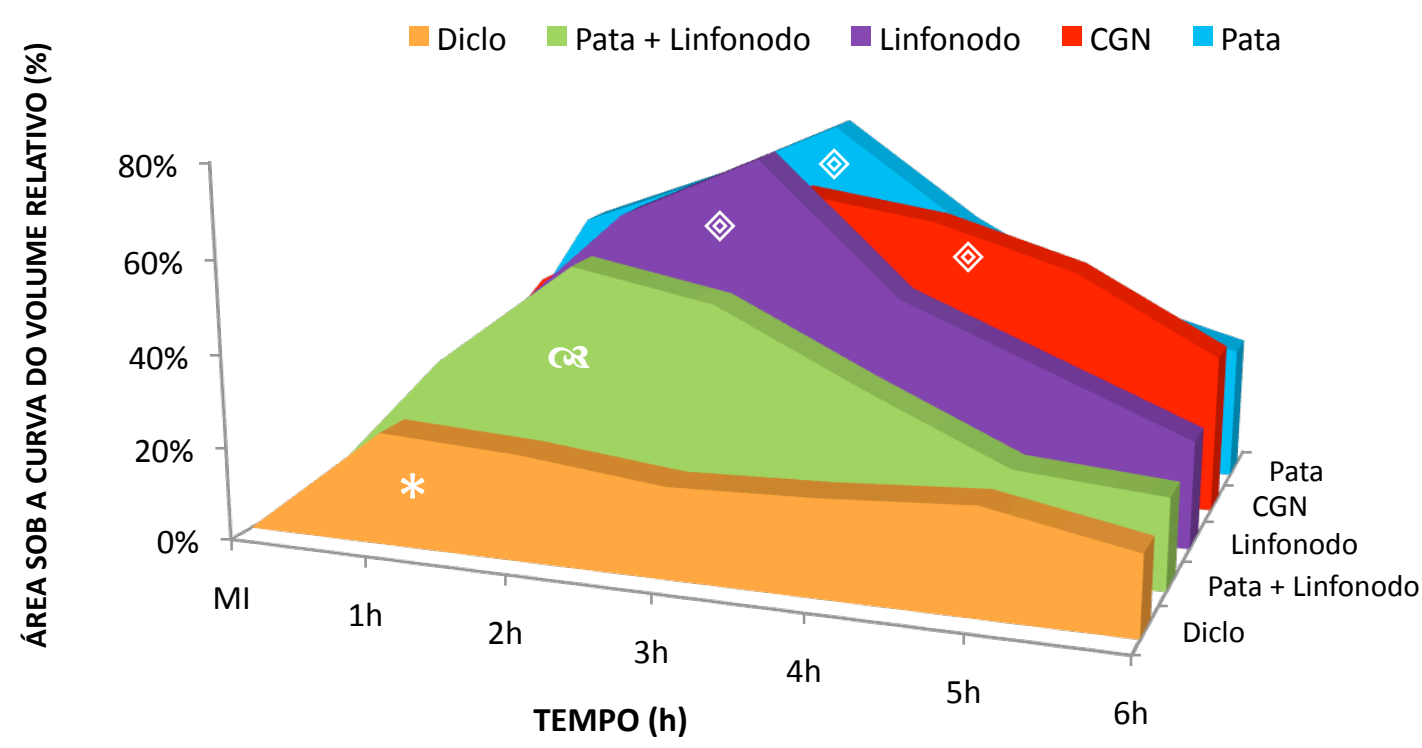

FIGURA 20 - Gráfico representando a área sob a curva do volume relativo (\%) em relação ao tempo experimental $(6 \mathrm{~h})$ da etapa $2 A$. Símbolos diferentes significam diferença estatística $(p<0,05)$

Ao longo das 6 horas experimentais, a dupla irradiação (pata + linfonodo) demonstrou ter ação inibitória na formação do edema e ser a melhor opção entre os grupos irradiados quando uma intervenção preventiva de $2 \mathrm{~h}$ e $1 \mathrm{~h}$ antes da carragenina for realizada. A segunda opção seria a irradiação isolada no linfonodo, que apresentou efeito inibitório pontual, na $4^{\mathrm{a}}$ hora, ou ainda a irradiação na pata, que mesmo sem efeito na redução total do edema medido pela área sob a curva mostraram uma queda no volume a partir da $2^{\mathrm{a}}$ e $3^{\mathrm{a}}$ horas respectivamente. Clinicamente, estes resultados poderiam resultar em um maior conforto ao paciente submetido, por exemplo, a uma cirurgia cujo edema é significativo no pós operatório. Esta consideração é bastante importante e trabalhos clínicos devem ser realizados com o intuito de verificar a efetividade da laserterapia preventiva sobre o edema e outros efeitos da inflamação em pós operatórios cirúrgicos.

Avaliadas em $4 \mathrm{~h}$ experimentais, a área sob a curva mostrou que o volume total de edema formado pelos grupos irradiados foram semelhantes ao volume do grupo CGN sendo 
o grupo Diclo o único tratamento com redução significativa no edema em relação ao controle (CGN) (TAB. 24).

TABELA 24 - Valores de $p$ obtidos pelo teste $Z$ para a comparação da área sob dos diferentes grupos experimentais da etapa $2 \mathrm{~A}$ nas 4 horas experimentais. Os valores de $p$ foram corrigidos para múltiplas comparações pelo procedimento de Ryan-Holm Stepdown Bonferroni. $\mathrm{N}=27$ para grupo $\mathrm{CGN}, \mathrm{N}=13$ para - grupo Diclo e $\mathrm{N}=5$ para os demais grupos. As diferenças estatisticamente significantes estão em negrito e itálico $(p<0,05)$.

\begin{tabular}{ccccc} 
& Diclo & Linfonodo & CGN & Pata \\
\hline \hline Linfonodo & $<0,0001$ & & & \\
CGN & $<0,0001$ & 0,7301 & & \\
Pata & $<0,0001$ & 0,9935 & 0,9440 & \\
Pata + Linfonodo & $<0,0001$ & 0,1656 & 0,2591 & 0,0556 \\
\hline
\end{tabular}

A ativação benéfica da resposta imunológica de forma preventiva foi verificada no grupo pata + linfonodo, mostrando a importância tanto da ação indireta nos linfonodos como a ação direta sobre a pata. A inibição significativa em relação ao grupo CGN na $4^{a}$ hora mostrou um efeito tardio da irradiação preventiva. Comparando os três sítios de irradiação, a dupla irradiação foi a única cujos efeitos puderam ser estatisticamente relevantes, porém o perfil do comportamento dos grupos pata e linfonodo apresentado no gráfico ao longo das 6 horas experimentais mostrou uma tendência positiva da laserterapia. Neste sentido, a hipótese que pode ser levantada é que a quantidade de energia depositada, que foi maior na dupla irradiação pode ser uma possível explicação sobre a efetividade deste grupo em relação aos outros irradiados. A irradiação preventiva parece ter acelerado o processo inflamatório, inibindo a formação do edema de forma dependente da dose e do sítio de irradiação realizada. Ainda, podemos considerar que o período de $2 \mathrm{~h}$ entre a irradiação e a indução do edema pode ter influenciado nos resultados. Os efeitos do laser não perduraram com força suficiente para inibir o edema de forma significativa, mas conseguiu acelerar o 
processo inflamatório. A irradiação em dois sítios (pata + linfonodo) pode ter contribuído para que os efeitos da irradiação perdurassem, sendo desta forma, significativos em relação ao grupo CGN. Curiosamente, estes efeitos observados foram tardios, não observados em $4 \mathrm{~h}$ mas em 6 horas experimentais mostrando a importância da realização de estudos com prolongado tempo de observação quando o efeito preventivo é analisado. Os resultados sugerem que a dupla irradiação e a potência influenciam na durabilidade dos efeitos e estes, podem ser tardios quando irradiações preventivas são realizadas. Uma hipótese para explicar estes efeitos é a ativação das células imunológicas pela radiação de forma a preparar uma resposta imunológica preventiva, acelerando a resposta inflamatória.

A análise da migração de neutrófilos através da atividade da MPO neste momento experimental mostrou um menor acúmulo de neutrófilos no grupo pata $6 \mathrm{~h}$ após a indução do edema por carragenina (FIG. 21). Curiosamente o grupo duplamente irradiado não demonstrou menor número de neutrófilos ao final das $6 \mathrm{~h}$ experimentais.

Analisando os efeitos do laser no edema e no infiltrado e correlacionando com o tipo de protocolo utilizado é possível sugerir que dois padrões de respostas são encontrados. Uma ação pró-inflamatória da radiação, acelerando o processo inflamatório e um padrão antiinflamatório que não necessariamente acelera o processo mas sim modula a inflamação. O primeiro padrão é encontrado nas irradiações diretas na pata ou no linfonodo e o segundo padrão na dupla irradiação. Ainda, a redução do infiltrado inflamatório parece estar relacionado com o local da irradiação, local onde foi realizada a análise histológica, o que justifica os resultados desta etapa. O número de neutrófilos reduzido indica que a irradiação preventiva na pata acelerou a resolução do processo inflamatório. O declínio do edema observado a partir da $3^{\mathrm{a}}$ hora, apesar de tardio confirma a ação da radiação laser acelerando a resposta inflamatória após a irradiação direta na pata. Por outro lado, a dupla irradiação 
teve uma ação anti-inflamatória, cuja modulação apesar de não ter influenciado no infiltrado inflamatório, resultou na inibição do edema.

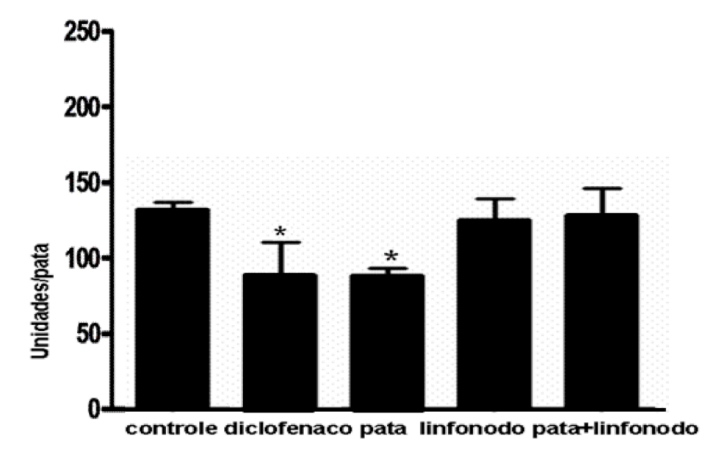

FIGURA 21 - Valores médios + DP (desvio padrão) de Unidades de Mieloperoxidase (MPO) medidos após $6 \mathrm{~h}$ da injeção da carragenina na etapa $2 A$. $N=5$ animais por grupo, ${ }^{*} p<0,05$.

\subsubsection{ETAPA 2B - AVALIAÇÃO DO EFEITO PREVENTIVO DA IRRADIAÇÃO (IRRADIAÇÕES FEITAS $1 \mathrm{H}$ E IMEDIATAMENTE ANTES DA INJEÇÃO DA CARRAGENINA)}

Neste experimento a irradiação também preventiva, realizada $1 \mathrm{~h}$ e imediatamente antes da indução do edema mostrou uma tendência totalmente diferente aos resultados obtidos no momento A. O grupo duplamente irradiado (pata+linfonodo) não teve nenhum efeito sobre a evolução do edema, comportando-se de forma similar ao grupo controle (CGN) ao longo das 6h experimentais (FIG. 22). Já o grupo irradiado no linfonodo, apresentou menor edema em relação ao grupo controle (CGN) e foi similar ao grupo Diclo na $2^{a}$ e $3^{a}$ horas experimentais (TAB. 28 e 26). Apesar de não ter apresentado diferença estatística em relação ao grupo controle (CGN), o grupo irradiado na pata apresentou um edema exacerbado entre a $3^{a}$ e $4^{a}$ horas. Na quarta hora experimental, o grupo irradiado no linfonodo teve um súbito aumento no seu volume, e neste momento, todos os grupos irradiados foram semelhantes ao grupo controle (CGN) (TAB. 27) 
As análises da área sob a curva tanto de 4 como de 6 horas experimentais mostraram que a única irradiação preventiva capaz de inibir o edema foi o grupo irradiado no linfonodo. Ambos os grupos, linfonodo e Diclo apresentaram resultados similares quando comparados aos outros grupos (TAB. 28 à 31).

A análise da migração de neutrófilos através da atividade da MPO neste tempo experimental mostrou um menor acúmulo de neutrófilos em todos os grupos tratados quando comparados ao grupo controle (FIG. 24). Em todos os grupos e na $4^{\text {a }}$ hora do grupo linfonodo uma ação pró-inflamatória foi observada, acelerando o processo inflamatório e portanto diminuindo o infiltrado inflamatório em todos os grupos estudados.

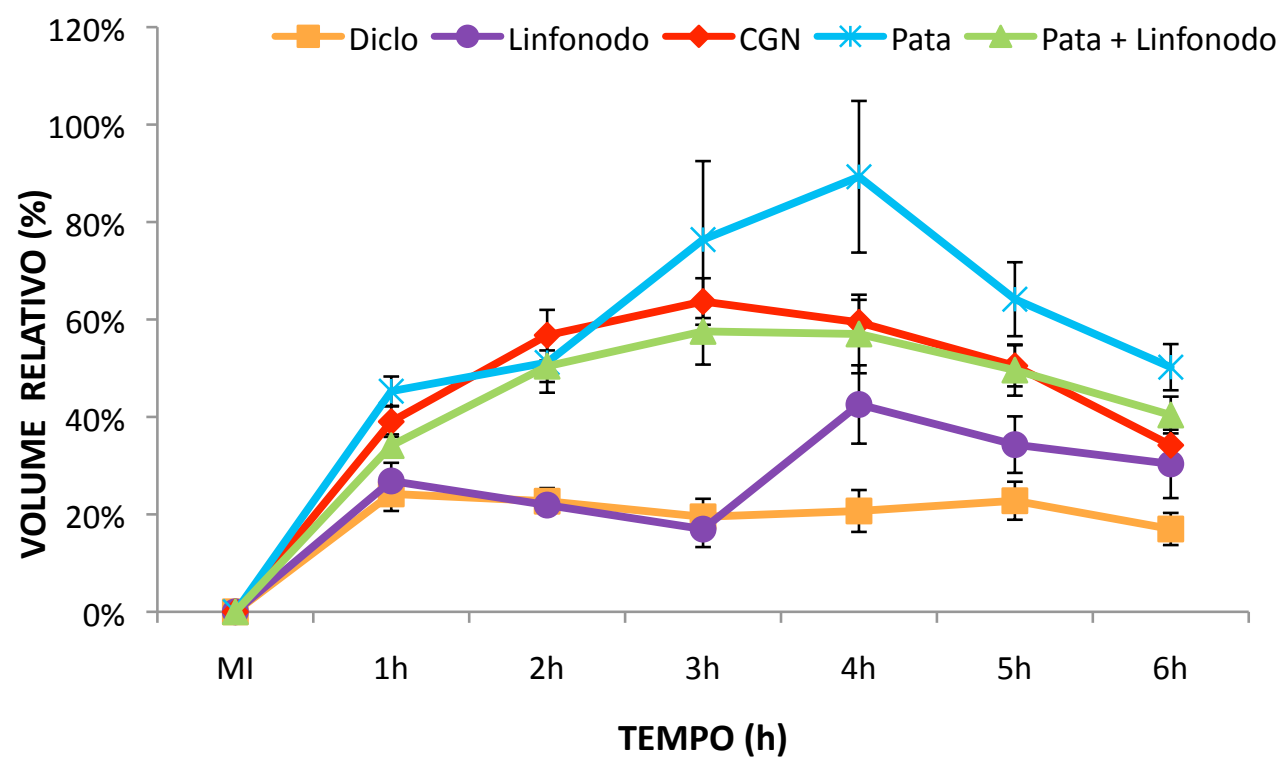

FIGURA 22 - Gráfico das médias do volume relativo do edema (\%) com os respectivos erros padrão da etapa 2B. As irradiações foram feitas $1 \mathrm{~h}$ e imediatamente antes da injeção de carragenina em MI. N=27 para grupo CGN, $\mathrm{N}=13$ para o grupo Diclo e $\mathrm{N}=5$ para os demais grupos.

TABELA 25 - Valores de p obtidos pelo teste $t$ e corrigidos pelo procedimento de Ryan-Holm Stepdown Bonferroni para a comparação das médias do volume relativo na $2^{\mathrm{a}}$ hora experimental da etapa $2 \mathrm{~B}$. As diferenças estatisticamente significantes estão em negrito e itálico $(p<0,05)$.

\begin{tabular}{ccccc}
$2 \mathrm{H}$ & $\mathrm{CGN}$ & Diclo & Linfonodo & Pata \\
\hline \hline Diclo & $<0,0001$ & & & \\
Linfonodo & $<0,0001$ & 1,0000 &
\end{tabular}




\begin{tabular}{cllll} 
Pata & 1,0000 & $\mathbf{0 , 0 3 8 7}$ & $\mathbf{0 , 0 3 7 2}$ & \\
Pata+Linfonodo & 1,0000 & $\mathbf{0 , 0 0 0 5}$ & $\mathbf{0 , 0 0 1 6}$ & 0,9167 \\
\hline
\end{tabular}

TABELA 26 - Valores de $p$ obtidos pelo teste $t$ e corrigidos pelo procedimento de Ryan-Holm Stepdown Bonferroni para a comparação das médias do volume relativo na $3^{\text {a }}$ hora experimental da etapa $2 \mathrm{~B}$. As diferenças estatisticamente significantes estão em negrito e itálico $(p<0,05)$.

\begin{tabular}{ccccc} 
3H & CGN & Diclo & Linfonodo & Pata \\
\hline \hline Diclo & $<0,0001$ & & & \\
Linfonodo & $<0,0001$ & 0,6359 & & \\
Pata & 0,9707 & 0,1116 & 0,1157 & \\
Pata+Linfonodo & 1,0000 & $\mathbf{0 , 0 1 4 9}$ & $\mathbf{0 , 0 1 4 3}$ & 1,0000 \\
\hline
\end{tabular}

TABELA 27 - Valores de $p$ obtidos pelo teste $Z$ e corrigidos pelo procedimento de Ryan-Holm Stepdown Bonferroni para a comparação das médias do volume relativo na $4^{a}$ hora experimental da etapa $2 \mathrm{~B}$. As diferenças estatisticamente significantes estão em negrito e itálico $(p<0,05)$.

\begin{tabular}{ccccc} 
4H & CGN & Diclo & Linfonodo & Pata \\
\hline \hline Diclo & $<0,0001$ & & & \\
Linfonodo & 0,1388 & 0,2536 & & \\
Pata & 0,3011 & 0,0772 & 0,2230 & \\
Pata+Linfonodo & 0,5726 & 0,0575 & 0,4790 & 0,4607 \\
\hline
\end{tabular}

TABELA 28 - Área sob a curva ( \pm erro) calculados nas 6 horas experimentais e \% (porcentagem) de redução do edema ( \pm erro da \% redução) calculados em relação ao grupo controle (CGN) da etapa $2 B$.

\begin{tabular}{ccccc} 
2B & Área & (士Erro) & \% Redução & (士Erro \% Redução) \\
\hline \hline CGN & 2,86 & 0,18 & & \\
Diclo & 1,18 & 0,10 & 58,7 & 3,8 \\
linfonodo & 1,58 & 0,14 & 44,9 & 5,3 \\
pata & 3,51 & 0,30 & -23 & 11 \\
pata+linfonodo & 2,69 & 0,30 & 6 & 11 \\
\hline
\end{tabular}

TABELA 29 - Valores de $p$ obtidos pelo teste $Z$ para a comparação da área sob a curva dos diferentes grupos experimentais da etapa 2B nas 6 horas experimentais. Os valores de $p$ foram corrigidos para múltiplas comparações pelo procedimento de Ryan-Holm Stepdown Bonferroni. N=27 para grupo CGN, $\mathrm{N}=13$ para $\circ$ grupo Diclo e $\mathrm{N}=5$ para os demais grupos. As diferenças estatisticamente significantes estão em negrito e itálico $(p<0,05)$.

\begin{tabular}{|c|c|c|c|c|}
\cline { 2 - 5 } \multicolumn{1}{c|}{} & Diclofenaco & Linfonodo & Controle & Pata \\
\hline Linfonodo & 0,10 & $<0,0001$ & & \\
Controle & $<0,0001$ & $<0,0001$ & 0,13 & \\
Pata & $<0,0001$ & $<0,00037$ & 0,61 & 0,16 \\
Pata + Linfonodo & $<0,0001$ & $\mathbf{0 , 0 0 0 1}$ & \\
\hline
\end{tabular}


TABELA 30 - Área sob a curva ( \pm erro) calculados nas 4 horas experimentais e \% (porcentagem) de redução do edema ( \pm erro da \% redução) calculados em relação ao grupo controle (CGN) da etapa 2B.

\begin{tabular}{ccccc} 
2B & Área & (士Erro) & \% Redução & (士Erro \% Redução) \\
\hline \hline CGN & 1,80 & 0,12 & & \\
Diclo & 0,77 & 0,07 & 57,4 & 4,3 \\
Linfonodo & 0,87 & 0,08 & 51,7 & 4,8 \\
Pata & 2,17 & 0,22 & -21 & 13 \\
Pata+Linfonodo & 1,71 & 0,19 & 5 & 11 \\
\hline
\end{tabular}

TABELA 31 - Valores de $p$ obtidos pelo teste $Z$ para a comparação da área sob a curva dos diferentes grupos experimentais da etapa 2B nas 4 horas experimentais. Os valores de $p$ foram corrigidos para múltiplas comparações pelo procedimento de Ryan-Holm Stepdown Bonferroni. N=27 para grupo CGN, $\mathrm{N}=13$ para 0 grupo Diclo e $\mathrm{N}=5$ para os demais grupos.As diferenças estatisticamente significantes estão em negrito e itálico $(p<0,05)$.

\begin{tabular}{ccccc} 
& Diclo & Linfonodo & CGN & Pata \\
\hline \hline Linfonodo & 0,69 & & & \\
CGN & $<0,0001$ & $<0,0001$ & & \\
Pata & $<0,0001$ & $<0,0001$ & 0,40 & \\
Pata + Linfonodo & $<0,0001$ & $\mathbf{0 , 0 0 0 3}$ & 0,68 & 0,43 \\
\hline
\end{tabular}

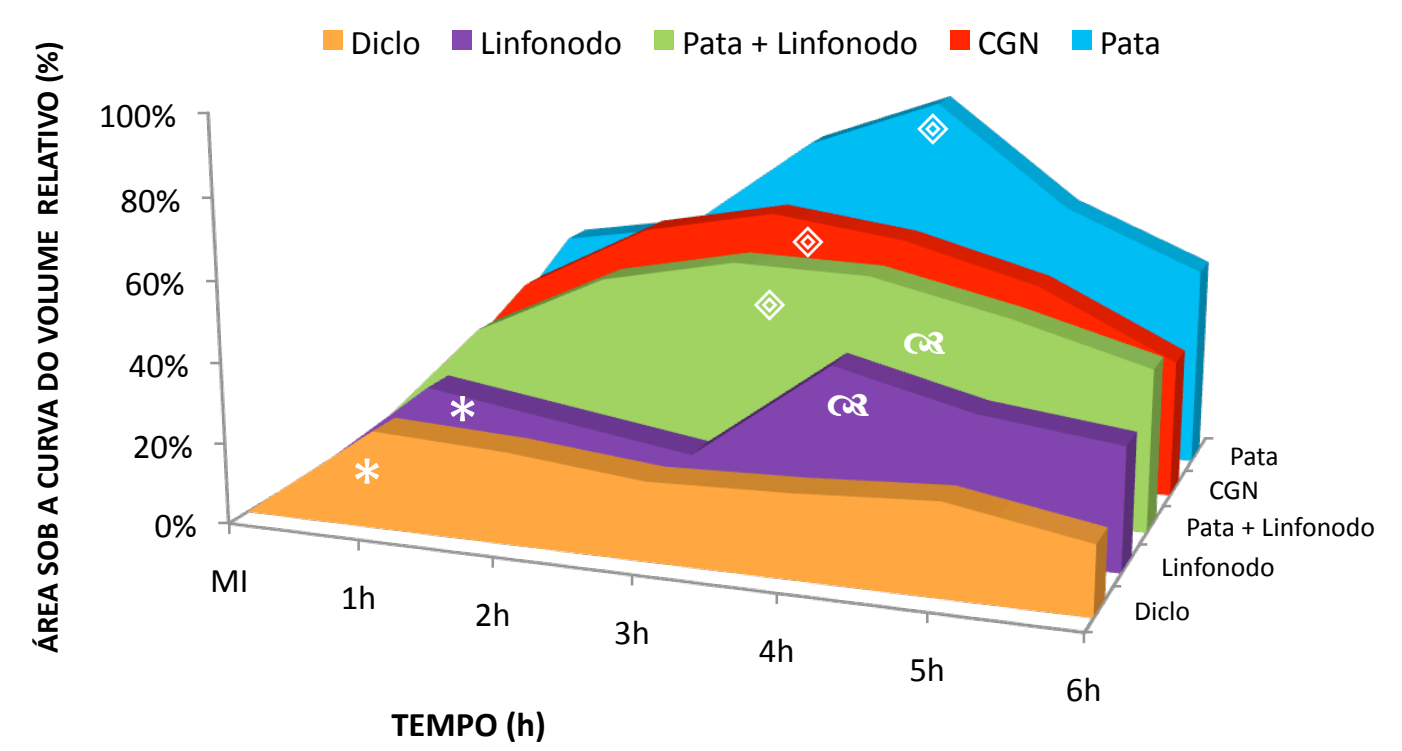

FIGURA 23: Gráfico representando a área sob a curva do volume relativo (\%) em relação ao tempo experimental (6h) da etapa 2B. Símbolos diferentes significam diferença estatística $(p<0,05)$. 


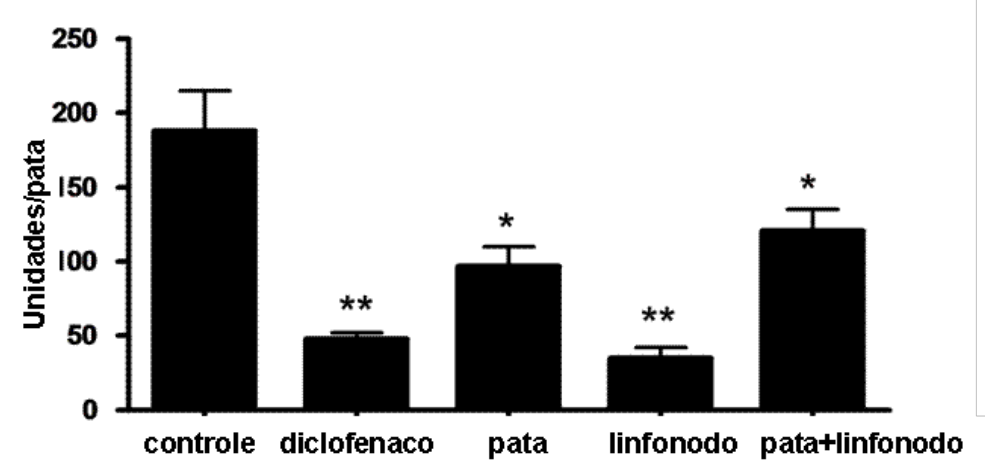

FIGURA 24 - Valores médios + DP (desvio padrão) de Unidades de Mieloperoxidase (MPO) medidos após $6 \mathrm{~h}$ da injeção da carragenina na etapa $2 \mathrm{~B}$. $\mathrm{N}=5$ animais por grupo, ${ }^{*} \mathrm{p}<0,05,{ }^{* *} \mathrm{p}<0,01$.

Ao contrário do momento $A$, a dupla irradiação não foi eficaz na inibição do edema. $O$ que evidencia a importância do tempo decorrido entre a irradiação e a injeção da carragenina assim como o tempo decorrido até as medições de volume. A dupla irradiação só foi eficaz no intervalo temporal maior, 2 e $1 \mathrm{~h}$, sendo que quando realizadas $1 \mathrm{~h}$ e imediatamente antes da carragenina não foram eficazes na inibição do edema. O interessante, no entanto, é que o volume máximo de edema atingido é perpetuado ao longo das $6 \mathrm{~h}$ experimentais caracterizando um platô que pode ser indicativo da presença de uma modulação da resposta inflamatória, sem promover a redução do edema.

O grupo irradiado na pata apresentou um efeito pró inflamatório entre a $3^{\mathrm{a}}$ e $4^{\mathrm{a}}$ horas já demonstrado na literatura por Albertini e cols. (2004), ao irradiarem a pata imediatamente antes da injeção da carragenina. Muito provavelmente, a ativação da microcirculação local promovida pela irradiação (MAEGAWA et al., 2000) pode justificar tal evento. Imediatamente antes da injeção, o aumento do fluxo sanguíneo pode ter estimulado a difusão da carragenina pelos tecidos da pata aumentando a amplitude do seu efeito tóxico. Este efeito na pata, pode ainda ter se sobreposto ao efeito indireto da radiação sobre o linfonodo, sendo o principal responsável pelo resultado observado no grupo pata + linfonodo.

A ativação da resposta imunológica através da irradiação nos linfonodos $1 \mathrm{~h}$ e imediatamente antes da ação do agente agressor (carragenina) foi a mais eficaz na 
prevenção do edema, mostrando que este momento de irradiação pode ser o momento ideal na obtenção de efeitos sistêmicos para a modulação da inflamação, inibindo a formação do edema.

O menor número de neutrófilos ao final das 6 horas experimentais em todos os grupos tratados mostrou que o diclofenaco 30' antes e as irradiações preventivas aceleram a resolução da inflamação, podendo ou não inibir a formação do edema. $\mathrm{O}$ momento de irradiação, 1h e imediatamente antes da carragenina mostrou ser eficiente em todos os grupos irradiados para a modulação da inflamação, no entanto para a inibição do edema o melhor sitio de irradiação é o linfonodo.

\subsubsection{ETAPA 2C - AVALIAÇÃO DO EFEITO INIBITÓRIO DA IRRADIAÇÃO (irradiações} feitas $1 \mathrm{~h}$ e $2 \mathrm{~h}$ depois da injeção da carragenina)

A irradiação realizada $1 \mathrm{~h}$ e $2 \mathrm{~h}$ após a injeção da carragenina teve o propósito de avaliar a influência do laser na evolução do edema em sua trajetória ascendente. Este protocolo segue o que já foi publicado na literatura por Albertini e colaboradores (2004), demonstrando que a redução do edema com laser foi efetivo quando pelo menos duas irradiações laser foram feitas iniciando $1 \mathrm{~h}$ após a injeção da carragenina. Os efeitos da irradiação realizada em sítios diferentes da pata, como no linfonodo e em ambos locais (pata+linfonodo) até então não tinham sido estudados na literatura.

Os efeitos da irradiação na $2^{\mathrm{a}}, 3^{\mathrm{a}}$ e $4^{\mathrm{a}}$ hora após a CGN mostraram que tanto a irradiação na pata quanto diretamente sobre os linfonodos foi eficiente na inibição do edema em relação ao grupo controle (CGN) (FIG. 25). Mas somente o grupo pata teve a mesma inibição que o grupo tratado com diclofenaco $30^{\prime}$ antes na $2^{\mathrm{a}}$ e $3^{\mathrm{a}}$ horas (TAB. 32 e 33), e na $4^{\mathrm{a}}$ hora o grupo linfonodo também foi similar ao grupo Diclo (TAB. 34). O grupo pata+linfonodo por sua vez, apresentou uma queda gradativa no edema, a partir da $2^{\mathrm{a}}$ hora, 
sendo semelhante ao grupo linfonodo na $3^{\mathrm{a}}$ hora e menor que o grupo controle $(\mathrm{CGN})$ na $4^{\mathrm{a}}$ hora (TAB. 33 e 34).

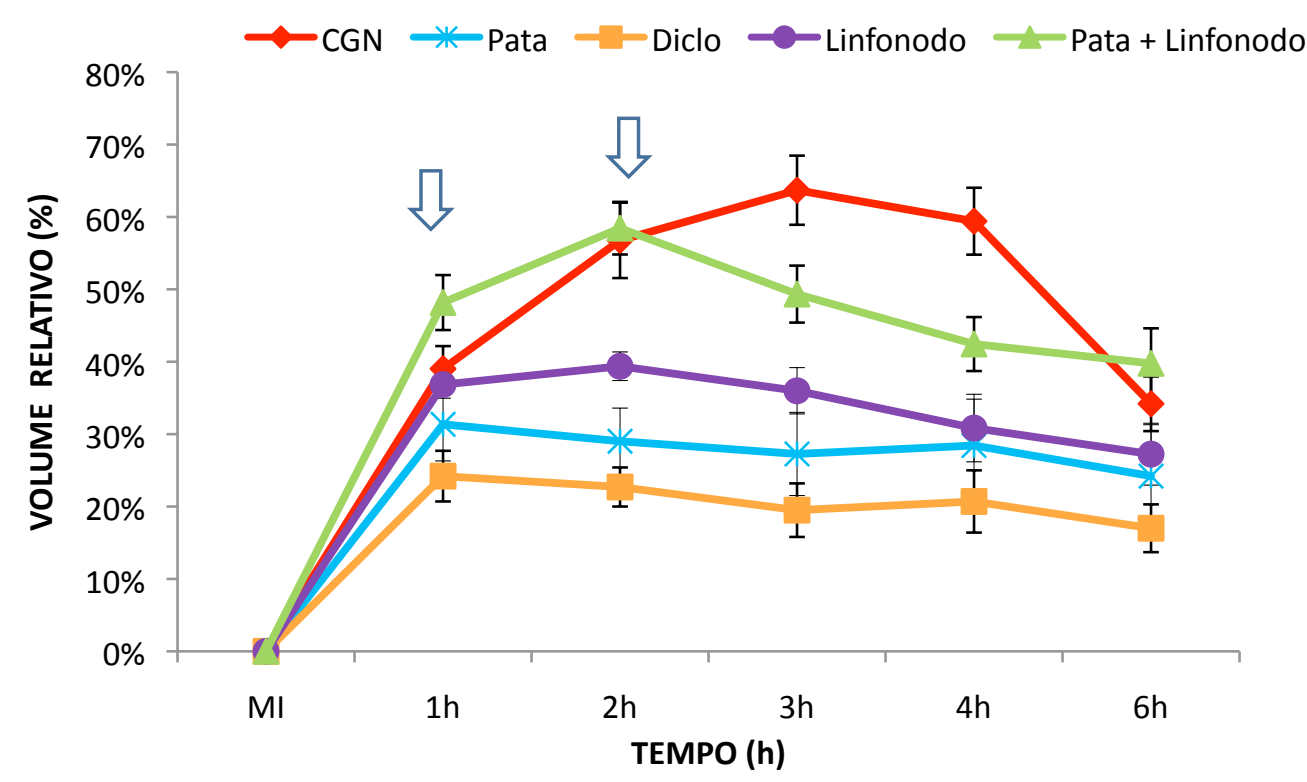

FIGURA 25 - Gráfico das médias do volume relativo do edema (\%) com os respectivos erros padrão da etapa $2 \mathrm{C}$. As irradiações foram feitas $1 \mathrm{~h}$ e $2 \mathrm{~h}$ depois da injeção de carragenina em MI (setas). N=27 para grupo CGN, $\mathrm{N}=13$ para o grupo Diclo e $\mathrm{N}=5$ para os demais grupos.

TABELA 32 - Valores de $\mathrm{p}$ obtidos pelo teste $\boldsymbol{t}$ e corrigidos pelo procedimento de Ryan-Holm Stepdown Bonferroni para a comparação das médias do volume relativo na $2^{\mathrm{a}}$ hora experimental da etapa $2 \mathrm{C}$. As diferenças estatisticamente significantes estão em negrito e itálico $(p<0,05)$.

\begin{tabular}{ccccc} 
2H & CGN & Diclo & Linfonodo & Pata \\
\hline \hline Diclo & $<0,0001$ & & & \\
Linfonodo & $\mathbf{0 , 0 1 5 3}$ & $\mathbf{0 , 0 0 0 7}$ & & \\
Pata & $\mathbf{0 , 0 0 3 5}$ & 0,5239 & 0,2129 & \\
Pata+Linfonodo & 0,7931 & $<0,0001$ & $\mathbf{0 , 0 0 5 7}$ & $\mathbf{0 , 0 0 2 4}$ \\
\hline
\end{tabular}

TABELA 33 - Valores de p obtidos pelo teste $t$ e corrigidos pelo procedimento de Ryan-Holm Stepdown Bonferroni para a comparação das médias do volume relativo na $3^{\mathrm{a}}$ hora experimental da etapa $2 \mathrm{C}$. As diferenças estatisticamente significantes estão em negrito e itálico $(p<0,05)$.

\begin{tabular}{ccccc} 
3H & CGN & Diclo & Linfonodo & Pata \\
\hline \hline Diclo & $<0,0001$ & & & \\
Linfonodo & $\mathbf{0 , 0 0 0 3}$ & $\mathbf{0 , 0 1 9 8}$ & & \\
Pata & $\mathbf{0 , 0 0 1 3}$ & 0,2808 & 0,4314 & \\
Pata+Linfonodo & 0,0871 & $\mathbf{0 , 0 0 0 4}$ & 0,0871 & $\mathbf{0 , 0 4 6 5}$ \\
\hline
\end{tabular}


TABELA 34 - Valores de p obtidos pelo teste $t$ e corrigidos pelo procedimento de Ryan-Holm Stepdown Bonferroni para a comparação das médias do volume relativo na $4^{\mathrm{a}}$ hora experimental da etapa $2 \mathrm{C}$. As diferenças estatisticamente significantes estão em negrito e itálico $(p<0,05)$.

\begin{tabular}{ccccc} 
4H & CGN & Diclo & Linfonodo & Pata \\
\hline \hline Diclo & $<0,0001$ & & & \\
Linfonodo & $<0,0001$ & 0,3842 & & \\
Pata & $\mathbf{0 , 0 0 1 0}$ & 0,6740 & 0,7665 & \\
Pata+Linfonodo & $\mathbf{0 , 0 0 0 6}$ & $\mathbf{0 , 0 0 7 8}$ & 0,3733 & 0,3565 \\
\hline
\end{tabular}

Neste experimento, a irradiação local na pata mostrou ser a melhor opção de tratamento, inibindo a evolução do edema de forma similar ao grupo tratado com diclofenaco de sódio ao longo das 6h experimentais na avaliação da área sob a curva (TAB. 36 e FIG. 26). O grupo irradiado no linfonodo apresentou resultados semelhantes ao grupo pata, com menor edema que o grupo controle, mas não o suficiente para ser semelhante ao grupo tratado com o diclofenaco. A irradiação na pata+linfonodo apesar de demonstrar declínio a partir da $2^{a}$ hora e edema estatisticamente menor que o grupo controle na $4^{a}$ hora (TAB. 34 ), ao longo das 6 horas experimentais mostrou volume total do edema semelhante ao grupo controle (TAB. 35, 36 e FIG. 26).

TABELA 35 - Área sob a curva ( \pm erro) calculados nas 6 horas experimentais e \% (porcentagem) de redução do edema ( \pm erro da \% redução) calculados em relação ao grupo controle (CGN) da etapa 2 C.

\begin{tabular}{ccccc} 
2C & Área & (士Erro) & \% Redução & ( \pm Erro \% Redução) \\
\hline \hline CGN & 2,86 & 0,15 & & \\
Diclo & 1,18 & 0,09 & 58,7 & 3,3 \\
linfonodo & 1,57 & 0,10 & 45,2 & 3,9 \\
pata & 1,28 & 0,13 & 55,2 & 4,8 \\
pata+linfonodo & 2,18 & 0,13 & 23,7 & 5,1 \\
\hline
\end{tabular}


TABELA 36 - Valores de $p$ obtidos pelo teste $Z$ para a comparação da área sob a curva dos diferentes grupos experimentais da etapa $2 \mathrm{C}$ nas 6 horas experimentais. Os valores de $\mathrm{p}$ foram corrigidos para múltiplas comparações pelo procedimento de Ryan-Holm Stepdown Bonferroni. N=27 para grupo CGN, $\mathrm{N}=13$ para $\circ$ grupo Diclo e $\mathrm{N}=5$ para os demais grupos.As diferenças estatisticamente significantes estão em negrito e itálico $(p<0,05)$.

\begin{tabular}{ccccc} 
& Controle & Pata & Diclofenaco & Linfonodo \\
\hline \hline Pata & $<0,0001$ & & & \\
Diclofenaco & $<0,0001$ & 0,12 & & \\
Linfonodo & 0,0001 & 0,18 & $<0,0001$ & \\
Pata + Linfonodo & 0,38 & $<0,0001$ & $<0,0001$ & 0,0011 \\
\hline
\end{tabular}

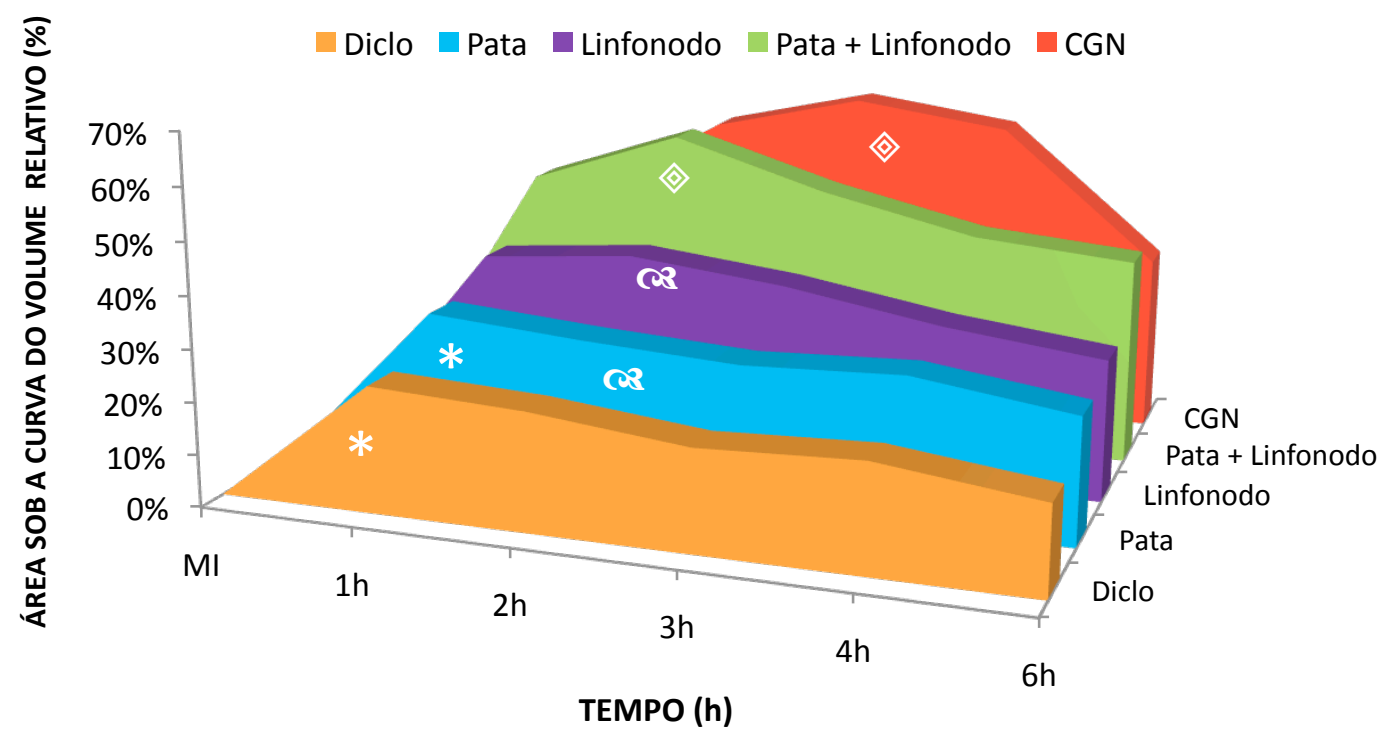

FIGURA 26 - Gráfico representando a área sob a curva do volume relativo (\%) em relação ao tempo experimental (6h) da etapa $2 \mathrm{C}$. Símbolos diferentes significam diferença estatística $(p<0,05)$.

Avaliando o efeito dos diferentes tratamentos ao longo de 4 horas experimentais, os dados da área sob a curva mostram que os grupos linfonodo e pata + linfonodo tiveram volume de edema total semelhante ao grupo controle (CGN) (TAB. 37 e 38). Isso contribui para a hipótese que os efeitos da irradiação sobre os linfonodos são percebidos ao longo da evolução do edema, de forma tardia e de acordo com o processo de funcionamento da 
resposta imunológica que não é imediata. Quando irradiados ambos os sítios, a dupla dosagem pode não ter inibido a evolução do edema, mas pode ter acelerado o processo inflamatório adiantando o pico do edema para a $2^{\mathrm{a}}$ hora.

TABELA 37 - Área sob a curva ( \pm erro) calculados nas 4 horas experimentais e \% (porcentagem) de redução do edema ( \pm erro da \% redução) calculados em relação ao grupo controle (CGN) da etapa $2 \mathrm{C}$.

\begin{tabular}{ccccc} 
2C 4H & Área & (士Erro) & \% Redução & (士Erro \% Redução) \\
\hline \hline CGN & 1,12 & 0,08 & & \\
Diclo & 0,57 & 0,06 & 49,2 & 5,3 \\
Linfonodo & 0,94 & 0,06 & 15,5 & 5,9 \\
Pata & 0,74 & 0,08 & 33,6 & 7,8 \\
Pata+Linfonodo & 1,31 & 0,09 & $-17,7$ & 8,8 \\
\hline
\end{tabular}

TABELA 38 - Valores de $p$ obtidos pelo teste $Z$ para a comparação da área sob dos diferentes grupos experimentais da etapa $2 \mathrm{C}$ nas 4 horas experimentais. Os valores de $\mathrm{p}$ foram corrigidos para múltiplas comparações pelo procedimento de Ryan-Holm Stepdown Bonferroni. N=27 para grupo CGN, N=13 para - grupo Diclo e $\mathrm{N}=5$ para os demais grupos.As diferenças estatisticamente significantes estão em negrito e itálico $(p<0,05)$.

\begin{tabular}{ccccc} 
& CGN & Pata & Diclo & Linfonodo \\
\hline \hline Pata & $\mathbf{0 , 0 0 4 9}$ & & & \\
Diclo & $<0,0001$ & 0,16 & & \\
Linfonodo & 0,2174 & 0,18 & $<0,0001$ & \\
Pata + Linfonodo & 0,09 & $<0,0001$ & $<0,0001$ & $\mathbf{0 , 0 0 2 0}$ \\
\hline
\end{tabular}

Este experimento repete um grupo já realizado na etapa $1 \mathrm{~A}$, cuja irradiação foi realizada na pata, no protocolo de 1J, 100mW (FIG. 14 e 25). Os resultados destes grupos são correspondentes, apesar da linhagem de camundongos ter sido diferente: na etapa $1 \mathrm{~A}$ foram utilizados camundongos Balb-c e em 2C, SWISS. A taxa de redução do edema em relação ao controle foi de 30,2 e 36,8\% em 4 e 6 h respectivamente na etapa 1A e de 33,6 e 
45,7\% em 2C, mostrando a inibição do edema durante sua evolução em relação ao grupo controle.

A análise da migração de neutrófilos através da atividade da MPO neste tempo experimental mostrou um menor acúmulo de neutrófilos nos grupos diclofenaco, pata e linfonodo quando comparados ao grupo controle e com o grupo que recebeu dupla irradiação, na pata+linfonodo (FIG. 27). Estes resultados estão em concordância com a ação da laserterapia sobre o edema e confirmam que os melhores locais de irradiação durante a evolução do edema são a pata (de forma similar ao diclofenaco) e o linfonodo.

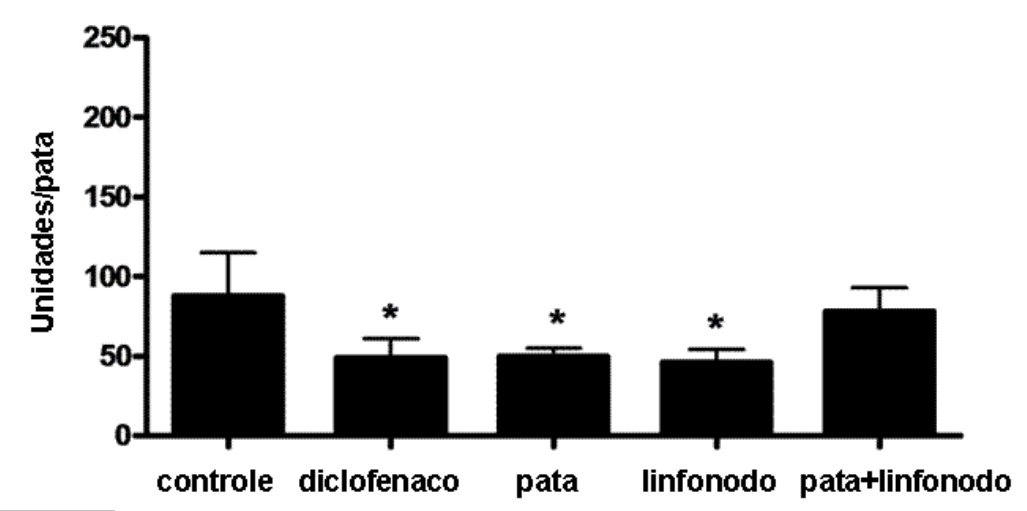

FIGURA 27 - Valores médios + DP (desvio padrão) de Unidades de Mieloperoxidase (MPO) medidos após $6 \mathrm{~h}$ da injeção da carragenina na etapa $2 \mathrm{C}$. $\mathrm{N}=5$ animais por grupo, ${ }^{*} p<0,05$.

\subsubsection{ETAPA 2D - AVALIAÇÃO DO EFEITO DO LASER NO TRATAMENTO DO EDEMA (irradiações feitas 3,5h e 4,5h depois da injeção da carragenina)}

O objetivo de realizar irradiações após 3,5 e 4,5 horas da injeção da CGN foi avaliar o efeito da radiação laser em diferentes locais (pata, linfonodo e pata+linfonodo) no tratamento do edema, uma vez que neste modelo experimental este momento de irradiação coincide com o edema já instalado, estando no seu volume máximo (pico).

Uma vez que as irradiações laser só foram iniciadas após $3,5 \mathrm{~h}$, na $2^{\mathrm{a}}$ e $3^{\mathrm{a}}$ hora, os grupos irradiados e controle (CGN) apresentaram comportamento estatisticamente 
semelhante e diferentes do grupo Diclo, já que este foi injetado 30' antes da CGN, atuando preventivamente (TAB. 39 e 40, FIG. 28).

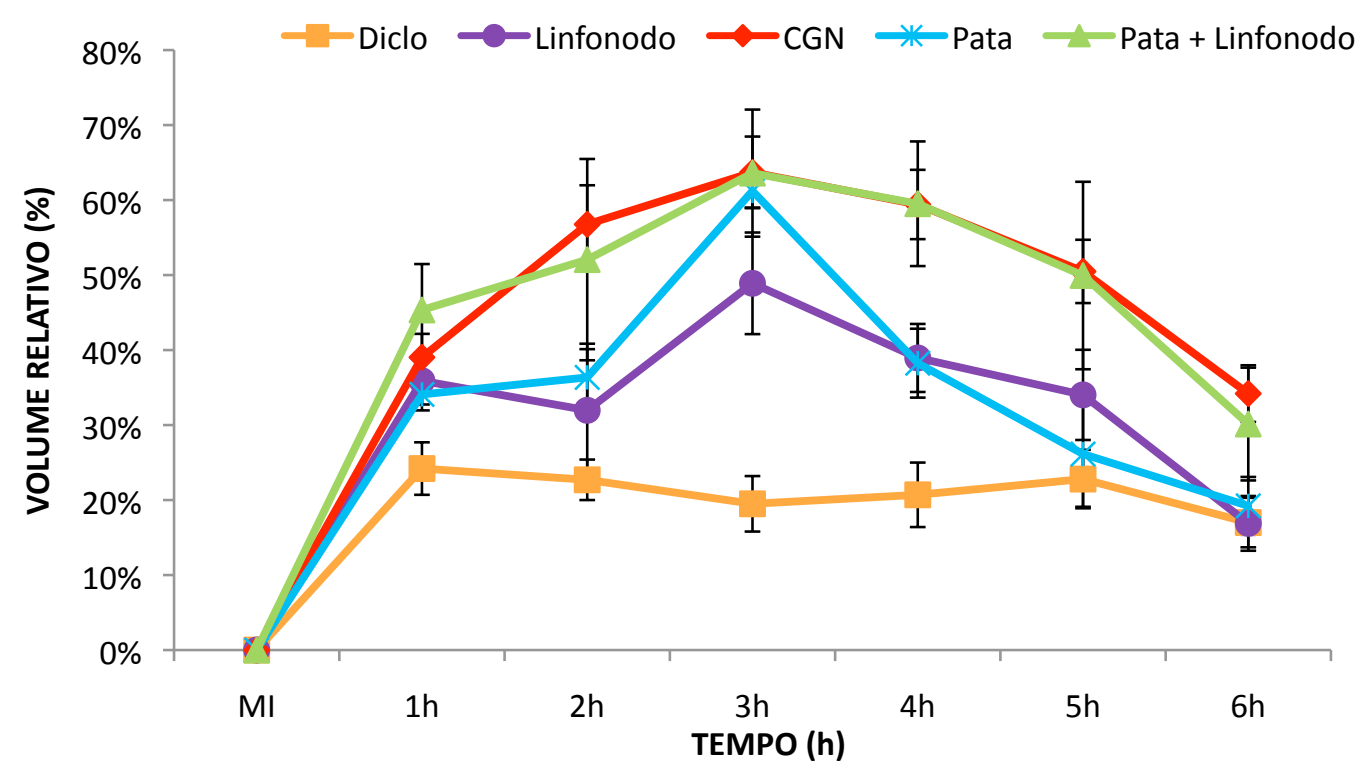

FIGURA 28 - Gráfico das médias do volume relativo do edema (\%) com os respectivos erros padrão da etapa 2D. As irradiações foram feitas 3,5h e 4,5h após a injeção de carragenina em MI (setas). N=27 para grupo $\mathrm{CGN}, \mathrm{N}=13$ para 0 grupo Diclo e $\mathrm{N}=5$ para os demais grupos.

TABELA 39 - Valores de p obtidos pelo teste $t$ e corrigidos pelo procedimento de Ryan-Holm Stepdown Bonferroni para a comparação das médias do volume relativo na $2^{\mathrm{a}}$ hora experimental da etapa 2D. As diferenças estatisticamente significantes estão em negrito e itálico $(p<0,05)$.

\begin{tabular}{ccccc} 
2H & CGN & Diclo & Linfonodo & Pata \\
\hline Diclo & $<0,0001$ & & & \\
Linfonodo & 0,2755 & 0,9906 & & \\
Pata & 0,0768 & 0,2418 & 1,0000 & \\
Pata+Linfonodo & 0,7563 & 0,5590 & 1,0000 & 1,0000 \\
\hline
\end{tabular}


TABELA 40 - Valores de p obtidos pelo teste $\boldsymbol{t}$ e corrigidos pelo procedimento de Ryan-Holm Stepdown Bonferroni para a comparação das médias do volume relativo na $3^{\text {a }}$ hora experimental da etapa $2 \mathrm{D}$. As diferenças estatisticamente significantes estão em negrito e itálico $(p<0,05)$.

\begin{tabular}{ccccc} 
3H & CGN & Diclo & Linfonodo & Pata \\
\hline \hline Diclo & $<0,0001$ & & & \\
Linfonodo & 0,6562 & 0,0527 & & \\
Pata & 1,0000 & $<0,0001$ & 0,7326 & \\
Pata+Linfonodo & 0,9921 & $\mathbf{0 , 0 2 9 7}$ & 0,8573 & 1,0000 \\
\hline
\end{tabular}

Após a primeira irradiação ocorrida na $3^{a}$ hora e meia, e cujos efeitos puderam ser avaliados na $4^{a}$ hora, os grupos irradiados na pata e linfonodo apresentaram acentuado declínio de volume relativo sendo menor estatisticamente que o grupo controle e semelhante ao grupo Diclo (TAB. 41). Na $5^{\mathrm{a}}$ hora, no entanto, com a esperada queda do grupo controle, os grupos irradiados ficaram com volume de edema intermediário entre os grupos controle e diclofenaco (TAB. 42). A mesma tendência da $4^{\mathrm{a}}$ hora, no entanto, voltou na $6^{\mathrm{a}}$ hora, separando estatisticamente os grupos pata, linfonodo e Diclo dos grupos controle e pata+linfonodo com maior volume relativo (TAB. 43).

TABELA 41 - Valores de $p$ obtidos pelo teste $t$ e corrigidos pelo procedimento de Ryan-Holm Stepdown Bonferroni para a comparação das médias do volume relativo na $4^{\mathrm{a}}$ hora experimental da etapa $2 \mathrm{D}$. As diferenças estatisticamente significantes estão em negrito e itálico $(p<0,05)$.

\begin{tabular}{ccccc} 
4H & CGN & Diclo & Linfonodo & Pata \\
\hline Diclo & $<0,0001$ & & & \\
Linfonodo & $\mathbf{0 , 0 0 1 9}$ & 0,0806 & & \\
Pata & $\mathbf{0 , 0 0 1 9}$ & 0,0861 & 0,9169 & \\
Pata+Linfonodo & 0,5754 & $\mathbf{0 , 0 3 8 4}$ & 0,2145 & 0,2592 \\
\hline
\end{tabular}

TABELA 42 - Valores de $\mathrm{p}$ obtidos pelo teste $\boldsymbol{t}$ e corrigidos pelo procedimento de Ryan-Holm Stepdown Bonferroni para a comparação das médias do volume relativo na $5^{\text {a }}$ hora experimental da etapa 2D. As diferenças estatisticamente significantes estão em negrito e itálico $(p<0,05)$.

\begin{tabular}{ccccc}
$5 \mathrm{H}$ & $\mathrm{CGN}$ & Diclo & Linfonodo & Pata \\
\hline \hline Diclo & 0,0030 &
\end{tabular}




\begin{tabular}{cllll} 
Linfonodo & 0,4282 & 1,0000 & & \\
Pata & 0,1819 & 1,0000 & 1,0000 & \\
Pata+Linfonodo & 0,9685 & 0,9640 & 1,0000 & 0,8742 \\
\hline
\end{tabular}

TABELA 43 - Valores de $p$ obtidos pelo teste $t$ e corrigidos pelo procedimento de Ryan-Holm Stepdown Bonferroni para a comparação das médias do volume relativo na $6^{\text {a }}$ hora experimental da etapa $2 \mathrm{D}$. As diferenças estatisticamente significantes estão em negrito e itálico $(p<0,05)$.

\begin{tabular}{ccccc} 
6H & CGN & Diclo & Linfonodo & Pata \\
\hline \hline Diclo & $\mathbf{0 , 0 0 2 8}$ & & & \\
Linfonodo & $\mathbf{0 , 0 0 8 9}$ & 0,9905 & & \\
Pata & $\mathbf{0 , 0 2 5 7}$ & 1,0000 & 1,0000 & \\
Pata+Linfonodo & 1,0000 & 1,0000 & 0,9959 & 1,0000 \\
\hline
\end{tabular}

Analisando a eficácia dos tratamentos ao longo das $6 \mathrm{~h}$ experimentais pela área sob a curva, os grupos irradiados na pata e no linfonodo foram mais efetivos no tratamento do edema que o grupo pata + linfonodo quando comparados ao grupo controle (FIG. 29 e TAB. 44, 45).

TABELA 44 - Área sob a curva ( \pm erro) calculados nas 6 horas experimentais e \% (porcentagem) de redução do edema ( \pm erro da \% redução) calculados em relação ao grupo controle (CGN) da etapa 2D.

\begin{tabular}{ccccc} 
2D & Área & (士Erro) & \% Redução & (士Erro \% Redução) \\
\hline \hline CGN & 2,86 & 0,18 & & \\
Diclo & 1,18 & 0,10 & 58,7 & 3,7 \\
Linfonodo & 1,98 & 0,17 & 30,8 & 6,3 \\
pata & 2,06 & 0,14 & 28,0 & 5,4 \\
Pata+Linfonodo & 2,86 & 0,37 & 0 & 13 \\
\hline
\end{tabular}

TABELA 45 - Valores de $p$ obtidos pelo teste $Z$ para a comparação da área sob dos diferentes grupos experimentais da etapa 2D nas 6 horas experimentais. Os valores de $p$ foram corrigidos para múltiplas comparações pelo procedimento de Ryan-Holm Stepdown Bonferroni. N=27 para grupo CGN, N=13 para 
o grupo Diclo e $\mathrm{N}=5$ para os demais grupos. As diferenças estatisticamente significantes estão em negrito e itálico $(p<0,05)$.

\begin{tabular}{ccccc} 
& Diclo & Linfonodo & CGN & Pata \\
\hline \hline Linfonodo & $\mathbf{0 , 0 0 0 3}$ & & & \\
CGN & $<0,0001$ & $\mathbf{0 , 0 0 1 6}$ & & \\
Pata & $<0,0001$ & 1,0000 & $\mathbf{0 , 0 0 1 9}$ & \\
Pata + linfonodo & $\mathbf{0 , 0 0 0 1}$ & 0,12 & 0,98 & 0,13 \\
\hline
\end{tabular}

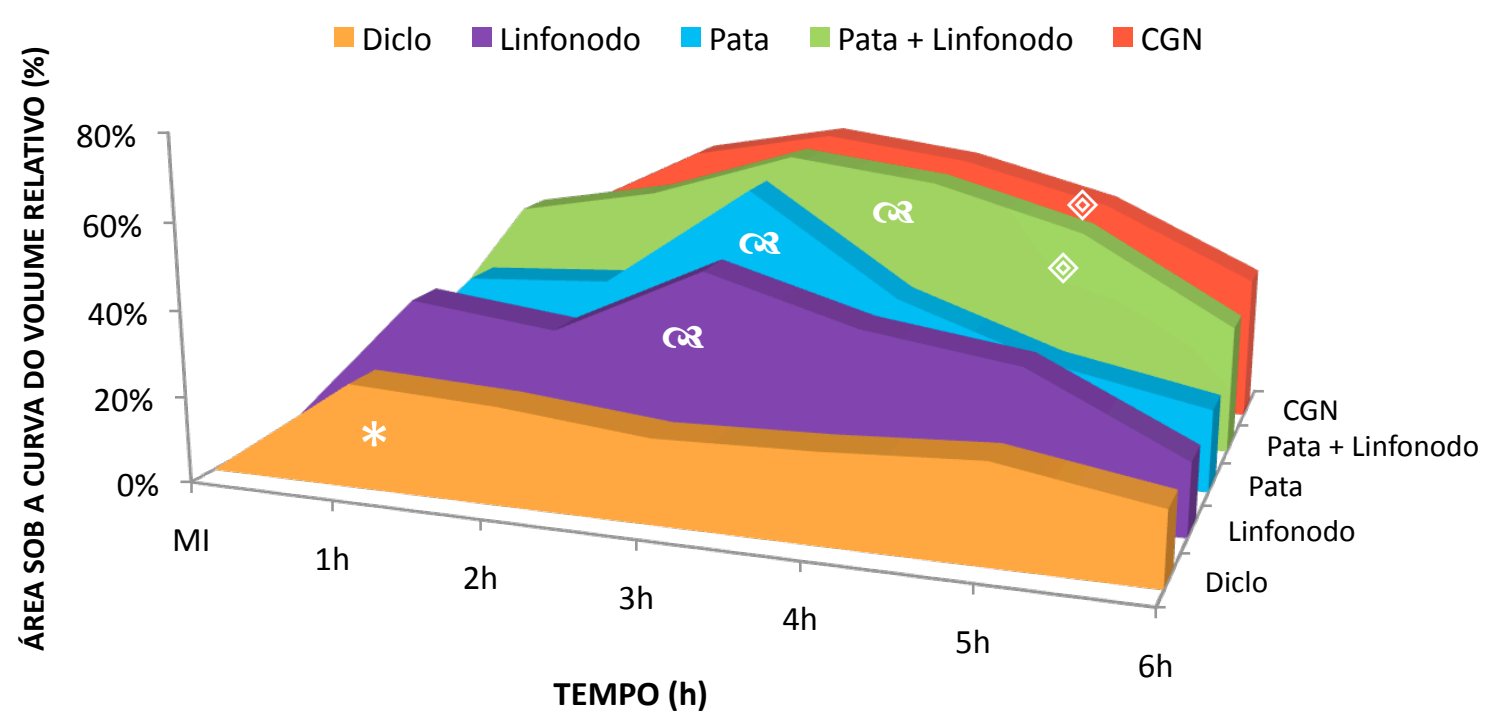

FIGURA 29 - Gráfico representando a área sob a curva do volume relativo (\%) em relação ao tempo experimental $(6 \mathrm{~h})$ da etapa $2 \mathrm{D}$. Símbolos diferentes significam diferença estatística $(p<0,05)$.

Mais uma vez, a dupla irradiação não foi eficaz para o tratamento do edema, enquanto que, isoladamente, a irradiação da pata e do linfonodo reduziu o edema total formado nas 6 horas experimentais. Estes efeitos, no entanto, só puderam ser observados em 6 horas, já que as irradiações foram feitas após 3,5 e 4,5h. Os dados da área sob a curva de 4 h se referem, desta forma, aos efeitos obtidos após uma única irradiação e, apesar da redução do edema ter sido de $24,3 \%$ no grupo linfonodo e $16,2 \%$ no grupo pata, a eficácia total do tratamento não foi significantemente melhor que o grupo controle, apenas do grupo Diclo (TAB. 46 e 47 ). 
TABELA 46 - Área sob a curva ( \pm erro) calculados nas 4 horas experimentais e \% (porcentagem) de redução do edema ( \pm erro da \% redução) calculados em relação ao grupo controle (CGN) da etapa 2D.

\begin{tabular}{ccccc} 
2D 4H & Área & (士Erro) & \% Redução & (士Erro \% Redução) \\
\hline \hline CGN & 1,800 & 0,119 & & \\
Diclo & 0,768 & 0,073 & 57,4 & 4,3 \\
Linfonodo & 1,362 & 0,132 & 24,3 & 7,7 \\
Pata & 1,508 & 0,096 & 16,2 & 6,0 \\
Pata+Linfonodo & 1,908 & 0,259 & -6 & 14,8 \\
\hline
\end{tabular}

TABELA 47 - Valores de $p$ obtidos pelo teste $Z$ para a comparação da área sob a curva dos diferentes grupos experimentais da etapa 2D nas 4 horas experimentais. Os valores de $p$ foram corrigidos para múltiplas comparações pelo procedimento de Ryan-Holm Stepdown Bonferroni. N=27 para grupo CGN, $\mathrm{N}=13$ para o grupo Diclo e $\mathrm{N}=5$ para os demais grupos. As diferenças estatisticamente significantes estão em negrito e itálico $(p<0,05)$.

\begin{tabular}{ccccc} 
& Diclo & Linfonodo & CGN & Pata \\
\hline \hline Linfonodo & $\mathbf{0 , 0 0 0 5}$ & & & \\
CGN & $<0,0001$ & 0,0823 & & \\
Pata & $<0,0001$ & 1,0000 & 0,2776 & \\
Pata+Linfonodo & $\mathbf{0 , 0 0 0 2}$ & 0,24 & 0,71 & 0,44 \\
\hline
\end{tabular}

A análise da migração de neutrófilos através da atividade da MPO neste tempo experimental mostrou um menor acúmulo de neutrófilos em todos os grupos tratados quando comparados com o grupo controle (FIG. 30). O efeito sobre os neutrófilos mostrou ser mais evidente logo após a irradiação, e este grupo foi o que a irradiação foi mais próxima da análise da MPO realizada em 6h. Mais uma vez confirma os efeitos modulatórios da laserterapia na inflamação aguda no modelo experimental de edema de pata.

O laser mostrou contribuir favoravelmente no processo inflamatório agudo, prevenindo, modulando e tratando o edema e acelerando o processo inflamatório. A laserterapia mostrou promover efeitos que estimulam a resposta inflamatória, bem como efeitos que inibem os sinais da resposta inflamatória, como o edema. Estes efeitos parecem depender não só do estágio natural do processo inflamatório como também do momento, local e associação de 
sítios de irradiação. Independentemente do melhor parâmetro encontrado, a irradiação apresentou na maioria dos protocolos efeitos favoráveis ao tecido, contribuindo para a resolução da inflamação e sendo no final do processo sempre melhor que a não irradiação. O resumo dos melhores protocolos testados na etapa 2 está ilustrado na FIG. 31.

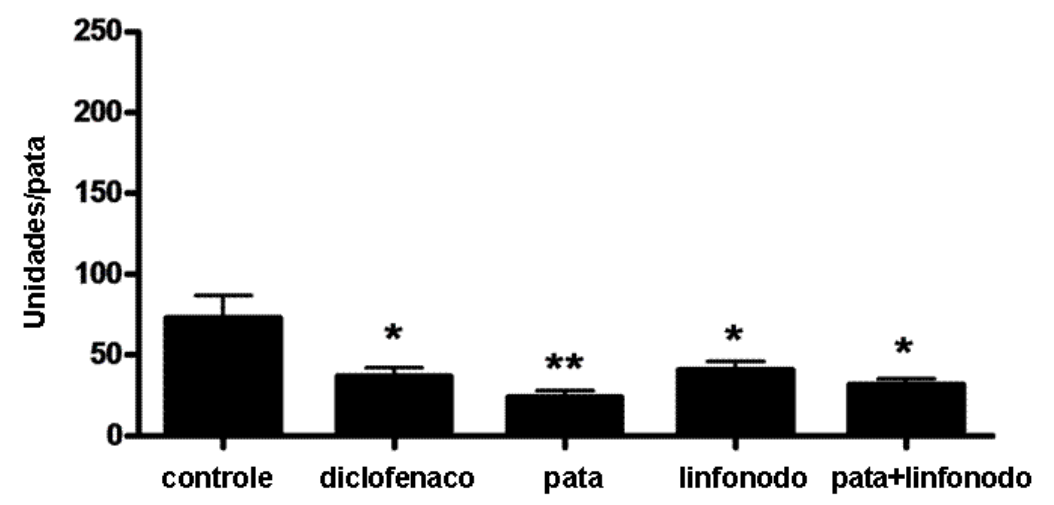

FIGURA 30 - Valores médios + DP (desvio padrão) de Unidades de Mieloperoxidase (MPO) medidos após $6 \mathrm{~h}$ da injeção da carragenina na etapa 2D. $\mathrm{N}=5$ animais por grupo, ${ }^{*} \mathrm{p}<0,05$.

RESULTADOSETAPA 2:

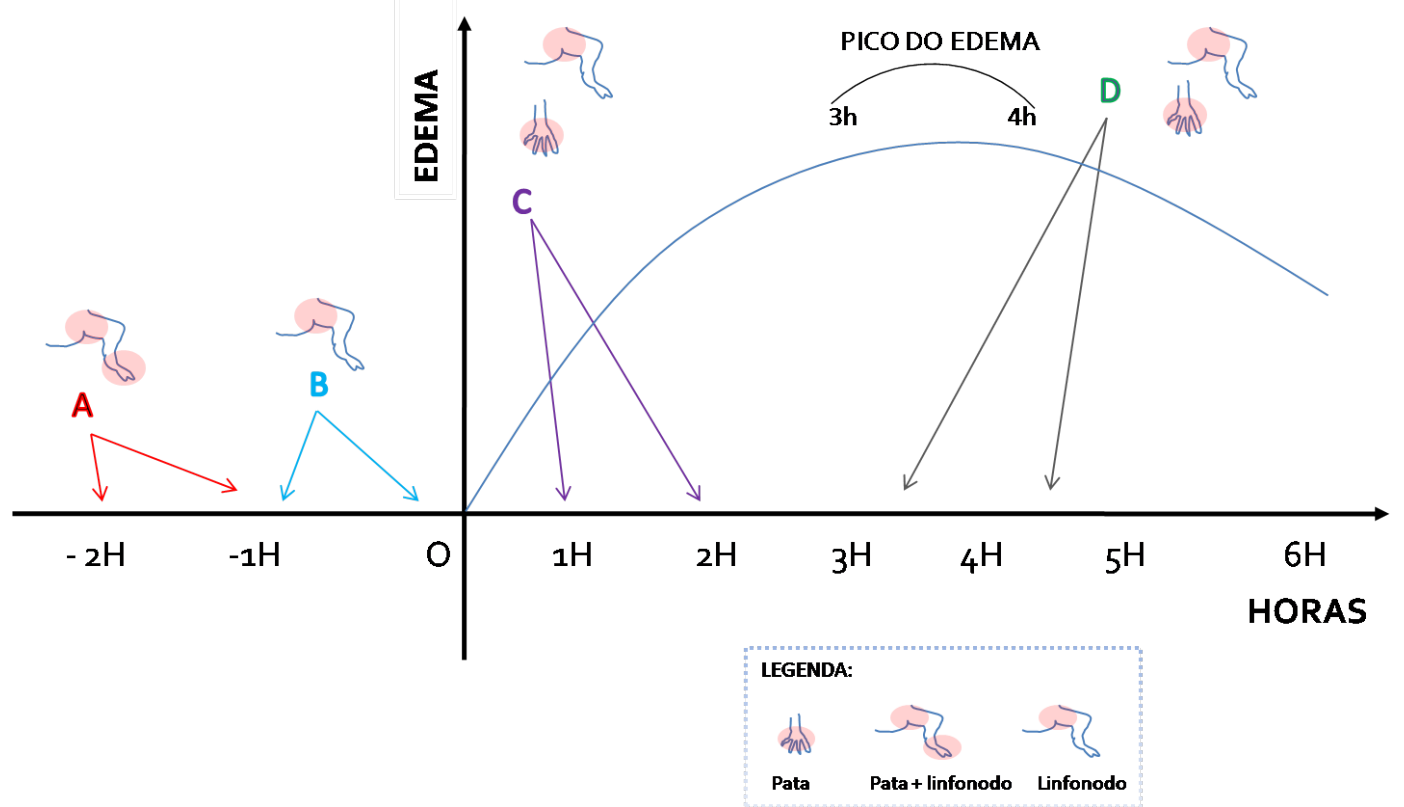

FIGURA 31 - Esquema dos resultados da etapa 2. Melhores sítios de irradiação (legenda) e os momentos (A, B, C e D). 


\subsection{ETAPA 3: AVALIAÇÃO DA INFLUÊNCIA DOSIMÉTRICA EM DIFERENTES LINHAGENS DE CAMUNDONGOS}

Nesta etapa foram selecionados os melhores momentos e locais de irradiação e realizados experimentos com duas linhagens de camundongos, Balb-c, albinos isogênicos e C57BL/6 camundongos pretos isogênicos.

É sabido que a comparação direta entre as linhagens não é possível ser feita já que cada uma possui características diferentes, apresentando também diferenças na sua resposta imunológica. No entanto, uma vez que a luz interage com os cromóforos do tecido irradiado, e estes interferem no seu espalhamento pelo aumento da absorção, o estudo de alguns parâmetros dosimétricos nestas linhagens com colorações opostas (albinos e pretos) pode trazer resultados interessantes e servirem como guia para futuros novos experimentos.

\subsubsection{ETAPA 3A: LINHAGEM BALB-C}

Analisando a evolução do edema ao longo das 6 horas experimentais, o grupo linfonodo irradiado $1 \mathrm{~h}$ e imediatamente antes da indução do edema destacou-se dos demais grupos mantendo a inibição do edema de forma similar ao grupo diclofenaco e diferente do grupo controle na $2^{\mathrm{a}}, 3^{\mathrm{a}}$ e $4^{\mathrm{a}}$ hora experimental (TAB. 48, 49 e 50 e FIG. 32). A análise da área sob a curva tanto em $6 \mathrm{~h}$ como em $4 \mathrm{~h}$ experimentais confirmou que a irradiação preventiva ( $\mathrm{Li}$ 1h e imediatamente antes da CGN) foi o melhor tratamento realizado, sendo o único com a mesma eficácia do grupo Diclo (TAB. 52 e 54). Os outros tratamentos (grupos Pata 1 e $2 \mathrm{~h}$ e Li 3,5 e 4,5h) também apresentarem edema total menor que o grupo controle, concordando com os resultados demonstrados na etapa 2 com SWISS, mas não foram tão eficazes quanto o grupo de irradiação preventiva e Diclo (FIG. 33). 
O grupo controle apresentou o pico do edema deslocado para a $4^{\mathrm{a}}$ hora, diferente do que ocorreu com a linhagem SWISS na etapa 2 (FIG. 32). Apesar do pico estar na $4^{a}$ hora, o volume é estatisticamente semelhante a $3^{a}$ e $6^{a}$ hora experimental e provavelmente isso ocorreu devido ao número de animais ter sido menor que na etapa 2 , o que deixa o gráfico mais suscetível a pequenas variações de volume. No grupo Diclo também observamos uma leve ascensão entre a $4^{\mathrm{a}}$ e $6^{\mathrm{a}}$ horas, que também pode estar relacionada com o número de animais ou ainda, que nesta linhagem, o efeito preventivo da injeção de diclofenaco 30' antes com dose de $1 \mathrm{mg} / \mathrm{kg}$ tenha reduzido seu efeito após a $4^{\mathrm{a}}$ hora. Isso, no entanto, não interfere nos resultados gerais do experimento, mantendo o mesmo padrão encontrado na etapa 2 (FIG. 33).

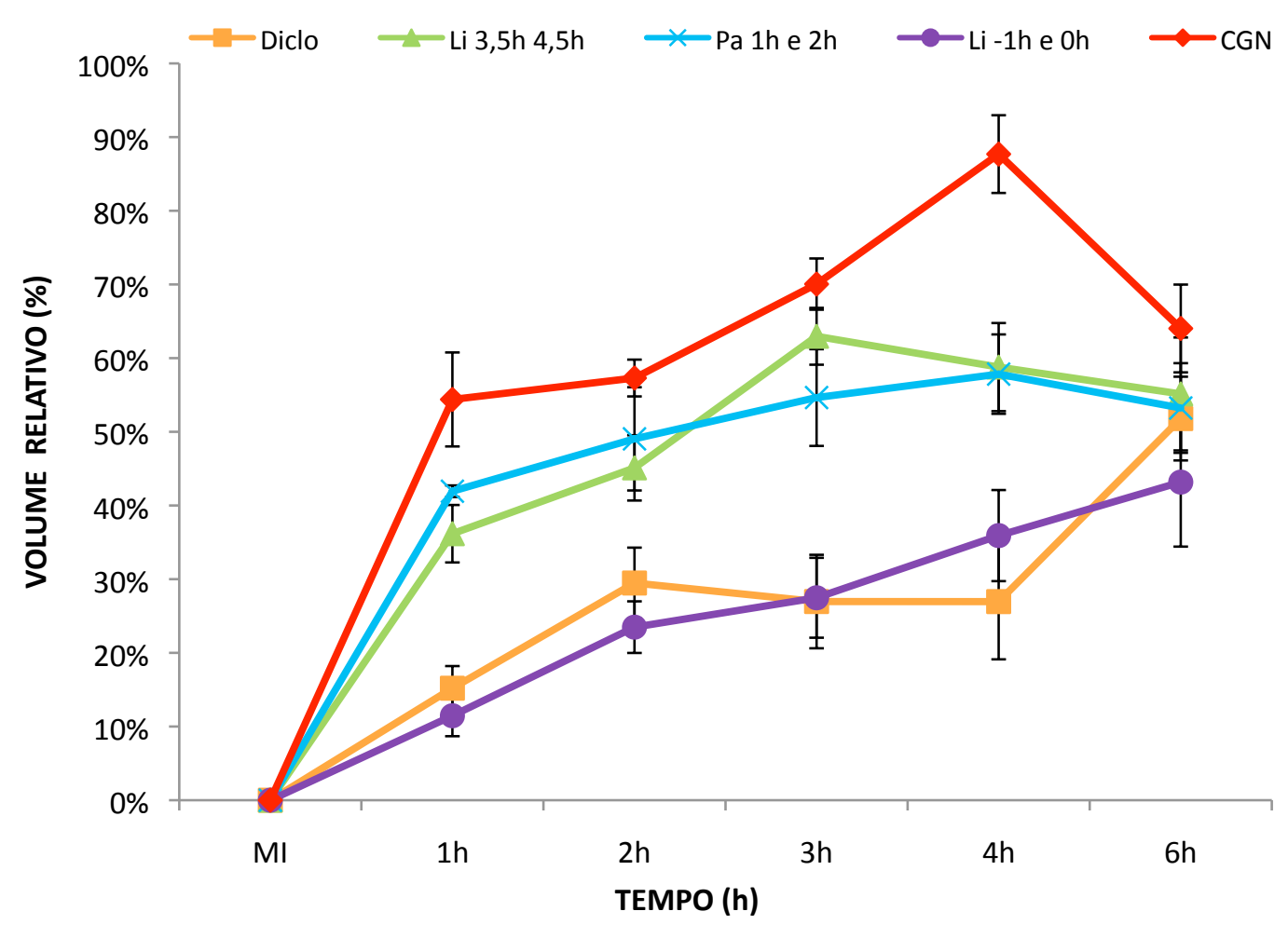

FIGURA 32 - Gráfico das médias do volume relativo do edema (\%) com os respectivos erros padrão da etapa 3A. As irradiações foram feitas conforme o grupo experimental. $\mathrm{N}=5$ animais por grupo. 


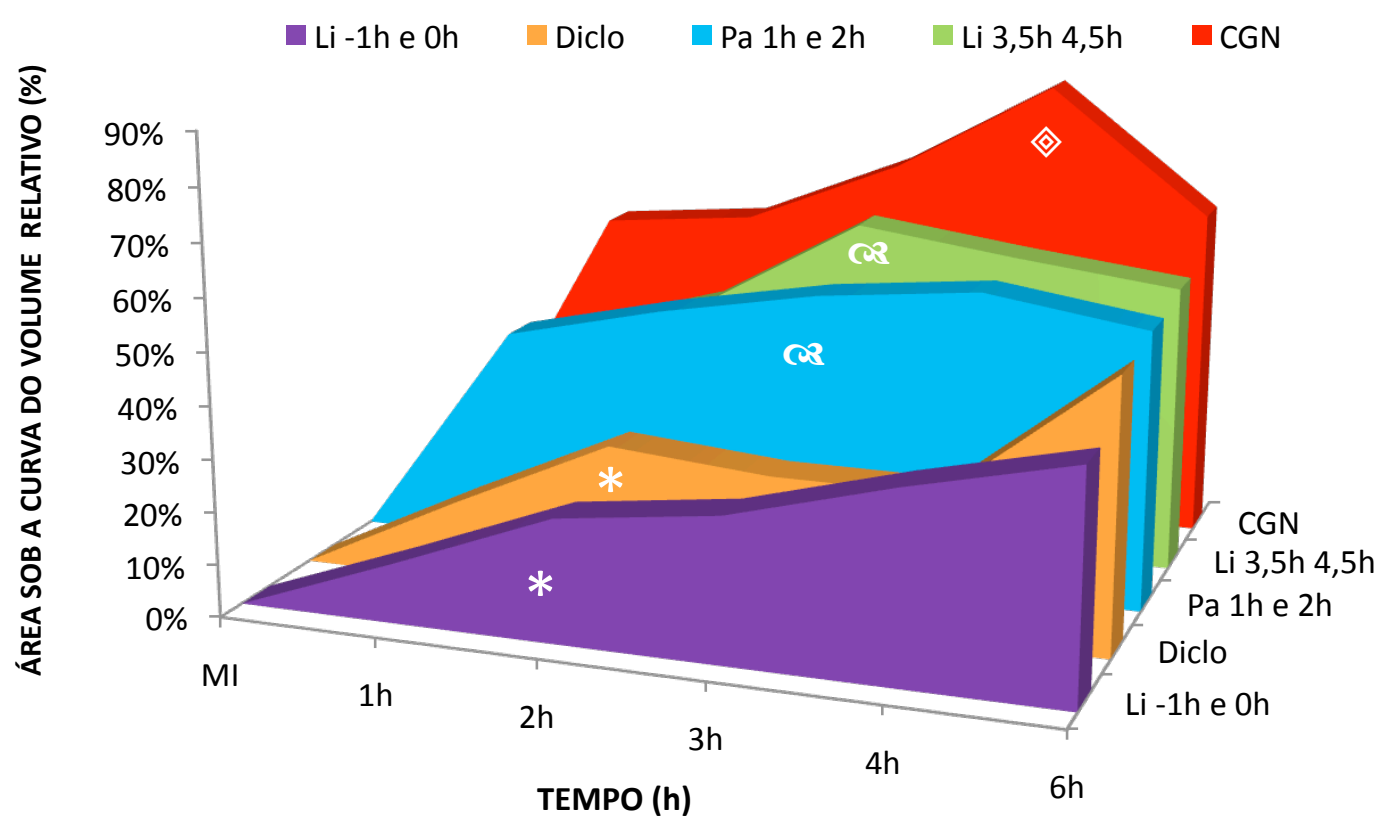

FIGURA 33 - Gráfico representando a área sob a curva do volume relativo (\%) em relação ao tempo experimental $(6 \mathrm{~h})$ da etapa 3A. Símbolos diferentes significam diferença estatística $(p<0,05)$.

TABELA 48 - Valores de $p$ obtidos pelo teste $t$ e corrigidos pelo procedimento de Ryan-Holm Stepdown Bonferroni para a comparação das médias do volume relativo na $2^{\mathrm{a}}$ hora experimental da etapa $3 \mathrm{~A}$. As diferenças estatisticamente significantes estão em negrito e itálico $(p<0,05)$.

\begin{tabular}{ccccc} 
2H & CGN & Diclo & Li -1h e 0h & Pa 1h e 2h \\
\hline \hline Diclo & $\mathbf{0 , 0 1 7 5}$ & & & \\
Li -1h e 0h & $\mathbf{0 , 0 0 0 5}$ & 0,6917 & & \\
Pa 1h e 2h & 0,9513 & 0,2172 & 0,1238 & \\
Li 3,5h 4,5h & 0,2494 & 0,2637 & $\mathbf{0 , 0 4 4 4}$ & 0,6495 \\
\hline
\end{tabular}

TABELA 49 - Valores de $p$ obtidos pelo teste $t$ e corrigidos pelo procedimento de Ryan-Holm Stepdown Bonferroni para a comparação das médias do volume relativo na $3^{\text {a }}$ hora experimental da etapa $3 \mathrm{~A}$. As diferenças estatisticamente significantes estão em negrito e itálico $(p<0,05)$.

\begin{tabular}{ccccc} 
3H & CGN & Diclo & Li -1h e 0h & Pa 1h e 2h \\
\hline \hline Diclo & $\mathbf{0 , 0 1 7 5}$ & & & \\
Li -1h e 0h & $\mathbf{0 , 0 0 0 5}$ & 0,6917 & & \\
Pa 1h e 2h & 0,9513 & 0,2172 & 0,1238 & \\
Li 3,5h 4,5h & 0,2494 & 0,2637 & $\mathbf{0 , 0 4 4 4}$ & 0,6495 \\
\hline
\end{tabular}


TABELA 50 - Valores de p obtidos pelo teste $t$ e corrigidos pelo procedimento de Ryan-Holm Stepdown Bonferroni para a comparação das médias do volume relativo na $4^{\mathrm{a}}$ hora experimental da etapa $3 \mathrm{~A}$. As diferenças estatisticamente significantes estão em negrito e itálico $(p<0,05)$.

\begin{tabular}{ccccc} 
4H & CGN & Diclo & Li -1h e 0h & Pa 1h e 2h \\
\hline \hline Diclo & $\mathbf{0 , 0 1 7 5}$ & & & \\
Li -1h e 0h & $\mathbf{0 , 0 0 0 5}$ & 0,6917 & & \\
Pa 1h e 2h & 0,9513 & 0,2172 & 0,1238 & \\
Li 3,5h 4,5h & 0,2494 & 0,2637 & $\mathbf{0 , 0 4 4 4}$ & 0,6495 \\
\hline
\end{tabular}

TABELA 51 - Área sob a curva ( \pm erro) calculados nas 6 horas experimentais e \% (porcentagem) de redução do edema ( \pm erro da \% redução) calculados em relação ao grupo controle (CGN) da etapa $3 A$.

\begin{tabular}{ccccc} 
& Área & (士Erro) & \% Redução & (士Erro \% Redução) \\
\hline \hline CGN & 3,77 & 0,23 & & \\
Diclo & 1,64 & 0,18 & 56,6 & 4,8 \\
Li 3,5h 4,5h & 2,88 & 0,20 & 23,8 & 5,7 \\
Pa 1h e 2h & 2,86 & 0,20 & 24,3 & 5,8 \\
Li -1h e 0h & 1,59 & 0,17 & 57,7 & 4,6 \\
\hline
\end{tabular}

TABELA 52 - Valores de $p$ obtidos pelo teste $Z$ para a comparação da área sob a curva dos diferentes grupos experimentais da etapa $3 A$ nas 6 horas experimentais. Os valores de $p$ foram corrigidos para múltiplas comparações pelo procedimento de Ryan-Holm Stepdown Bonferroni. $\mathrm{N}=5$ animais por grupo. As diferenças estatisticamente significantes estão em negrito e itálico $(p<0,05)$.

\begin{tabular}{ccccc} 
& CGN & Diclo & Li 3,5h 4,5h & Pa 1h e 2h \\
\hline \hline Diclo & $<0,0001$ & & & \\
Li 3,5h 4,5h & 0,0087 & $<0,0001$ & & \\
Pa 1h e 2h & 0,0096 & $<0,0001$ & 0,95 & \\
Li -1h e 0h & $<0,0001$ & 1,0000 & $<0,0001$ & $<0,0001$ \\
\hline
\end{tabular}

TABELA 53 - Área sob a curva ( \pm erro) calculados nas 4 horas experimentais e \% (porcentagem) de redução do edema ( \pm erro da \% redução) calculados em relação ao grupo controle (CGN) da etapa $3 A$.

\begin{tabular}{ccccc} 
& Área & (士Erro) & \% Redução & (士Erro \% Redução) \\
\hline \hline CGN & 2,26 & 0,14 & & \\
Diclo & 0,85 & 0,10 & 62,3 & 4,7 \\
Li 3,5h 4,5h & 1,74 & 0,12 & 23,0 & 5,7 \\
Pa 1h e 2h & 1,75 & 0,13 & 22,6 & 6,3 \\
Li -1h e 0h & 0,80 & 0,09 & 64,4 & 4,0 \\
\hline
\end{tabular}


TABELA 54 - Valores de $p$ obtidos pelo teste $Z$ para a comparação da área sob dos diferentes grupos experimentais da etapa 3A nas 4 horas experimentais. Os valores de $p$ foram corrigidos para múltiplas comparações pelo procedimento de Ryan-Holm Stepdown Bonferroni. $\mathrm{N}=5$ animais por grupo. As diferenças estatisticamente significantes estão em negrito e itálico $(p<0,05)$.

\begin{tabular}{ccccc} 
& CGN & Diclo & Li 3,5h 4,5h & Pa 1h e 2h \\
\hline \hline Diclo & $<0,0001$ & & & \\
Li 3,5h 4,5h & 0,0163 & $<0,0001$ & & \\
Pa 1h e 2h & 0,0237 & $<0,0001$ & 0,96 & \\
Li -1h e 0h & $<0,0001$ & 1,0000 & $<0,0001$ & $<0,0001$ \\
\hline
\end{tabular}

grupo pata $1 \mathrm{~h}$ e $2 \mathrm{~h}$ mostrou manter um platô após a $1^{\mathrm{a}}$ irradiação, com volume relativo constante até o final do experimento e sem diferença com o grupo CGN quando comparações pontuais em cada hora experimental foram realizadas (TAB. 48,49 e 50). O grupo linfonodo 3,5 e 4,5h também não apresentou diferenças pontuais durante as 6 horas experimentais em relação ao grupo CGN, mas foi tão eficiente quanto o grupo pata $1 \mathrm{~h}$ e $2 \mathrm{~h}$ na avaliação geral dos tratamentos avaliada pelas diferenças entre as áreas sob a curva dos grupos em 4 e 6 horas (TAB. 52 e 54).

O infiltrado inflamatório na etapa 1, foi estudado com o objetivo de avaliar os efeitos de diferentes combinações dosimétricas na modulação da inflamação. Na literatura a redução do infiltrado inflamatório promovida pela irradiação já é bastante aceita, mas a maioria dos trabalhos analisou apenas o local de irradiação. Nesta etapa, em dois grupos a irradiação foi realizada a distância do local da inflamação, buscando saber se a irradiação atua sistemicamente, modulando a resposta inflamatória através dos linfonodos, que estão relacionados com a ativação sistêmica da resposta inflamatória.

A comparação entre o número de células inflamatórias encontradas na pata esquerda dos animais dos grupos testados mostrou uma redução significativa dos grupos Diclo, Pata 1 e $2 \mathrm{~h}$ e Li $1 \mathrm{~h}$ Imed. em relação ao grupo controle (FIG. 34, APÊNDICE 2). O grupo irradiado no linfonodo 3,5 e 4,5 horas após a instalação do edema, apesar de ter sido eficaz como 
tratamento de edema em relação ao grupo controle, apresentou infiltrado inflamatório semelhante ao controle (FIG. 34). Muito provavelmente nesta linhagem o tempo decorrido entre a irradiação e a análise histológica não foi suficiente para que os efeitos do laser fossem percebidos e talvez uma avaliação com maior intervalo de tempo poderia esclarecer tal resultado.

HISTOLOGIA ETAPA 3A. BALB-C

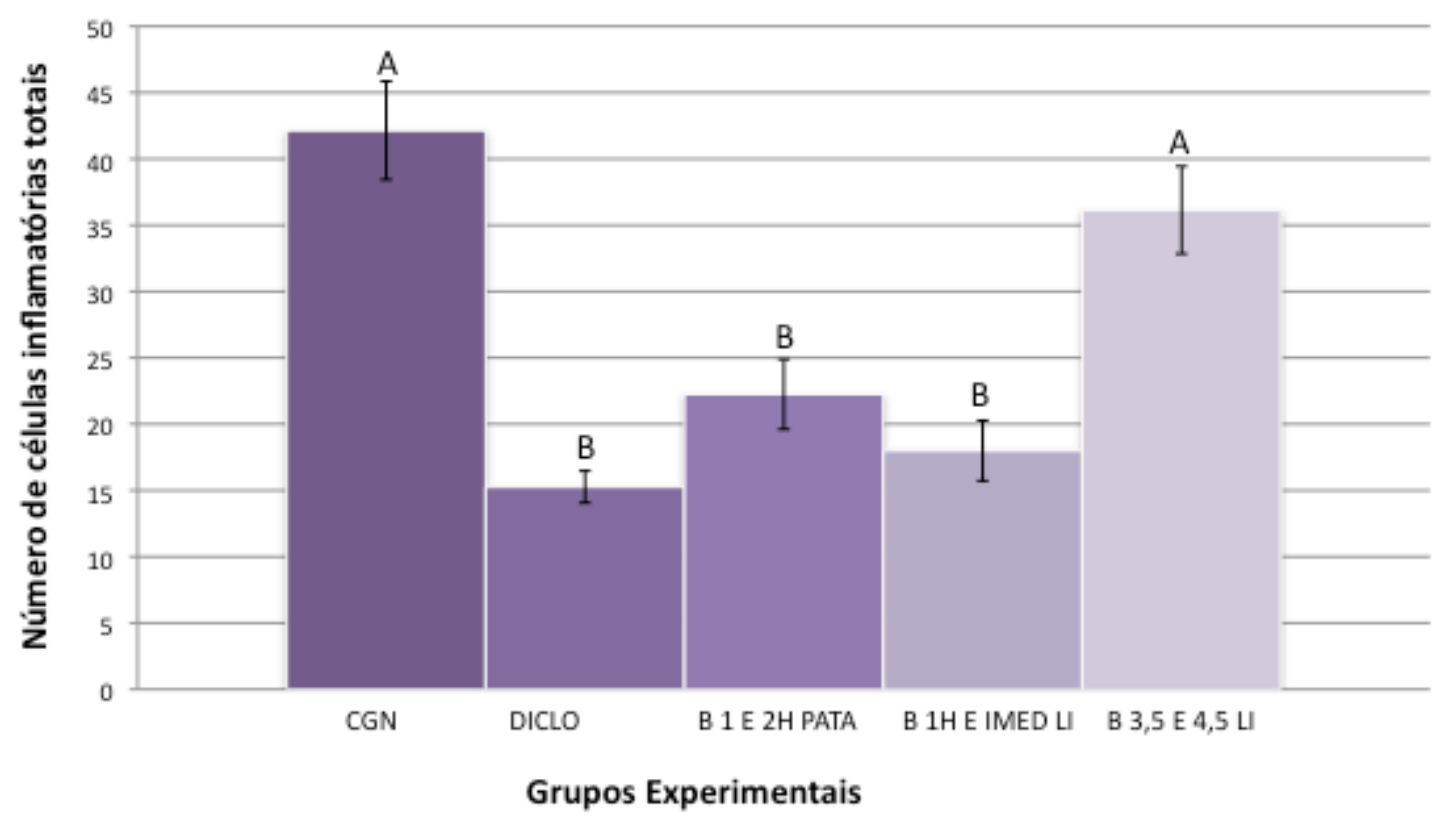

FIGURA 34 - Gráfico do número de células inflamatória totais dos grupos experimentais da etapa 3A realizada com a linhagem Balb-c. Letras diferentes significam diferença estatística $(p<0,05)$.

\subsubsection{ETAPA 3B: LINHAGEM C57BL/6}

Os diferentes tipos de pele e as possíveis diferenças de absorção e espalhamento da luz podem influenciar nos efeitos esperados da laserterapia. Muitos são os fatores que interferem na absorção de luz na pele, mas é possível considerar que a atenuação está diretamente relacionada à concentração de melanina, bem como à espessura da pele. $\mathrm{O}$ fenótipo da pele humana é determinado principalmente pelo número, tamanho, agregação e 
distribuição de melanossomas, que por sua vez são agrupamentos de melanina. Em peles escuras os melanossomas são maiores, mais pigmentados, e se distribuem uniformemente; nas peles mais claras os melanossomas são menores, com menos melanina e formam agregados. Para levar em conta a quantidade de luz absorvida por diferentes fenótipos de pele, Souza (2010) realizou um experimento de transmissão por solução aquosa de um composto artificial que simula o espectro de absorção da melanina. Os resultados mostraram que para uma mesma espessura de pele e concentração de melanina $(125 \mu \mathrm{g} / \mathrm{mL})$ os fótons atingem uma profundidade de $3,21 \mathrm{~mm}$ em $633 \mathrm{~nm}$ e $8,62 \mathrm{~mm}$ em $820 \mathrm{~nm}$ respectivamente. Ainda, ao aumentar a concentração de melanina, maior foi a absorção de luz, e a intensidade dos feixes de 633nm e 820nm diminuiu exponencialmente (Souza, 2010).

A pigmentação da pele é, portanto, um fator a ser considerado ao realizar a laserterapia e por isso são necessários estudos sobre o assunto. Nesta etapa realizamos os mesmos experimentos que na etapa anterior, no entanto utilizamos uma linhagem de camundongos pretos (C57BL/6) com o intuito de avaliar a influência da cor da pele da pata nos efeitos da laserterapia.

Nesta linhagem de camundongos pretos C57BL/6 a irradiação preventiva realizada no linfonodo $1 \mathrm{~h}$ e imediatamente antes da carragenina também foi o melhor resultado obtido e único entre os grupos irradiados a apresentar diferença estatística em relação ao grupo controle (TAB. 59 e 61 e FIG. 36). A porcentagem de redução, no entanto, observada na irradiação preventiva no linfonodo foi de $26,6 \%$ em 4 h e de $23,2 \%$ em 6 h (TAB. 57 e 55), valor bem inferior à redução encontrada nas outras linhagens estudadas, sendo a redução de 64,4 e $57,7 \%$ respectivamente na linhagem Balb-c e 51,7 e 44,9\% na linhagem SWISS (TAB. 62). Nesta linhagem, a penetração da luz pode ter sido reduzida pela absorção da luz 
pela pigmentação da pele, contribuindo para esta diminuição na eficácia do tratamento. Além disso, apesar da inibição do edema em relação ao grupo CGN, o grupo linfonodo 1 h e imed. apresentou um padrão de curva de evolução do edema correspondente a evolução normal do edema, com pico em 3h (FIG. 35) que condiz com um efeito não preventivo da irradiação.

O grupo irradiado no linfonodo na 3,5h e 4,5h apresentou um padrão de declínio acentuado a partir da 3h, indicando o efeito imediato da irradiação, mas não o suficiente para ser melhor que o grupo CGN (TAB. 55, 56 e 57). Mais uma vez, ao compararmos a \% de redução do edema em relação ao grupo controle entre as linhagens estudadas, observamos que os efeitos da irradiação na linhagem C57BL6 foram muito menores que nas outras linhagens. Neste grupo, a \% de redução do edema foi de $1,9 \%$ em $4 \mathrm{~h}$ e $6,9 \%$ em $6 \mathrm{~h}$, muito inferior a redução encontrada nos camundongos Balb-c (23 e 23,8\%) e SWISS (24,3 e $30,8 \%)$.

Interessantemente, no grupo irradiado na pata $1 \mathrm{~h}$ e $2 \mathrm{~h}$ mostrou um padrão de curva de evolução do edema deslocada para a esquerda, com pico do edema em 2h (FIG. 35). Ainda, a evolução do edema entre a $1^{\mathrm{a}}$ e $2^{\mathrm{a}} \mathrm{h}$ mostrou um efeito com tendência pró-inflamatória da irradiação realizada na $1^{\mathrm{a}}$ hora. Avaliando a \% de redução do edema e comparando com as outras linhagens testadas é possível perceber diferenças ainda mais significantes, sendo 0,7\% em $4 \mathrm{~h}$, indicando que o edema aumentou ao invés de diminuir, e $0,3 \%$ em $6 \mathrm{~h}$, redução praticamente insignificante. Nas linhagens Balb-c e SWISS, ao contrário, a \% de redução foram respectivamente de 22,6 e $24,3 \%$ e 33,6 e $45,7 \%$. Mais uma vez é verificado que os efeitos da irradiação foram minimizados nesta linhagem de camundongos e isto pode ser atribuído em menor proporção a diferente resposta inflamatória da linhagem C57BI/6, já que a linhagem Balb-c também isogênica não apresentou tal comportamento, e mais provavelmente à coloração desta linhagem de camundongos pretos, cuja pigmentação pode 
ter absorvido a irradiação chegando menor quantidade de energia na região da inflamação e, portanto, ter apresentado menores efeitos sobre o tratamento do edema.

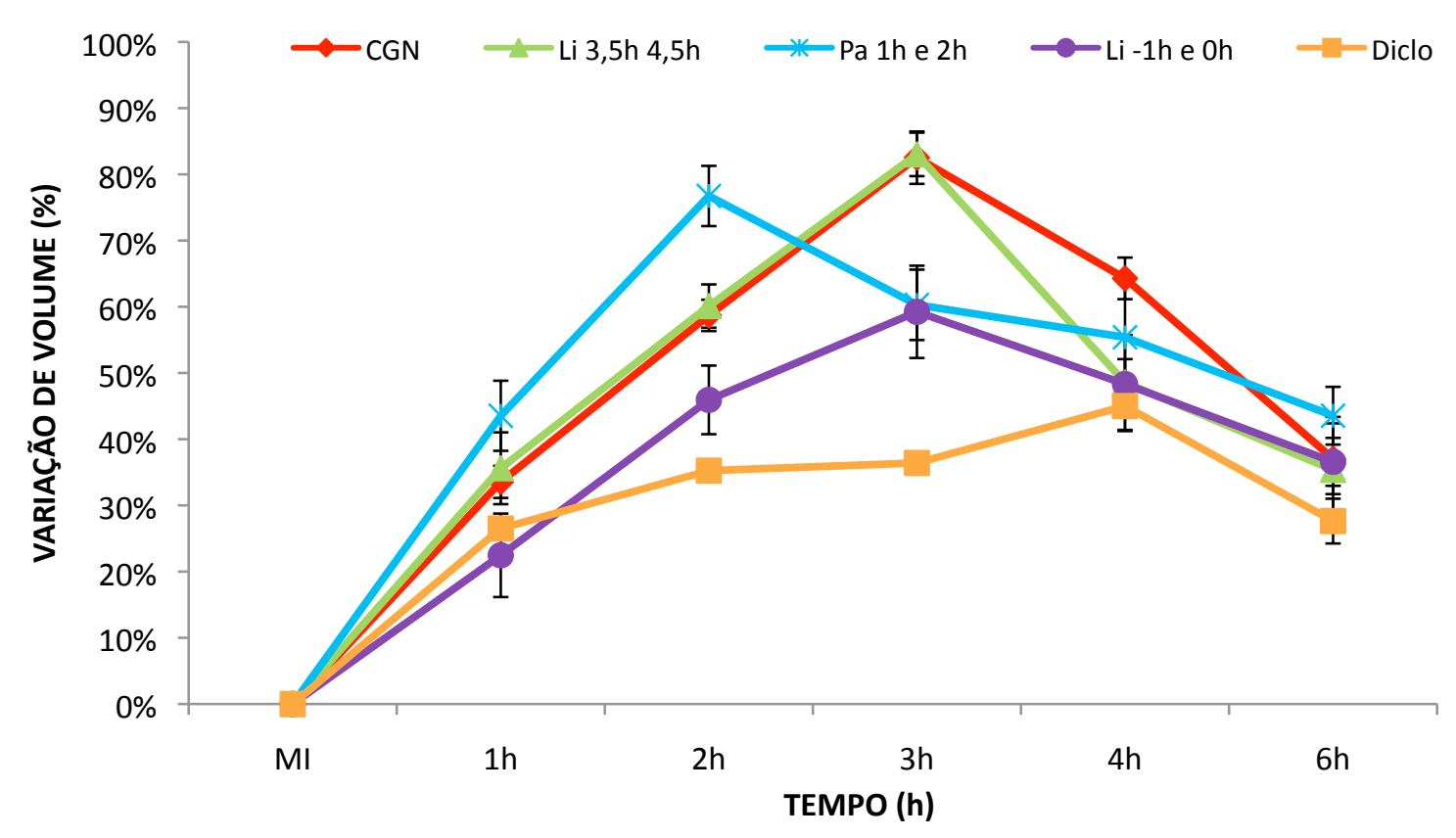

FIGURA 35 - Gráfico das médias do volume relativo do edema (\%) com os respectivos erros padrão da etapa 3B. As irradiações foram feitas conforme o grupo experimental. $\mathrm{N}=5$ animais por grupo.

TABELA 55 - Valores de p obtidos pelo teste $t$ e corrigidos pelo procedimento de Ryan-Holm Stepdown Bonferroni para a comparação das médias do volume relativo na $2^{\mathrm{a}}$ hora experimental da etapa $3 \mathrm{~B}$. As diferenças estatisticamente significantes estão em negrito e itálico $(p<0,05)$.

\begin{tabular}{ccccc} 
2H & CGN & Diclo & Li -1h e 0h & Pa 1h e 2h \\
\hline \hline Diclo & $\mathbf{0 , 0 0 1 3}$ & & & \\
Li -1h e 0h & 0,2543 & 0,2581 & & \\
Pa 1h e 2h & 0,0749 & $\mathbf{0 , 0 0 4 3}$ & $\mathbf{0 , 0 2 4 4}$ & \\
Li 3,5h 4,5h & 0,7393 & $\mathbf{0 , 0 1 8 9}$ & 0,2722 & 0,1081 \\
\hline
\end{tabular}


TABELA 56 - Valores de p obtidos pelo teste $t$ e corrigidos pelo procedimento de Ryan-Holm Stepdown Bonferroni para a comparação das médias do volume relativo na $3^{\text {a }}$ hora experimental da etapa $3 B$. As diferenças estatisticamente significantes estão em negrito e itálico $(p<0,05$.

\begin{tabular}{ccccc} 
3H & CGN & Diclo & Li -1h e 0h & Pa 1h e 2h \\
\hline \hline Diclo & $\mathbf{0 , 0 0 1 2}$ & & & \\
Li -1h e 0h & 0,1388 & 0,1321 & & \\
Pa 1h e 2h & 0,0675 & 0,0742 & 1,8164 & \\
Li 3,5h 4,5h & 0,9259 & $\mathbf{0 , 0 0 1 8}$ & 0,1683 & 0,0682 \\
\hline
\end{tabular}

TABELA 57 - Valores de $\mathrm{p}$ obtidos pelo teste $\boldsymbol{t}$ e corrigidos pelo procedimento de Ryan-Holm Stepdown Bonferroni para a comparação das médias do volume relativo na $4^{\text {a }}$ hora experimental da etapa $3 B$. As diferenças estatisticamente significantes estão em negrito e itálico $(p<0,05)$.

\begin{tabular}{ccccc} 
4H & CGN & Diclo & Li -1h e 0h & Pa 1h e 2h \\
\hline Diclo & 0,0546 & & & \\
Li -1h e 0h & 0,1204 & 1,0000 & & \\
Pa 1h e 2h & 1,0000 & 1,0000 & 1,0000 & \\
Li 3,5h 4,5h & 0,5280 & 1,0000 & 0,9782 & 1,0000 \\
\hline
\end{tabular}

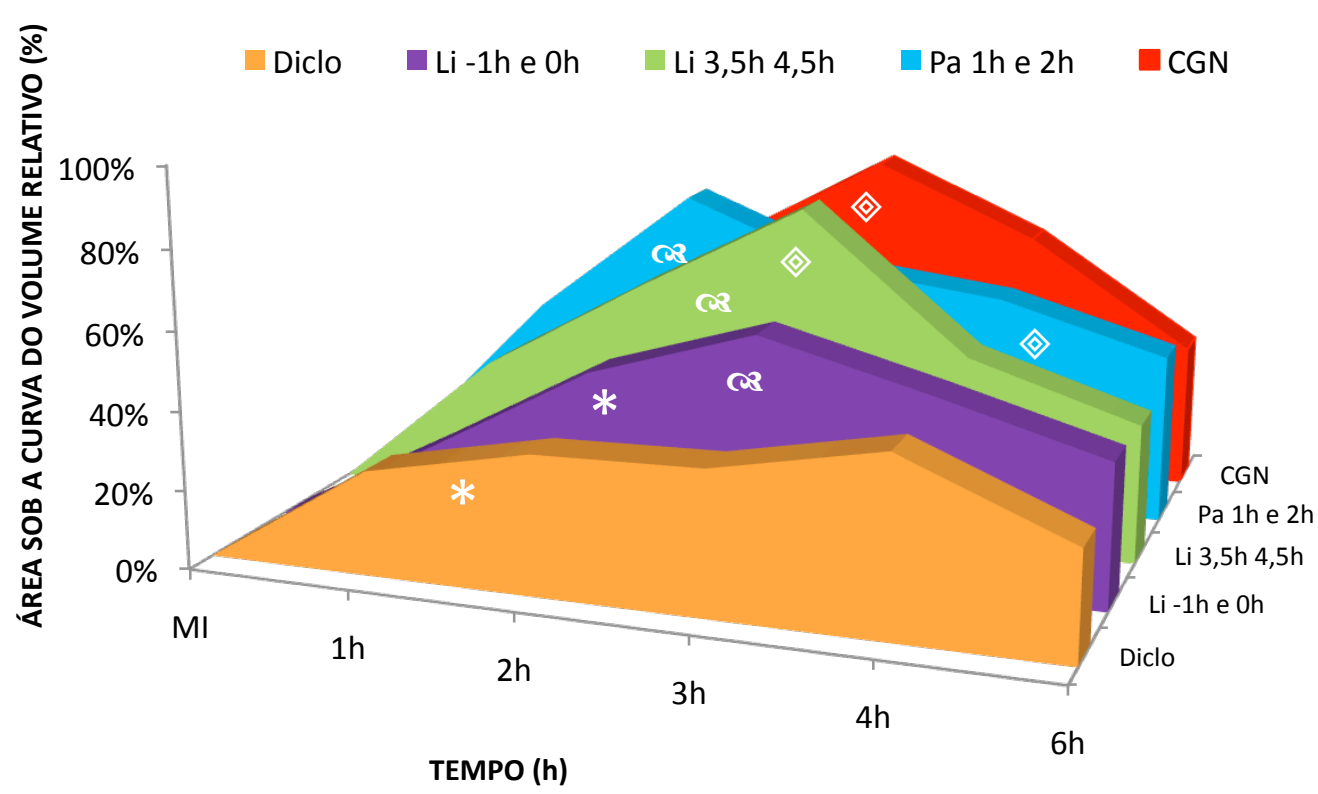

FIGURA 36 - Gráfico representando a área sob a curva do volume relativo (\%) em relação ao tempo experimental (6h) da etapa 3B. Símbolos diferentes significam diferença estatística $(p<0,05)$. 
TABELA 58 - Área sob a curva ( \pm erro) calculados nas 6 horas experimentais e \% (porcentagem) de redução do edema ( \pm erro da \% redução) calculados em relação ao grupo controle (CGN) da etapa 3B.

\begin{tabular}{ccccc} 
& Área & (士Erro) & \% Redução & (士Erro \% Redução) \\
\hline \hline CGN & 3,08 & 0,18 & & \\
Diclo & 1,93 & 0,12 & 37,3 & 4,3 \\
Li 3,5h 4,5h & 2,87 & 0,21 & 6,9 & 7,3 \\
Pa 1h e 2h & 3,07 & 0,22 & 0,3 & 7,7 \\
Li -1h e 0h & 2,37 & 0,17 & 23,2 & 6,0 \\
\hline
\end{tabular}

TABELA 59 - Valores de $p$ obtidos pelo teste $Z$ para a comparação da área sob a curva dos diferentes grupos experimentais da etapa 3B nas 6 horas experimentais. Os valores de $p$ foram corrigidos para múltiplas comparações pelo procedimento de Ryan-Holm Stepdown Bonferroni. $\mathrm{N}=5$ animais por grupo. As diferenças estatisticamente significantes estão em negrito e itálico $(p<0,05)$.

\begin{tabular}{ccccc} 
& CGN & Diclo & Li 3,5h 4,5h & Pa 1h e 2h \\
\hline \hline Diclo & $<0,0001$ & & & \\
Li 3,5h 4,5h & 1,0000 & $\mathbf{0 , 0 0 0 8}$ & & \\
Pa 1h e 2h & 0,9702 & $<0,0001$ & 1,0000 & \\
Li -1h e 0h & $\mathbf{0 , 0 2 7 5}$ & 0,19 & 0,2567 & 0,0704 \\
\hline
\end{tabular}

TABELA 60 - Área sob a curva ( \pm erro) calculados nas 4 horas experimentais e \% (porcentagem) de redução do edema ( \pm erro da \% redução) calculados em relação ao grupo controle (CGN) da etapa 3B.

\begin{tabular}{ccccc} 
& Área & (士Erro) & \% Redução & (士Erro \% Redução) \\
\hline \hline CGN & 2,07 & 0,12 & & \\
Diclo & 1,207 & 0,067 & 41,7 & 3,6 \\
Li 3,5h 4,5h & 2,03 & 0,13 & 1,9 & 6,8 \\
Pa 1h e 2h & 2,08 & 0,14 & $-0,7$ & 7,4 \\
Li -1h e 0h & 1,52 & 0,14 & 26,6 & 6,9 \\
\hline
\end{tabular}

TABELA 61 - Valores de $p$ obtidos pelo teste $Z$ para a comparação da área sob a curva dos diferentes grupos experimentais da etapa 3B nas 4 horas experimentais. Os valores de $p$ foram corrigidos para múltiplas comparações pelo procedimento de Ryan-Holm Stepdown Bonferroni. $\mathrm{N}=5$ animais por grupo. As diferenças estatisticamente significantes estão em negrito e itálico $(p<0,05)$.

\begin{tabular}{ccccc} 
& CGN & Diclo & Li 3,5h 4,5h & Pa 1h e 2h \\
\hline \hline Diclo & $<0,0001$ & & & \\
Li 3,5h 4,5h & 1,0000 & $<0,0001$ & & \\
Pa 1h e 2h & 0,9417 & $<0,0001$ & 2,35 & \\
Li -1h e 0h & $\mathbf{0 , 0 1 5 3}$ & 0,16 & $\mathbf{0 , 0 3 2 3}$ & $\mathbf{0 , 0 2 5 2}$ \\
\hline
\end{tabular}


Analisando a quantidade de infiltrado inflamatório do tecido plantar desta linhagem notou-se, que a radiação laser foi suficiente para promover efeitos favoráveis no processo inflamatório. Ao contrário, a irradiação em todos os grupos tratados mostrou reduzir significativamente a quantidade de células inflamatórias em relação ao grupo controle (FIG. 37, APÊNDICE 3). Entre os grupos, no entanto, algumas diferenças foram encontradas sendo a irradiação preventiva (Li 1h e Imed) e tratamento realizado no linfonodo (Li 3,5 e 4,5h) os únicos grupos com infiltrado inflamatório tão baixo quanto o grupo Diclo. O grupo irradiado na pata foi semelhante ao grupo linfonodo 3,5 e 4,5h.

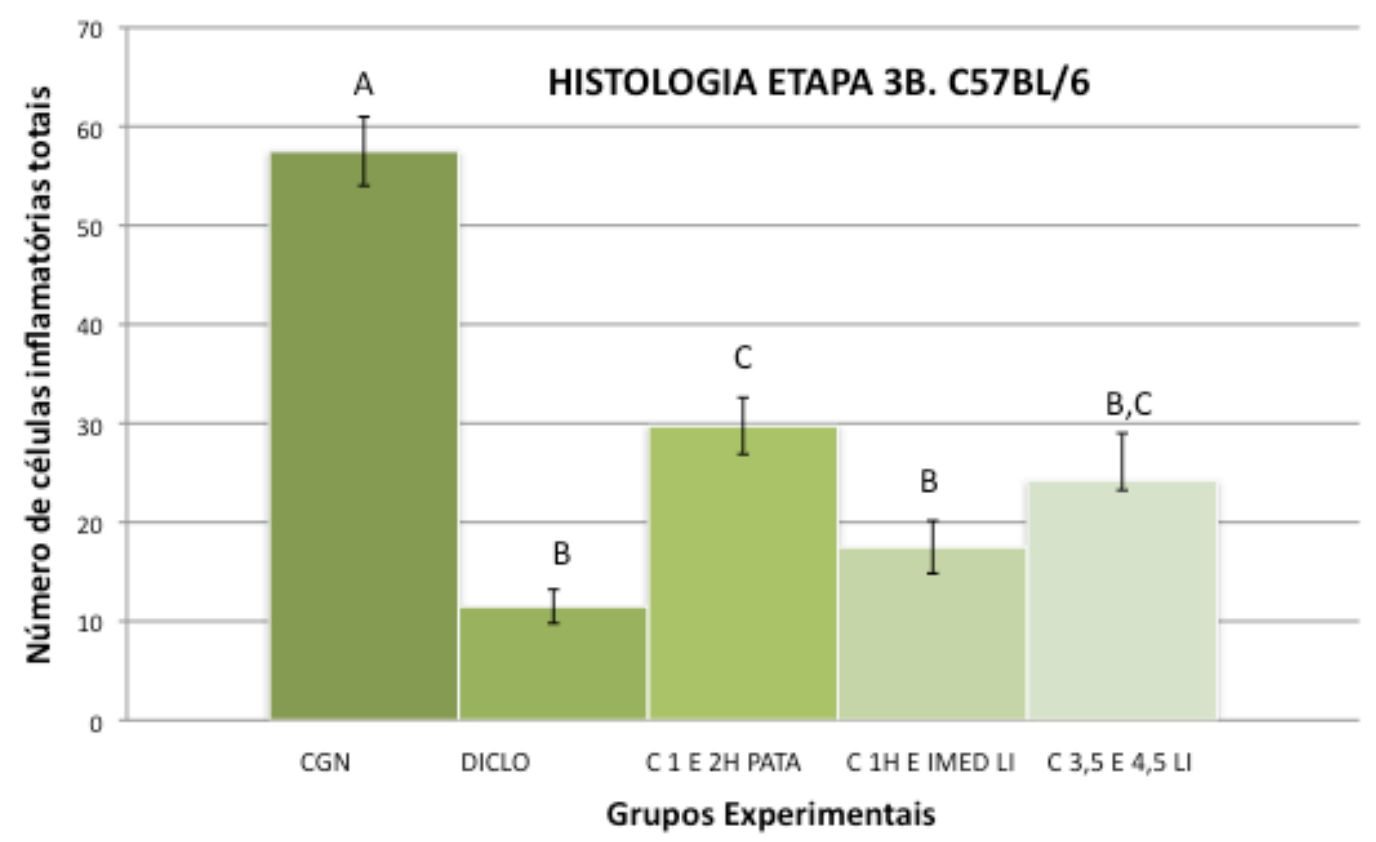

FIGURA 37 - Gráfico do número de células inflamatória totais dos grupos experimentais da etapa 3B realizada com a linhagem C57BL/6. Letras diferentes significam diferença estatística $(p<0,05)$.

Estes resultados sugerem que a quantidade de luz necessária para reduzir o infiltrado inflamatório pode ser muito menor do que a quantidade de luz capaz de promover a inibição do edema. No intuito de avaliar melhor a influência da irradiação nas duas linhagens utilizadas, foi realizada uma análise estatística com os dados da histologia comparando os mesmos grupos de ambas as linhagens. Os resultados mostraram uma curiosa associação 
entre os grupos. Nota-se que na linhagem C57BL/6 o infiltrado inflamatório foi mais intenso, e o número de células inflamatórias do grupo controle foi estatisticamente maior que no mesmo grupo da linhagem BALB-C. Apesar disso, todos os grupos irradiados e Diclofenaco quando comparados entre si mostraram ser semelhantes, ou seja, com a mesma quantidade de células inflamatórias que o grupo correspondente da outra linhagem (FIG. 38). Isso mostra que na linhagem de camundongos pretos, onde a inflamação foi mais exacerbada, a radiação foi mais eficiente na redução do infiltrado inflamatório. Levando em consideração que uma maior absorção da luz faz com que menos energia chegue em profundidade, a pigmentação da pele do camundongo pode justificar a menor eficiência da irradiação no tratamento do edema, já que para sua inibição maiores potências são necessárias, e confirmar seus efeitos favoráveis no infiltrado inflamatório, cuja combinação de parâmetros pode ser mais importante que a potência.

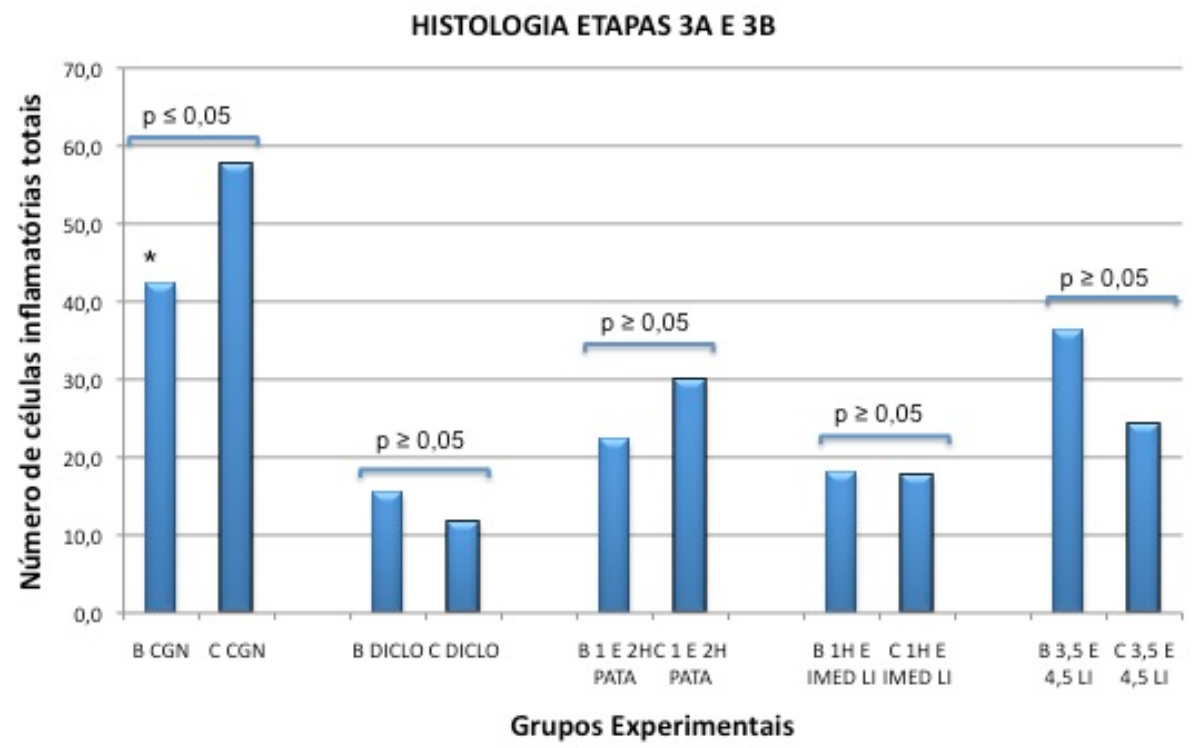

FIGURA 38 - Gráfico do número de células inflamatórias totais dos grupos das etapas 3A e 3B comparando os mesmos grupos de linhagens diferentes. Sendo B (BALB-C) e C (C57BI/6) e diferença estatisticamente significante se $p<0,05\left(^{*}\right)$. 
Com o intuito de facilitar as comparações entre os grupos e visualizar melhor os resultados encontrados, resumimos na tabela 62 os resultados das 3 etapas realizadas.

TABELA 62 - Resumo dos resultados das 3 etapas experimentais. "X controle $4 h$ " e "X controle $4 h$ " equivale ao resultado da área sob a curva nas $4 \mathrm{~h}$ e $6 \mathrm{~h}$ experimentais respectivamente do grupo correspondente em relação ao grupo controle, podendo ser semelhante estatisticamente ( ) ou diferente ( $¥)$. A “\% de redução em $4 h$ " e a "\% de redução em $6 h$ " mostra os valores obtidos em relação ao controle

$(100 \%)$

nas

4

e

$6 \mathrm{~h}$ experimentais.

\begin{tabular}{|c|c|c|c|c|c|c|c|c|}
\hline Etapa & UNHAGEM & PROTOCOLO & LOCAL IRRADIAÇĀO & IRRADIAÇĀ0 & Xcontrule th & Xcontrole 6h & ЖRHUСС̈ОЁМ 4H & ЖRHОUÇĀOEMGH \\
\hline \multirow{3}{*}{$\sqrt{5}$} & BAIB-C & ע / 30 & PATA & 1he Zh apois & $\sim$ & n & 4,4 & 6,4 \\
\hline & BAIB-C & $1 / 60 \mathrm{lnw}$ & PATA & lhe Th após & t & \pm & 24 & 28,5 \\
\hline & BAIB-C & 1 / 100 hnw & PATA & lhe 2h após & t & t & 30,2 & 36,8 \\
\hline \multirow{3}{*}{$\sqrt{0}$} & BAIB-C & 3) / 30Rrw & PATA & lhe Th após & $t$ & $t$ & 25,5 & 22,8 \\
\hline & BAIB-C & $3 / / 60 \mathrm{lnw}$ & PATA & lhe 2h apois & $\sim$ & $\sim$ & 17,9 & 18 \\
\hline & BAIB-C & 3) / $100 \mathrm{hrmw}$ & PATA & 1he Th após & $t$ & $t$ & $Z, 9$ & 28,3 \\
\hline \multirow{3}{*}{$2 \sqrt{5}$} & SMSS & 1 / $/ 100 \mathrm{hm}$ & PATA & The lhantes & $\sim$ & n & $-10,8$ & $-0,6$ \\
\hline & SWSS & 1 / / 100 hrw & UNFONODO & The th antes & $\sim$ & $\sim$ & $-3,3$ & 6,9 \\
\hline & SWSS & 1 / / 10:Thw & PATAHUNFONODO & The lh antes & $\sim$ & t & 17,1 & 28 \\
\hline \multirow{3}{*}{20} & SWSS & 1 / $/ 100 \mathrm{hrm}$ & PATA & the imed Antes & $\sim$ & n & -21 & -23 \\
\hline & SWSS & y / 100mw & UNFONODO & The imed Antes & $t$ & $t$ & 51,7 & 44,9 \\
\hline & SWSS & 1 / / 100 Trmw & PATAHUNFONODO & The imed Antes & $\sim$ & $\sim$ & 5 & 6 \\
\hline \multirow{3}{*}{20} & SWSS & 1 / / 100 Tnw & PATA & 1he Thapós & t & t & 33,6 & 45,7 \\
\hline & SWSS & 1 / / 100 & UNFONODO & the Th após & $\sim$ & t & 15,5 & 33,6 \\
\hline & SWSS & 1 / 10 lomw & PATAHUNFONODO & lhe 2h após & $\sim$ & $\sim$ & $-17,7$ & 7,5 \\
\hline \multirow{3}{*}{2[} & SWSS & 1 / / 100 Thw & PATA & 3,5e 4,5 aqós & $\sim$ & t & 16,2 & 28 \\
\hline & SWSS & 1 / / 10: hmw & UNFONODO & 3,5 e 4,5 após & $\sim$ & $t$ & 24,3 & 30,8 \\
\hline & SWSS & 1 / / 100 Thw & PATAHUNFONODO & 3,5 e 4,5 aqós & n & $n$ & -6 & 0 \\
\hline \multirow{3}{*}{$3 / 5$} & BAIB-C & 1 / / 100 $\mathrm{mw}$ & PATA & 1he Th apoís & t & $t$ & 22,6 & 24,3 \\
\hline & BAIB-C & 1 / / 100 hrw & UNFONODO & lhe imed Antes & t & t & 64,4 & 57,7 \\
\hline & BAIB-C & 1 / 10 $10 \mathrm{hm}$ & UNFONODO & 3,5 e 4,5 aqús & t & t & $\mathbf{2 3}$ & 23,8 \\
\hline \multirow{3}{*}{35} & c5/186 & 1 / / 100Tww & PATA & the Th após & $\sim$ & $\sim$ & $-0,7$ & 0,3 \\
\hline & G/180 & 1 / 10:0hw & UNFONODO & The imed Antes & t & $t$ & 26,6 & 23,2 \\
\hline & $5 / 848$ & $1 \mathrm{~L} / 10 \mathrm{l} \mathrm{nm}$ & UNFONODO & 3,5e4,5 aqós & $\sim$ & $\sim$ & 1,9 & 6,9 \\
\hline
\end{tabular}




\section{CONCLUSÕES}

- A FLBI foi capaz de prevenir, inibir e acelerar a resolução do edema formado em processo inflamatório agudo causado por carragenina em pata de camundongos

- A FLBI mostrou ser efetiva na redução do edema independentemente da linhagem de camundongos (SWISS, BALB-C e C57B16)

- Em todas as linhagens testadas, a irradiação preventiva realizada no linfonodo inguinal $1 \mathrm{~h}$ e imediatamente antes da CGN foi o melhor dos tratamentos a laser realizados sendo semelhante aos efeitos preventivos do Diclofenaco de sódio administrado 30'antes da CGN.

- Os parâmetros, a localização da irradiação e fase da evolução do edema influenciaram nos efeitos obtidos com a FLBI sendo:

$\Rightarrow$ Os melhores parâmetros capazes de inibir o edema nas condições deste estudo foram: 1J/100 mW, 3J/30 mW e 3J/100 mW.

$\Rightarrow A$ prevenção do edema foi obtida através da irradiação nos linfonodos $1 \mathrm{~h} e$ imediatamente antes da injeção da carragenina com os parâmetros $1 \mathrm{~J} / 100 \mathrm{~mW}$

$\Rightarrow A$ inibição da evolução do edema foi obtido pela irradiação $1 \mathrm{~h}$ e $2 \mathrm{~h}$ após a injeção da carragenina com os parâmetros 1J/100 mW, 3J/30 mW e 3J/100 mW diretamente sobre a pata e também pela irradiação $2 \mathrm{~h}$ e $1 \mathrm{~h}$ antes da injeção da carragenina através da irradiação dupla: pata+ linfonodo com 1J/100 mW.

$\Rightarrow A$ redução do edema após o seu pico foi obtida pela irradiação da pata ou linfonodo após $3,5 \mathrm{~h}$ e 4,5h da injeção da carragenina com os parâmetros de $1 \mathrm{~J} / 100 \mathrm{~mW}$ 
- A radiação laser reduziu o infiltrado inflamatório de forma dependente da potência utilizada, local e momento de irradiação e independente da energia e linhagem de camundongos utilizadas.

- Os efeitos do laser na redução do edema na linhagem C57BL/6 foram percentualmente menores que nas linhagens Balb-c e SWISS.

- Em todas as combinações dosimétricas entre energia e potência testadas, a irradiação diminuiu o infiltrado inflamatório quando comparado com o grupo controle não irradiado (CGN). 


\section{REFERÊNCIAS BIBLIOGRÁFICAS}

- AGAIBY, A.D.; GHALI L.R.; WILSON R.; DYSON M. Laser modulation of angiogenic factor production by T-lymphocytes. Lasers Surg. Med., v.26, n.4, p.357-363, 2000.

- AIMBIRE F.; ALBERTINE R.; MAGALHÃES R.G.; LOPES-MARTINS R.A.B.; CASTRO-FARIANETO R.A.; ZÂNGARO R.A.; CHAVANTES M.C.; PACHECO M.T.T. Effect of LLLT Ga-Al-As (685 $\mathrm{nm}$ ) on LPS-induced inflammation of the airway and lung in the rat. Lasers Med Sci.,v.20, p. 1120, 2005.

- AIMBIRE F.; ALBERTINI R.; PACHECO M.T.; CASTRO-FARIA-NETO H.C.; LEONARDO P.S.; IVERSEN V.V.; LOPES-MARTINS R.A.B.; BJORDAL J.M. Low-level laser therapy induces dosedependent reduction of TNFalpha levels in acute inflammation. Photomed Laser Surg. V.24, n.1, p33-7, 2006

- ALBERTINI R.; AIMBIRE F.; VILLAVERDE A.B.; SILVA JR. J.A.; COSTA M.S. COX-2 mRNA expression decreases in the subplantar muscle of rat paw subjected to carrageenan-induced inflammation after low level laser therapy. Inflamm. Res., v.56, p. 228-229, 2007.

- ALBERTINI R.; AIMBIRE F.S.C.; CORREA F.I.; RIBEIRO W.; COGO J.C.; ANTUNES E.; TEIXEIRA S.A.; DE NUCCI G.; CASTRO-FARIA-NETO H.C.; ZÂNGARO R.A.; LOPES-MARTINS R.A.B. Effects of different protocol doses of low power gallium-aluminum-arsenate (Ga-Al-As) laser radiation $(650 \mathrm{~nm})$ on carrageenan induced rat paw oedema. J Photochem Photobiol B., v.74, p.101-107, 2004.

- ALBERTINI R.; VILLAVERDE A.B.; AIMBIRE F.; SALGADO M.A.; BJORDAL J.M.; ALVES L.P.; MUNIN E.; COSTA M.S. Anti-inflammatory effects of low-level laser therapy (LLLT) with two different red wavelengths $(660 \mathrm{~nm}$ and $684 \mathrm{~nm})$ in carrageenan-induced rat paw edema. $J$ Photochem Photobiol B., v.89, n.1, p. 50-55, 2007.

- ALBERTINI R.; VILLAVERDE A.B.; AIMBIRE F.; BJORDAL J.M.; BRUGNERA JR A.; MITTMANN J. SILVA JR. J.A.; COSTA M.S. Cytokine mRNA Expression Is Decreased in the Subplantar Muscle of Rat Paw Subjected to Carrageenan-Induced Inflammation after Low-Level Laser Therapy. Photome Laser Surg., v.26, n.1, p.19-24, 2008.

- AMAT A.; RIGAU J.; NICOLAU R.; AALDERS M.; FENOLL M.R.; VAN GEMERT M.J.C.; TOMAÖS J. Effect of red and near-infrared laser light on adenosine triphosphate (ATP) in the luciferineluciferase reaction. J. Photochem. Photobiol. A., v.168, p. 59-65, 2004.

- AMAT A.; RIGAU J.; WAYNANT R.W.; ILEV I.K.; ANDERS J.J. The electric field induced by light can explain cellular responses to electromagnetic energy: a hypothesis of mechanism. $\boldsymbol{J}$ Photochem Photobiol B., v.82, n.2, p.152-60, 2006. 
- AMAT A.; RIGAU J.; WAYNANT R.W.; ILEV I.K.; TOMAÖS J.M.; ANDERS J.J. Modification of the intrinsic fluorescence and biochemical behavior of adenosine triphosphate ATP after irradiation with visible and near- infrared laser light. J. Photochem. Photobiol. B., v.81, p. 26-32, 2005.

- ANDERS JJ, BORKE RC, WOOLERY SK, VAN DE MERWE WP. Low power laser irradiation alters the rate of regeneration of the rat facial nerve. Lasers Surg Med., v.13, n.1, p. 72-82, 1993.

- BASFORD, J.R., HALLMAN H.O.; MATSUMOTO J.Y.; MOYER S.K.; BUSS J.M.; BAXTER G.D. Effects of $830-\mathrm{nm}$ continuous wave laser diode irradiation on median nerve function in normal subjects. Lasers Surg. Med., v.13, n. 6, p. 597-604, 1993

- BAUMANN, H.; GAULDIE, J. The acute phase response. Immunol. Today, v. 15, p. 74-80, 1994.

- BAXTER GD. Therapeutic lasers: theory and practice. United States of America: Ed. Churchill Livingstone, 1997.

- BJORDAL JM, COUPPE, C., CHOW, R.T., TUNÉR J, LJUNGGREN EA. A systematic review of low-level laser therapy with location-specific doses for pain from chronic joint disorders. Aust. J. Physiother., v. 49, p. 107-116, 2003.

- BJORDAL JM, JOHNSON MI, IVERSEN V, AIMBIRE F, LOPES-MARTINS RA. Photoradiation in acute pain: a systematic review of possible mechanisms of action and clinical effects in randomized placebo-controlled trials. Photomed Laser Surg., v.24, n.2, p.158-68, 2006a.

- BJORDAL, J.M., LOPES-MARTINS, R.A., AND IVERSEN, V.V. A randomised, placebo controlled trial of low level laser therapy for activated Achilles tendinitis with microdialysis measurement of peritendinous prostaglandin E2 concentrations. Br. J. Sports Med., v. 40, p.76-80, 2006b.

- BLANK M. Na,K-ATPase function in alternating electric fields, FASEB J., v.6, n.7, p. 2434-2438, 1992.

- BOLOGNANI L, CAVALCA M, MAGNANI C, VOLPI N. ATP synthesis catalysed by myosin ATPase: effect of laser and e.m. field, Laser \& Technol., v. 2, n. 3, p.115-120, 1992.

- BORTONE F, SANTOS HA, ALBERTINI R, PESQUERO JB, COSTA MS, SILVA JA JR. Low level laser therapy modulates kinin receptors mRNA expression in the subplantar muscle of rat paw subjected to carrageenan-induced inflammation. Int Immunopharmacol. v.8, n.2, p. 206-10, 2008.

- BOSCHI ES, LEITE CE, SACIURA VC, CABERLON E, LUNARDELLI A, BITENCOURT S, MELO DA, OLIVEIRA JR. Anti-Inflammatory effects of low-level laser therapy $(660 \mathrm{~nm})$ in the early phase in carrageenan-induced pleurisy in rat. Lasers Surg Med. v. 40, n.7, p.500-8, 2008.

- BOULNOIS JL. Photophysical processes in recent medical laser development: a review. Lasers Med Sci. v.1, p. 47-66, 1985.

- CAMPANA V, MOYA M, GAVOTTO A, JURI H, PALMA JA. Effects of diclofenac sodium and HeNe laser irradiation on plasmatic fibrinogen levels in inflammatory processes. $J$ Clin Laser Med Surg v.16, n.6, p.317-320, 1998. 
- CAMPOS MM, LEAL PC, YUNES RA, CALIXTO JB.Non-peptide antagonists for kinin B1 receptors: new insights into their therapeutic potential for the management of inflammation and pain. Trends Pharmacol Sci. v.27, n.12, p. 646-51, 2006.

- CARVALHO PTC, MAZZER N, REIS FA, BELCHIOR ACG, SILVA IS. Análise da influência do laser de baixa potência (HeNe) na cicatrização de feridas cutâneas em ratos diabéticos e não diabéticos. Acta Cirúrgica Brasileira, v.21, n.3, p.177-183, 2006

- CASTANO AP, DAI T, YAROSLAVSKY I, COHEN R, APRUZZESE WA, SMOTRICH MH, HAMBLIN MR. Low-Level Laser Therapy for Zymosan-Induced Arthritis in Rats: Importance of Illumination Time. Lasers in Surgery and Medicine v.39, p. 543-550, 2007.

- CATÃo MH. Os benefícios do lasers de baixa intensidade na clínica odontológica na estomatologia. Revista Brasileira de Patologia Oral v.3, n.4, p.214-18, 2004.

- CHANG WH, CHEN LT, SUN JS, LIN FH. Effect of pulse-burst electromagnetic field stimulation on osteoblast cell activities, Bioelec- tromagnetics v.25, n.6, p. 457-465, 2004.

- CHOW RT, DAVID MA, ARMATI PJ. $830 \mathrm{~nm}$ laser irradiation induces varicosity formation, reduces mitochondrial membrane potential and blocks fast axonal flow in small and medium diameter rat dorsal root ganglion neurons: implications for the analgesic effects of $830 \mathrm{~nm}$ laser. $\boldsymbol{J}$ Peripher Nerv Syst. v.2, n., p. 28-39. 2007

- CIRINO G, DISTRUTTI E, WALLACE JL. Nitric oxide and inflammation. Inflamm Allergy Drug Targets v.5, n. 2, p.115-9, 2006.

- CORREA F, LOPES MARTINS RA, CORREA JC, IVERSEN VV, JOENSON J, BJORDAL JM. Low-level laser therapy (GaAs lambda $=904 \mathrm{~nm}$ ) reduces inflammatory cell migration in mice with lipopolysaccharide-induced peritonitis. Photomed Laser Surg. Aug;25(4):245-9. 2007.

- DEMIDOVA-RICE TN, SALOMATINA EV, YAROSLAVSKY AN, HERMAN IM, HAMBLIN MR.Lowlevel light stimulates excisional wound healing in mice. Lasers Surg Med. 2007 Oct;39(9):706-15.

- DI ROSA M. Pharmacological properties of carrageenan, J. Pharm. Pharmacol v.24, p. 89-102, 1972.

- EDUARDO C.P. Lasers em Odontologia. Guanabara-Koogan, Rio de Janeiro, 2010.

- EFENDIEV AI, TOLSTYKH PI, DADASHEV AI, AZIMOV SA. Increasing the scar strength after preventive skin irradiation with low-intensity lasers. Klin Khir; v.1, p.23-5, 1992.

- ENWEMEKA CS. Intricacies of Dose in Laser Phototherapy for Tissue Repair and Pain Relief. Photomedicine and Laser Surgery v.27,n.3, p. 1-7, 2009.

- FERREIRA DM, ZÂNGARO RA, BALBIN VILLAVERDE A, CURY Y, FRIGO L, PICCOL G, LONGO I, BARBOSA DG. Analgesic effect of He-Ne $(632,8 \mathrm{~nm})$ low-level lasers therapy on acute inflammatory pain. Photom Lasers Surg; v.23, n.2, p.177-81, 2005.

- FILLIPIN LI, MAURIZ JL, VEDOVELLI K, MOREIRA AJ, ZETTLER CG, LECH O, MARRONI NP, GONZÁLEZ-GALLEGO J. LLLT (LLLT) prevents oxidative stress and reduces fibrosis in rat traumatized Achilles tendon. Lasers Surg. Med. v.37, p. 293-300, 2005. 
- FRIEDMAN H, LUBART R. Photostimulation by light-induced cytosolic calcium oscillations. Lasers Ther. v.8, p.137-42, 1996.

- FRIEDMANN H, LUBART R, LAULICHT I, ROCHKIND S.APOSSIBLE explanation of laser-induced stimulation and damage of cell cultures. J. Photochem Photobiol. v.11, p.87-91, 1991.

- FU S, RAMANUJAM KS, WONG A, FANTRY GT, DRACHENBERG CB, JAMES SP, MELTZER SJ, WILSON DT. Increased expression and cellular localization of inducible nitric oxide synthase and cyclooxygenase 2 in Helicobacter Pylori gastritis. Gastroenterology v.116, p.1319, 1999.

- FULGA, C., FULGA, I.G., AND PREDESCU, M. (1995). Effect of laser therapy on experimental inflammation in rats. Rom J Intern Med v.33, p.247-261, 1995.

- GAGLIARDI S, ATLANTE A, PASSARELLA S. A novel property of adenine nucleotides: sensitivity to helium-neon laser in mitochondrial reactions, Biochem. Mol. Biol. Int. v.41, n.3, p. 449-460, 1997.

- GUAY J, BATEMAN K, GORDON R, MANCINI J, RIENDEAU D. Carrageenan-induced paw edema in rat elicits a predominant prostaglandin E2 (PGE2) response in the central nervous system associated with the induction of microsomal PGE2 synthase-1. J Biol Chem. v.279, n.23, p.24866-72, 2004.

- HANG HH, QUESHI AA, BIUNDO JR JJ. Sports and other soft tissue injuries, tendinitis, bursitis, and occupation-related syndromes. Curr Opin Rheumatol v.12, p.150-154, 2000.

- HARRELL MI, IRITANI BM, RUDDELL A. Technical note Lymph node mapping in the mouse. J. Immunol. Methods v.332, p. 170-174, 2008.

- HAWKINS DH, ABRAHAMSE $H$. The role of lasers fluence in cell viability, proliferation, and membrane integrity of wounded human skin fibroblasts following helium-neon lasers irradiation. Lasers Surg. Med. v.38, p.74-83, 2006.

- HAWKINS DH, ABRAHAMSE H. Time-dependent responses of wounded human skin fibroblasts following phototherapy. J. Photochem Photobiol B: v.88, p.147-155, 2007.

- HERMAN, JH, KHOSLA, RC. Nd:YAG laser modulation of synovial tissue metabolism, Clin. Exp. Rheumatol. v.7, p. 505-512, 1989.

- HONMURA A, YANASE M, OBATA J, HARUKI E. Therapeutic effect of Ga-Al-As diode laser irradiation on experimentally induced inflammation in rats. Lasers Surg. Med. v.12, n.4, p, 441449, 1992.

- HONMURA, I. AKEMI, Y. MASAHIRO, J. OBATA, E. HARUKI, Analgesic effect of Ga-Al-As diode laser irradiation on hiperalgesia in carrageenin-induced inflammation, Lasers Surg. Med. v.13 p. 463-469, 1993.

- IHSAN FRM. Low-Level Laser Therapy Accelerates Collateral Circulation and Enhances Microcirculation. Photom Laser Surg. v.23, n.3, p.289-294, 2005.

- INOUE K, NISHIOKA J, HUKUDA S. Altered lymphocyte pro- liferation by low dosage laser irradiation. Clin Exp Rheu- matol., v.7, p. 521-523,1989. 
- JARVIS, D., MACIVER, B., AND TANELIAN, D.L. Electrophysiologic recording and thermodynamic modeling demonstrate that helium neon laser irradiation does not affect peripheral Ad- or C-fiber nociceptors. Pain v. 43, p.235- 242, 1990.

- JONES MK, WANG H, PESKAR BM, LEVIN E, ITANI RM, SARFEH IJ, TARNAWSKI AS. Inhibition of angiogenesis by nonsteroidal anti-inflammatory drugs: insight into mechanisms and implications for cancer growth and ulcer healing. Nat Med., v.5, p.1418, 1999.

- KANDOLF-SEKULOVIC L ,KATARANOVSKI M, PAVLOVIC MD. Immunomodulatory effects of lowintensity near-infrared laser irradiation on contact hypersensitivity reaction. Photodermatol Photoimmunol Photomed; v.19, p. 203-212, 2003

- KUCEROVÁ H, DOSTÁLOVÁ T, HIMMLOVA L, BÁRTOVÁ J, MAZÁNEK J. Low-level laser therapy after molar extraction. J Clin Laser Med Surg. v.18, n.6, p.309-15, 2000.

- KARU T. Mechanisms of interaction of monochromatic light with cells. In: Karu T, Young AR, editors. Effects of low power light on biological systems. Washington, DC: Proceedings of the European Society of Photo-Optical Instrumentation Engineers; v.26, n.30, p. 2-9. 1996:

- KARU T. Mechanisms of low-power laser light action on cellular level. In: SIMUNOVIC, Z. Lasers in Medicine and Dentristry: Basic Science and Up-to-Date Clinical Application of LowEnergy Level Laser Therapy - LLLT, Cap. 4. Rijeka-Croácia, Vitagraf,. pp.99-125, 2000.

- KARU T. Photobiology of low-power lasers effects. Health Phys v.56, n.5, p. 691-704, 1989.

- KARU TI. Photobiological fundamentals of low-power lasers therapy. IEEE J Quantum Elect; v.23, n. 10, p. 1703-19, 1987.

- KESSENICH CR. Cyclo-Oxygenase 2 Inhibitors: An Important New Drug Classification. Pain Man Nursing v.2, n.1, p. 13-18, 2001

- KILANCZYK E, PALECZ D, BRYSZEWSKA M. Effect of red laser light on $\mathrm{Na+,K(+)-ATPase} \mathrm{activity}$ in human erythrocyte membranes sensi- tized with Zn-phthalocyanine, J. Clin. Laser Med. Surg. v.20 n.2, p. 71-75, 2002.

- KIM H.W, UH D.K, YOON S.Y, ROH D.H, KWON Y.B, HAN H.J, LEE H.J, BEITZ A.J, LEE J.H. Low-frequency electroacupuncture suppresses carrageenan-induced paw inflammation in mice via sympathetic post-ganglionic neurons, while high-frequency EA suppression is mediated by the sympathoadrenal medullary axis. Brain Res Bull. v.75, n.5, p.698-705, 2008

- KITCHEN S.S, PARTRIDGE C.J. A review of Low level laser therapy. Part I: Background, physiological effects and hazards. Physiotherapy v.77, p.161-168, 1991

- KLEBANOV GI, KREININA MV, POLTANOV EA, KHRISTOFOROVA TV, VLADIMIROV YA. Mechanism of therapeutic effect of low-intensity infrared laser radiation. Bull Exp Biol Med. v.131, n.3, p. 239-41, 2001.

- LAAKSO, L., RICHARDSON, C., AND CRAMOND, T. Pain scores and plasma beta-endorphin and $\mathrm{ACTH}$ levels in response to low level laser therapy-a possible mechanism of action. Presented at the 12th International Congress on Physical Therapy, Washington, DC, 1995. 
- LEAL JUNIOR EC, LOPES-MARTINS RA, BARONI BM, DE MARCHI T, TAUFER D, MANFRO DS, RECH M, DANNA V, GROSSELLI D, GENEROSI RA, MARCOS RL, RAMOS L, BJORDAL $\mathrm{JM}$.Effect of $830 \mathrm{~nm}$ low-level laser therapy applied before high-intensity exercises on skeletal muscle recovery in athletes. Lasers Med Sci. v.24, n.6, p.857-63, 2009.

- LEVINE IN. Physical Chemistry, (fifth ed.), Mc Graw-Hill Inc., NewYork, 2001 (Chapter 18).

- LIMPANICHKUL W, GODFREY K, SRISUK N, RATTANAYATIKUL C: Effects of low-level laser therapy on the rate of orthodontic tooth movement. Orthod Craniofacial Res v.9, p.38-43, 2006

- LIU Y, YANG H, TAKATSUKI H, SAKANISHI A. Effect of ultrasonic exposure on Ca(2+)-ATPase activity in plasma membrane from Aloe arborescens callus cells, Ultrason Sonochem., 2005.

- LOEVSCHALL H, ARENHOLT-BINDSLEV D. Effect of low level diode lasers irradiation of human oral mucosa fibroblasts in vitro. Lasers Surg Med., v.14, n.4, p. 347-354, 1994.

- LOPES-MARTINS RAB, ALBERTINI R, MARTINS PSLL, BJORDAL JM, FARIA NETO HCC. Spontaneous Effects of Low-Level Laser Therapy $(650 \mathrm{~nm})$ in Acute Inflammatory Mouse Pleurisy Induced by Carrageenan Photomedicine and Laser Surgery v. 23, n.4, p. 377-381, 2005.

- MA L, DEL SOLDATO P, WALLACE JL. Divergent effects of new cyclooxygenase inhibitors on gastric ulcer healing: shifting the angiogenic balance. Proc Natl Acad Sci USA v.99,13243, 1989.

- MAEGAWA Y, ITOH T, HOSOKAWA T, YAEGASHI K, NISHI M. Effects of near-infrared low-level laser irradiation on microcirculation. Laser Surg Med v.27, p. 427-437, 2000.

- MARQUES MM, PEREIRA AN, FUJIHARA NA, NOGUEIRA FN, EDUARDO CP. Effect of LowPower Lasers Irradiation on Protein Synthesis and Ultrastructure of Human Gingival Fibroblasts. Lasers Surg Med, v.34, p.260-65, 2004

- MENEGUZZO, DT. Influência do fracionamento da energia de irradiação na fototerapia com laser em baixa intensidade sobre o crescimento de fibroblastos de polpa dentária humana. 2007. Dissertação (Mestrado) - Faculdade de Odontologia da USP, São Paulo

- MENEGUZZO, D.T; EDUARDO, C.P; RIBEIRO, M.S; MARQUES,MM. Influence of the fractioned irradiation energy in the phototherapy with low intensity laser on the growth of human dental pulp fibroblasts. Progress in Biom. Optics Imag., v.9, n.5, p. 68460A1 -9, 2008.

- MENEGUZZO, D.T.; SOARES-FERREIRA, L.; CUNHA, F.; THOMAZ, L.A.; MORAES, P.C. Laser phototherapy in the treatment of trigeminal neuralgia - Adrressing clinical protocol. In: 8th International Congresso f the WALT, Abstracts. 25-28 Setembro, 2010. Bergen, Noruega.

- MESTER E, MESTER AF, MESTER A. The biomedical effects of laser application. Lasers Surg Med; v.5, p. 31-39, 1985.

- MESTER E, SPIRY T, SZENDE B, TOTA JG. Effect of lasers rays on wound healing. Am J Surg; v.122, n.4, p.532-5, 1971.

- MILOJEVIĆ M, KURUC V. Low Power laser biostimulation in the treatment of bronchial asthma. Med Pregl. v.56, n.9-10, p. 413-8, 2003a. 
- MILOJEVIC M, KURUC V.Laser biostimulation in the treatment of pleurisy. Med Pregl. v.56, n.1112, p.516-520, 2003b.

- MIRSKY N, KRISPEL Y, SHOSHANY Y, MALTZ L, ORON U. Promotion of angiogenesis by low energy laser irradiation. Antioxid Redox Signal. v. 4, n. 5, p. 785-90, 2002.

- MIZUNO H, SAKAMOTO C, MATSUDA K, WADA K, UCHIDA T, NOGUCHI H, AKAMATSU T, KASUGA M. Induction of cyclooxygenase 2 in gastric mucosal lesions and its inhibition by the specific antagonist delays healing in mice. Gastroenterology 112,387, (1997),

- MORAIS NC, BARBOSA AM, VALE ML, VILLAVERDE AB, DE LIMA CJ, COGO JC, ZAMUNER SR. Anti-inflammatory effect of low-level laser and light-emitting diode in zymosan-induced arthritis.Photomed Laser Surg. v.28, n.2, p.227-32, 2010

- MOORE PA, HERSH EV. Celecoxib and Rofecoxib: The role of COX-2 inhibitors in dental practice JADA v.132, p.451-6, 2001.

- NES AG , POSSO MBS. Patients with moderate chemotherapy-induced mucositis: pain therapy using low intensity lasers. International Council of Nurses, International Nursing Review v.52, p.68-72, 2005.

- NÚÑEZ SC, GARCEZ AS, SUZUKI SS, RIBEIRO MS. Management of mouth opening in patients with temporomandibular disorders through low-level laser therapy and transcutaneous electrical neural stimulation. Photomed Laser Surg. v.24, n.1, p.45-9, 2006.

- NÚÑEZ SC, MSC, NOGUEIRA GEC, PHD, RIBEIRO MS, PHD, GARCEZ AS, MSC,1 LAGEMARQUES JL. He-Ne Laser Effects on Blood Microcirculation During Wound Healing: A Method of In Vivo Study Through Laser Doppler Flowmetry. Lasers Surg. Med. v.35, p.363-368, 2004.

- OLSON JE, SCHIMMERLING W, TOBIAS CA. Lasers action spectrum of reduced excitability in nerve cells. Brain Res v.204, n. 2, p.436-40, 1981

- PASTORE D, GRECO M, PASSARELLA S, Specific helium-neon laser sensitivity of the purified cytochrome c oxidase, Int. J. Radiat. Biol. v.76, n.6, p. 863-870, 2000.

- PEREIRA AN, EDUARDO CDE P, MATSON E, MARQUES MM. Effect of low-power laser irradiation on cell growth and procollagen synthesis of cultured fibroblasts. Lasers Surg Med.; v.31, n.4, p.263-7, 2002

- QUADRI T, MIRANDA L, TUNE J, GUSTAFSSON A. Theshort-term effects of low-level lasers as adjunct therapy in the treatment of periodontal inflammation. J Clin Periodontol v.32, p.714-9, 2005.

- QUAGLINO D, CAPRI M, ZECCA L, FRANCESCHI C, RONCHETTI IP. The effect on rat thymocytes of the simultaneous in vivo exposure to $50-\mathrm{Hz}$ electric and magnetic field and to continuous light, Sci. World J. v.4, n.2, p.91-99, 2004.

- REDDY GK. Comparison of the Photostimulatory Effects of Visible He-Ne and Infrared Ga-As Lasers on Healing Impaired Diabetic Rat Wounds. Lasers in Surgery and Medicine v.33, p. 344$351,2003$. 
- ROCHKIND S, NISSAN M, RAZON N, SCHWARTZ M, BARTAL A Electrophysiological effect of HeNe laser on normal and injured sciatic nerve in the rat. Acta Neurochir (Wien). v.83, n.3-4, p.125-30, 1986.

- ROCHKIND S, ROUSSO M, NISSAN M, VILLARREAL M, BARR-NEA L, REES DG. Systemic effects of low-power laser irradiation on the peripheral and central nervous system, cutaneous wounds and burns. Lasers Surg Med v.9, p. 174-182, 1989.

- SALATE AC, BARBOSA G, GASPAR P, KOEKE PU, PARIZOTTO NA, BENZE BG, FOSCHIANI D. Effect of In-Ga-Al-P diode laser irradiation on angiogenesis in partial ruptures of Achilles tendon in rats. Photome. Laser Surg., v.23, p. 470-5, 2005.

- SCHAFFER M, BONEL H, SROKA R, ACHAFFER PM, BUSCH M, REISER M, DU"HMKE E. Effects of $780 \mathrm{~nm}$ diode laser irradiation on blood microcirculation preliminary findings on time dependent T1-weighted contrast-enhanced magnetic resonance imaging (MRI). $\boldsymbol{J}$ Photochem Photobiol B v.54, p.55-60, 2000.

- SCHINDL A, MERWALD H, SCHINDL L, KAUN C, WOJTA J. Direct stimulatory effect of lowintensity $670 \mathrm{~nm}$ laser irradiation on human endothelial cell proliferation. Br J Dermatol. v.148, n.2, p.334-6, 2003.

- SCHINDL A, SCHINDL M, PERNERSTORFER-SCHÖN H, SCHINDL L. Low-intensity lasers therapy: a review. J Investig Med; v.48, p.312-26, 2000.

- SCHINDL L, SCHINDL M, POLO L, JORI G, S. PERL, A. SCHINDL, Effects of low power laserirradiation on differential blood count and body temperature in endotoxin-preimmunized rabbits, Life Sci. v.19, p.1669-1677, 1995

- SHIMIZU N, YAMAGUCHI M, GOSEKI T, ET AL. Inhibition of prostaglandin E2 and interleukin 1beta production by low-power laser irradiation in stretched human periodontal ligament cells. $J$ Dent Res; v.74, p.1382-1388, 1995.

- SILFVAST WT. Laser Fundamentals, second ed., Cambridge University Press, Cambridge, p. 2337, 2004

- Sousa, M.V.P. Estudo e desenvolvimento de simuladores de tecido humano para utilização em fototerapia. 2010. Dissertação (Mestrado) - Instituto de Física da Universidade de São Paulo, São Paulo.

- STERGIOULAS A, STERGIOULA M, AARSKOG R, LOPES-MARTINS RA, BJORDAL JM. Effects of low-level laser therapy and eccentric exercises in the treatment of recreational athletes with chronic achilles tendinopathy. Am J Sports Med. v.36, n.5, p.881-7, 2008

- SWARTZ, M.A; HUBBELL J.A.; REDDY, S.T. Lymphatic drainage function and its immunological implications: from dendritic cell homing to vaccine design. Semin Immunol., v. 201, n.2, p. 147-56, 2008.

- TILLEY SL, COFFMAN TM, KOLLER BH. Mixed messages: modulation of inflammation and immune responses by prostaglandins and thromboxanes. J Clin Invest; v.108, p.15-23, 2001. 
- TONG M, LIU YF, ZHAO XN, YAN CZ, HU ZR, ZHANG ZX. Effects of Different Wavelengths of Low Level Laser Irradiation on Murine Immunological Activity and Intracellular Ca2+ in Human Lymphocytes and Cultured Cortical Neurogliocytes. Lasers Med Sci, v.15, p. 201-206, 2000

- TUBY H, MALTZ L, ORON U. Modulations of VEGF and iNOS in the rat heart by low level laser therapy are associated with cardioprotection and enhanced angiogenesis. Lasers Surg Med. v.38, n. 7, p. $682-8,2006$.

- TUNÉR J, HODE L. The New Laser Therapy Handbook. Sweden: Prima Books, 2010

- VANE JR, BAKHLE YS, BOTTING RM. Cyclooxygenases 1 and 2. Ann Rev Pharmacol Toxicol v.38, p. 97-120, 1998.

- VLADIMIROV YA, OSIPOV AN, KLEBANOV GI. Photobiological principles of therapeutic applications of laser radiation. Biochemistry (Mosc). v.69, n.1, p. 81-90, 2004.

- VOLTARELLI JC. FEBRE E INFLAMAÇÃo in: Simpósio SEMIOLOGIA E FISIOPATOLOGIA CLÍNICAS capítulo 1. Medicina, Ribeirão Preto, v.27, n.1, p. 7-48, 1994

- WALKER J, Relief from chronic pain by low power laser irradiation, Neurosci. Lett. v.43, p. 339$344,1983$.

- WINTER CA, RISLEY EA, NUSS GM, Carrageenin-induced oedema in the hind paw of the rat as an assay for anti-inflammatory drugs, Proc Soc Exp Biol. v.111, p.544-547, 1962.

- XIE W, CHIPMAN JG, ROBERTSON DL, ERIKSON RL, SIMMONS DL. Expression of a mitogenresponsive gene encoding prostaglandin synthase is regulated by mRNA splicing. Proc Natl Acad Sci USA., v.88, p.2692, 1991.

- XU ZZ, ZHANG L, LIU T, PARK JY, BERTA T, YANG R, SERHAN CN, JI RR. Resolvins RvE1 and RvD1 attenuate inflammatory pain via central and peripheral actions. Nat Med., v.16, n.5, p. 592-7, 2010. 


\section{ANEXO 1. APROVAÇÃO DO COMITÊ DE ÉTICA EM PESQUISA DO IPEN}

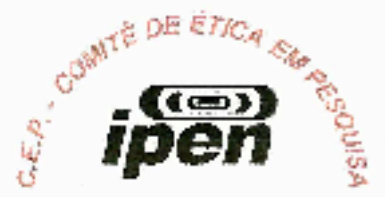

Parecer - Projeto N 21/CEPA-IPEN/SF

Com base nos pareceres apresenlados pelos relatores, o protocolo de peEquiga EFEITO DA FOTOTERAPIA COH LASER EM BAIXA INTENSIDADE EM PROCESSOS INFLAMATORIOS AGUDOS dO responsabilidade do pesquisador MARTHA SIMŌES RIBEIRO foi considerado APROVADO.

Tendo em vista a legislaçăo viganle, devem ser encaminhadtos, a este Comite, relalbrios anuais (panciais ou fineis, dependendo da durackido do projeto) referentes ao andamento da pesquisa. Apos o termino da pesquisa, uma copia do trabalho, am CD ou disquata, dewe ser encaminhada a este CEPA.

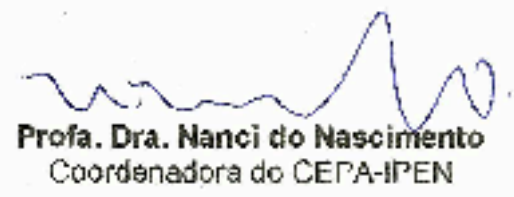




\section{APÊNDICES}

9.1. APÊNDICE 1. FOTOS DAS LÂMINAS DE HISTOLOGIA DA ETAPA 1A, EM AUMENTO DE 40X COM AS CINCO ÁREAS DE CONTAGEM DE CÉLULAS INFLAMATÓRIAS

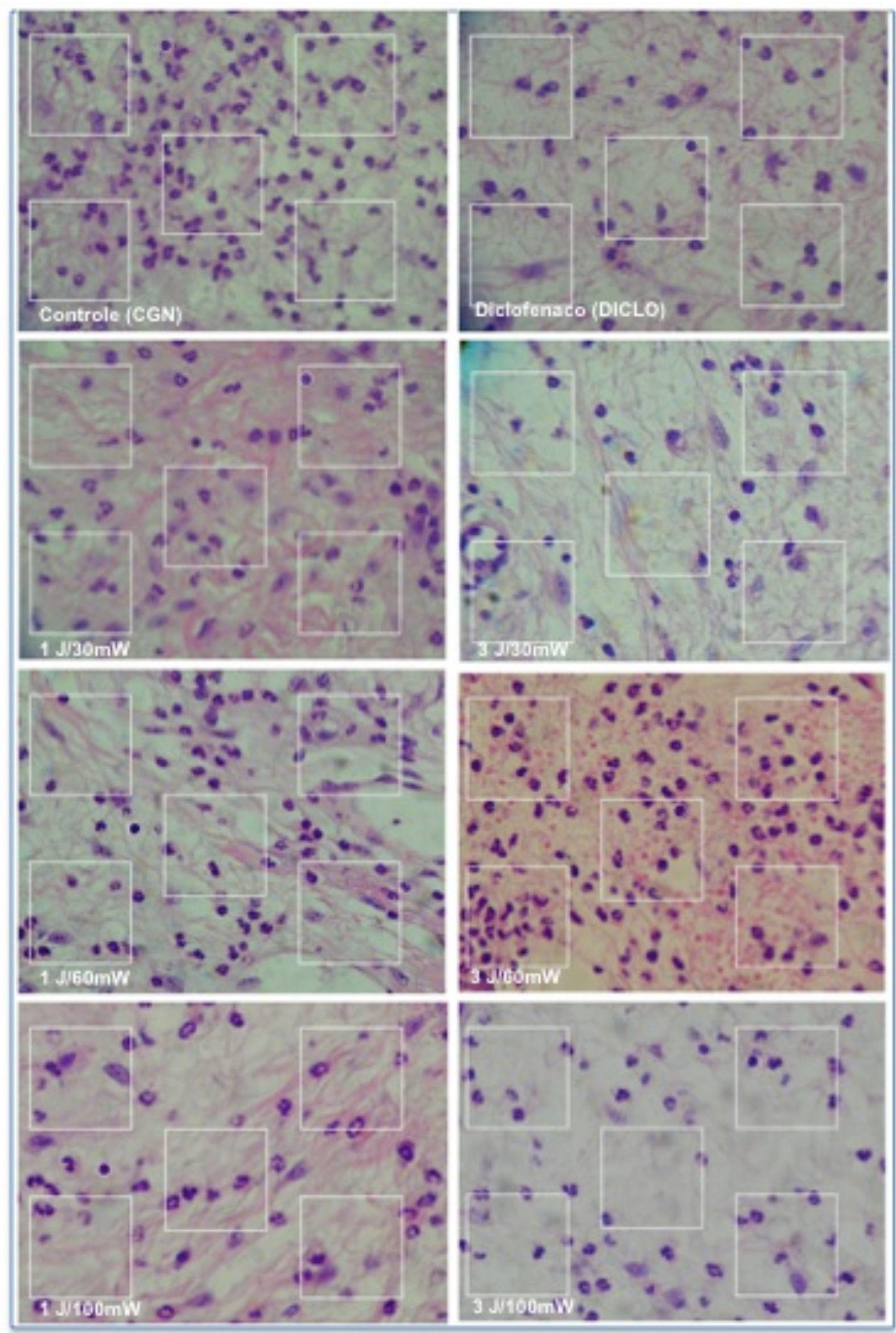


9.2. APÊNDICE 2. FOTOS DAS LÂMINAS DE HISTOLOGIA DA ETAPA 3A, EM AUMENTO DE 40X COM AS CINCO ÁREAS DE CONTAGEM DE CÉLULAS INFLAMATÓRIAS

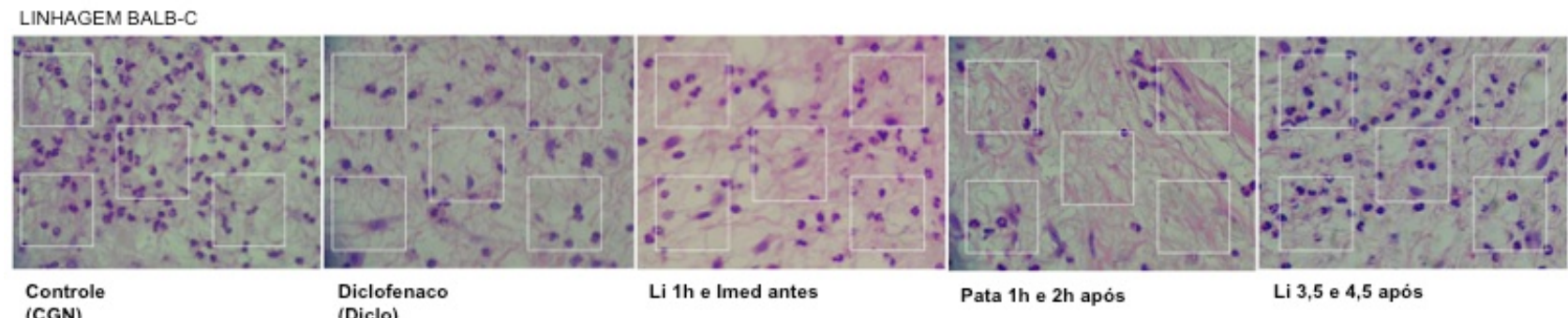

9.3. APÊNDICE 3. FOTOS DAS LÂMINAS DE HISTOLOGIA DA ETAPA 3B, EM AUMENTO DE 40X COM AS CINCO ÁREAS DE CONTAGEM DE CÉLULAS INFLAMATÓRIAS

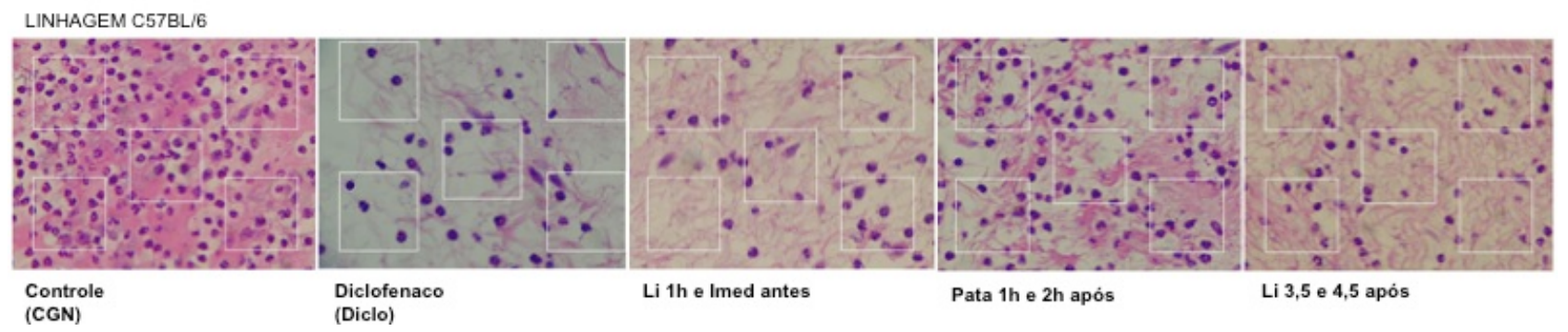




\subsection{APÊNDICE 4. DIFICULDADES ENCONTRADAS DURANTE A TESE}

Com o objetivo de auxiliar futuros colegas pós-graduandos resolvi incluir neste apêndice algumas questões que espero que sejam úteis e que de certa forma "diminuam" as possíveis dificuldades durante a pós-graduação.

Sobre a metodologia utilizada nesta tese, a medição do edema com pletismógrafo inicialmente foi muito difícil de ser realizada. Foram feitos vários pilotos e só depois de muito treino obtive a padronização das medições. Além disso, foi um experimento que exigiu bastante tempo para ser realizado e bastante concentração na metodologia. $\mathrm{O}$ treino é imprescindível para realizar este modelo experimental. E claro, utilize-o com camundongos! Animais maiores, ratos Wistar por exemplo, exigem ainda maior habilidade e anestesia em todo o período experimental. E muito anestésico, como sabemos, pode levar o animal à óbito antes do experimento terminar! (e lá se vai o n...)

Sobre os animais utilizados, investigue no Biotério a viabilidade de se conseguir o número de animais necessários por experimento, bem como o importante detalhe de todos os animais terem a mesma idade ou pelo menos, idades próximas. Tive muita dificuldade em conseguir 25 a 30 camundongos da mesma idade, ao mesmo tempo, de uma mesma linhagem. A velocidade dos experimentos foi quase que determinada pela disponibilidade de animais. E isso pode interferir nos prazos de defesa, etc, etc. Planejamento é tudo, e mais do que isso, depende dos outros também. É importante desta forma ter uma planejamento flexível. Imprevistos sempre ocorrerão! Um fato interessante que ocorreu no biotério do IPEN foi a necessidade de utilizar uma alimentação especial nos camundongos para estimular a procriação dos animais que estava lenta! Ou seja, até dos próprios animais depende nossos experimentos! 
Sobre a redação da tese, comece ontem. Isso é um pouco difícil de admitir, mas escrever depende da inspiração. E ela, não vem quando queremos... Por isso, se estiver inspirado, escreva! Isso aconteceu comigo alguma vezes, principalmente após eu obter resultados. A empolgação com eles me fazia ir até a literatura, ler, estudar e sempre saía um ou dois parágrafos que me foram muito úteis na redação. Mas eu deveria ter escrito mais, antes. A redação teria sido mais rápida, e a rapidez nos empolga. Ao contrário do que é feito muito lentamente, que nos leva a criar uma certa "aversão" à tese. Isso me aconteceu, não conseguia ver mais nada que fosse importante acrescentar na tese. Fui viajar, deixei a tese abandonada um tempo, e sabe que melhorou? Sim, a inspiração sempre volta.

Reuniões com o orientador? Anote tudo, todas as idéias... as sugestões, as hipóteses. Anote tudo. E anote em um único caderno. Guarde-o com carinho. Ele será o guia para tudo, principalmente para elaborar a discussão. Eu não anotei em um único caderno, e muitas coisas foram perdidas, apesar de anotadas! Mas fica aí a dica. E na elaboração da discussão, comece pelo final... ou melhor, pela última parte. Acho que temos a tendência de ir perdendo as forças ... A vontade de terminar logo nos domina, e isso ficará muito perceptível na banca. Pelo menos na minha foi! Ainda bem que aqui no IPEN temos um mês para entregar a versão final da tese.

E graças a este mês, e é claro, à sugestão da banca, escrevi este apêndice. Espero que seja útil a quem for ler, e a mim lembrará o tanto de "trabalho" que me deu este "trabalho". E mesmo sabendo que muitas batalhas perdemos (tanto esforço!)... como diz o ditado, ganhamos a guerra, que é muito, muito mais importante. E sim, existe vida após o doutorado. E ela continuará sendo o reflexo de nós mesmos. Só depende de nós. 